\title{
Conserved molecular mechanisms underlying the effects of small molecule xenobiotic chemotherapeutics on cells
}

\author{
HEMANT SARIN \\ Freelance Investigator in Translational Science and Medicine, Charleston, WV 25314, USA
}

Received November 24, 2015; Accepted December 8, 2015

DOI: $10.3892 / \mathrm{mco} .2015 .714$

\begin{abstract}
For proper determination of the apoptotic potential of chemoxenobiotics in synergism, it is important to understand the modes, levels and character of interactions of chemoxenobiotics with cells in the context of predicted conserved biophysical properties. Chemoxenobiotic structures are studied with respect to atom distribution over molecular space, the predicted overall octanol-to-water partition coefficient (Log OWPC; unitless) and molecular size viz a viz van der Waals diameter (vdWD). The Log OWPC-to-vdWD $\left(\mathrm{nm}^{-1}\right)$ parameter is determined, and where applicable, hydrophilic interacting moiety/core-to-vdWD $\left(\mathrm{nm}^{-1}\right)$ and lipophilic incorporating hydrophobic moiety/core-to-vdWD $\left(\mathrm{nm}^{-1}\right)$ parameters of their part-structures are determined. The cellular and sub-cellular level interactions of the spectrum of xenobiotic chemotherapies have been characterized, for which a classification system has been developed based on predicted conserved biophysical properties with respect to the mode of chemotherapeutic effect. The findings of this study are applicable towards improving the effectiveness of existing combination chemotherapy regimens and the predictive accuracy of personalized cancer treatment algorithms as well as
\end{abstract}

Correspondence to: Dr Hemant Sarin, Freelance Investigator in Translational Science and Medicine, 833 Carroll Road, Charleston, WV 25314, USA

E-mail: hsmd74@hotmail.com

Abbreviations: CM, cell membrane; poOWPC or OWPC, predicted overall Log octanol-to-water partition coefficient (unitless); vdWD, van der Waals diameter; predicted Log OWPC-to-vdWD ratio $\left(\mathrm{nm}^{-1}\right)$; Log incorpOWPC-to-vdWD ratio, predicted Log incorporating lipophilicity-to-vdWD ratio $\left(\mathrm{nm}^{-1}\right)$; Log interactOWPC-to-vdWD ratio, predicted Log interactability hydrophilicity-to-vdWD ratio $\left(\mathrm{nm}^{-1}\right) ; \mathrm{S}$, sufficient separation of charge; IS, insufficient separation of charge; Peri, peripheral/circumferential polyhydroxylation, carbonylation and/or etheroylation

Key words: molecular imaging, dendrimer nanoparticle, theranostic probe, charge, functional group, hydrophilicity, lipophilicity, predicted overall octanol-to-water partition coefficient, predicted van der Waals diameter, predicted OWPC-to-vdWD ratio, cell membrane receptormediated pressuromodulation, cell membrane perturbomodulation towards the selection of appropriate novel xenobiotics with the potential to be potent chemotherapeutics for dendrimer nanoparticle-based effective transvascular delivery.

\section{Introduction}

Small molecules non-endogenous to the biological system, often referred to as xenobiotics, include a diverse variety of molecules, simple organic toxicants with uncomplicated structures and natural eukaryotic antibiotics and synthetic molecules of more complicated structures and cytotoxic properties (1), the latter of which have chemotherapeutic properties. Although small molecule chemoxenobiotics, of various traditional classes, form the basis of present synergistic cancer treatment strategies, their clinical efficacy remains questionable for the treatment of solid and hematopoietic malignancies alike, upon surgical resection in the former, and during bone marrow irradiation-transplantation and after in the latter. For this reason, a better understanding of the modes and character underlying molecular cellular interactions is necessary, particularly for the purposes of improving the tumor tissue selectiveness of enhanced permeation and retention (EPR)-based chemotherapy (2), which has a prolonged blood half-life but is non-selective for solid tumor foci. Along these lines, there has been relatively recent translational advancement towards the development of optimally sized dendrimer nanoparticle-based small molecule chemotherapy at $\sim 9 \mathrm{~nm}\left(H_{\mathrm{D}}\right)$ (3-7), which selectively delivers small molecule chemoxenobiotics into solid malignancies at effective concentrations without systemic toxicity $(4,8)$. As such, with optimally sized dendrimer nanoparticle-based small molecule chemotherapy, there is the potential for complete tumor regression $(3,9)$ in lieu of the possibility for the development of drug resistance phenotypes $(10,11)$ and therapy-related malignancies (12) or myelodysplastic syndromes (13).

During the discovery and developmental stages, the testing of small molecule xenobiotics occurs at several levels: i) at the naked target, on chromatin or on a protein receptor/enzyme in isolation, which provides information on relative binding affinities for intra-cellular proteins; ii) at the cellular level in vitro, which provides information on the inhibitory concentrations needed to achieve tumor cell death and the overexpression status of induced pro- or anti-apoptotic protein forms, but does not take into consideration cell membrane (CM) phospholipid or $\mathrm{CM}$ protein receptor interactions, the most common level of 
interaction for secondary intra-cellular effects of non-permeable small molecule xenobiotics, either due to molecular size restriction to permeation or charge restriction to permeation $(4,8)$; iii) at the systemic level in vivo, which gives an idea of the dosing range necessary to achieve a chemotherapeutic effect and tumor regression, and in the case of more lipophilic chemoxenobiotics, the dosing required to overcome serum protein binding, this being the primary limitation to achieving effective transvascular delivery and intra-tumoral concentrations in cases of free small molecule xenobiotics, not linked to optimally sized nanoparticles (3-7).

Most recently, the conserved biophysical determinants for the interactions of small biomolecules, cations and anions in the biological system in the physiologic state have been elucidated, with respect to understanding permeation thresholds across microvascular and epithelial barriers (8) as well as understanding the modes, the levels and the character of interactions of small biomolecules with and within cells. With this novel approach, the biological interactions of any small molecule can be understood in terms of its 2-dimensional structure. This requires taking into consideration the following character of charge distribution over molecular space, determinations of the predicted overall octanol-to-water partition coefficient (Log OWPC; unitless), and the predicted molecular size [van der Waals diameter (vdWD; nm)] viz a viz the Log OWPC-to-vdWD $\left(\mathrm{nm}^{-1}\right)$ parameter. The biological interactions of the hydrophilic or hydrophobic parts of the molecule can be understood in terms of the 2-dimensional (2-D) part-structures, and determinations of the interacting hydrophilic moiety (or core)-to-vdWD ratio $\left(\mathrm{nm}^{-1}\right)$ and the incorporating lipophilicity of the hydrophobic core (or moiety)-to-vdWD ratio $\left(\mathrm{nm}^{-1}\right)$ parameters, respectively.

For the proper determination of the apoptotic potential of chemoxenobiotics in synergism, it is important to know whether interactions at the cellular level are with and across $\mathrm{CM}$ protein aqueous channels, with $\mathrm{CM}$ surface protein receptors and endocytic, with $\mathrm{CM}$ surface protein receptors and non-endocytic or directly with phospholipids. It is also important to know whether interactions at the sub-cellular level are nuclear, mitochondrial or microtubular. Therefore, in this research study, current small molecule chemoxenobiotics and xenobiotics not traditionally considered as chemoxenobiotics, are analyzed in terms of conserved biophysical determinants to determine the modes, levels and character of interactions of xenobiotics with cells and cell organelles. The insight to be gained is to be applicable for the selection of existing chemoxenobiotics most synergistic in cytotoxic effects and the development of more effective existing chemotherapy regimens utilizing small molecule chemoxenobiotics $(14,15)$. This knowledge is applicable for the discovery of alternative xenobiotics with chemotherapeutic potential to overcome chemotherapeutic resistance (16), as well as for the design and development of next generation biocompatible optimally sized drug carriers free from intravascular protein interactions, for effective transvascular delivery into solid tumor tissue cells (3-7).

\section{Materials and methods}

Data acquisition and determination of principal components for analysis of small molecule xenobiotics. Small molecule xenobiotics known to be chemotherapeutic and those with chemotherapeutic potential were identified for the database. Freely available and validated online biochemical molecule databases including http://www.chemicalize.org and http://www.chemspider.com were utilized for determinations of 2-D molecular structures and ionization state at physiologic $\mathrm{pH}$ of $\sim 7.4$, analogous to previous methodology for endogenous biomolecules (8). Molecular structure and configurations of xenobiotics were assessed for the type of covalent bonds within the structure, and to the backbone as is the presence or absence of associated molecular charge. The presence of halogenation $(0)$, hydroxylation $(0,-1)$, phosphorylation $(-1,-2)$, carboxylation $(-1)$, carbonylation $(\mathrm{C}=\mathrm{O})$, sulfonation $(0,+1)$ and amination $(0,+1)$, whether primary, secondary, tertiary or quaternary (+1) is noted. The amount of polar surface area (psa) is also noted.

The predicted octanol-to-water partition coefficient (poOWPC or OWPC; unitless), the predicted Log Pow, was applied for molecules in neutral or unionized states, and the predicted Log Dow, was applied for molecules in the ionized state. The predicted vdWD (nm) was applied as the measure of estimated molecular size, obtained from the predicted spherical van der Waals volume. The predicted Log OWPC-to-vdWD $\left(\mathrm{nm}^{-1}\right)$ was determined for the whole molecule, while the predicted incorporating lipophilicity octanol-to-water partition coefficient-to-van der Waals diameter ratio (Log incorpOWPC-to-vdWD; $\mathrm{nm}^{-1}$ ) was determined for the hydrophobic cores and moieties (hydrophobic moiety/core Log OWPC-to-vdWD; $\mathrm{nm}^{-1}$ ), and the predicted interactability octanol-to-water partition coefficient-to-van der Waals diameter ratio (Log interactOWPC-to-vdWD; $\mathrm{nm}^{-1}$ ) was determined for the hydrophilic moieties [or cores] (hydrophobic moiety Log OWPC-to-vdWD; $n m^{-1}$ ).

Classification of molecular philicity and charge. The presence of charge and its distribution over biomolecular space were assessed based on visual inspection of 2-D molecular structures. The classification scheme, as devised with slight modifications, was applied for the characterization of molecular charge over molecular space, as follows:

I. No overall charge: neutral (0), which can be a combination of hydroxylo $(\mathrm{OH})$, carbonylo $(\mathrm{C}=\mathrm{O})$, etheroylo $\left(\mathrm{O}-\mathrm{CH}_{3}\right)$, amidylo $(\mathrm{N}-\mathrm{C}=\mathrm{O})$, where the presence of peripheral neutral groups in a circumferential or semi-circumferential arrangement around a lipophilic core is designated as Peri or semi-Peri;

II. Sufficient molecular space separation of charge (S) was defined as the presence of focal charges separated in molecular space, in the form of sufficiently separated attractive + or charge that results in sufficiently separated contributions of cationicity (S 1+ 1+) or of anionicity (S 1- 1-);

III. Insufficient molecular space separation of charge (IS) was defined as the presence of focal charge in molecular space, in the form of insufficiently separated attractive + or - charge that results in insufficiently separated contributions of cationicity (IS 1+1+) or of anionicity (IS 1-1-), where cationoneutral molecular charge is defined as IS 1+1-.

Classification of small molecule xenobiotic mode and character of CM protein channel or receptor interaction. Small molecule xenobiotic mode and character of CM 
cholesterol/phospholipid glycerol-to-fatty acid-ester, CM protein channel or $\mathrm{CM}$ receptor interaction were classified, as follows:

I. Pure hydrophiles, defined as xenobiotics without intervening lipophilicity with predicted hydrophilic (-) Log OWPC-to-vdWD ratio $\left(\mathrm{nm}^{-1}\right)$ at a physiologic $\mathrm{pH}$ of 7.4, with non-charged pure hydrophiles being $\mathrm{CM}$ aqueous channel pore permeable at vdWDs $<0.78 \mathrm{~nm}$ and intra-cellularly localizing (0 1- 1+).

II. Hydro-lipophiles, defined as xenobiotics with intervening lipophilicity (Log incorpOWPC-to-vdWD; $\mathrm{nm}^{-1}$ ) with predicted hydrophilic (-) Log OWPC-to-vdWD ratio $\left(\mathrm{nm}^{-1}\right)$ at physiologic $\mathrm{pH}$ of 7.4 , and being $\mathrm{CM}$ aqueous channel pore impermeable, with $\mathrm{CM}$ non-channel receptor or $\mathrm{CM}$ receptor interaction instead, as follows: a) cationic polyhydroxylated/carbonylated/etheroylated [1+ Peri (0)]: channel receptor-mediated $\mathrm{CM}$ endocytosis (i.e., doxorubicin); b) cationic-cationic polyhydroxylated/carbonylated/etheroylated [S $1+1+$ Peri (0)]: channel receptor-mediated $\mathrm{CM}$ endocytosis (i.e., vincristine); c) di-cationic-cationic [S IS 1+ $1+$ IS $1+1+(0)]$ : effective cationicity $2+2+$ ): non-channel receptor-mediated $\mathrm{CM}$ endocytosis (i.e., AMD3100); d) di-carboxylated neutral [S 1- 1- 0 (0)]: non-channel folic acid receptor-mediated $\mathrm{CM}$ endocytosis (i.e., methotrexate).

III. Lipohiles, defined as non-charged less lipophilic toxicants with vdWDs $<0.78 \mathrm{~nm}$ (CM channel pore permeable sub-CM interactors), and as xenobiotics with vdWDs $>0.78 \mathrm{~nm}$ and overall lipophilicity $[(+)$ Log OWPC-to-vdWD ratio $\left(\mathrm{nm}^{-1}\right)$ ] with sufficient $(\mathrm{S})$ intervening lipophilicity (Log incorpOWPC-to-vdWD; $\mathrm{nm}^{-1}$ ) in the presence of molecular hydrophilicity (monohydroxylation/monocarbonylated/monoetheroylated/monocarboxylated; polyhydroxylated/ polycarbonylated/polyetheroylated; charge) either present isotropically [CM receptor hydrophobic core interactors with vdWDs $>0.78 \mathrm{~nm}$ (receptor-mediated CM endocytosis)], or present anisotropically (CM cholesterol/phospholipid glycerol-to-fatty acid-ester or CM receptor hydrophobic core interactors with vdWDs $>0.78 \mathrm{~nm}$ ): a) anisotrophic anionic [1- (0)] with linear structure (i.e., chlorambucil), anisotrophic cataniononeutral [IS 1+ 1- (0)] with linear structure (i.e., melphalan), anisotropic polyneutral [0 (0)] with linear structure (i.e., capecitabine), anisotropic polyneutral circular [circ (0)] (i.e., cyclosporine A): CM cholesterol or phospholipid glycerol-to-fatty acid-ester association or disruption; b) isotropic di-neutral [0 (0) 0] with sterol structure: non-channel steroid receptor-mediated pressuromodulation antagonism (i.e., abiraterone); non-channel receptor-mediated pressuromodulation (endogenous sex steroids, i.e., testosterone, estradiol); c) isotropic cationic-neutral [1+(0) 0$]$ with sterol mimicking structure: non-channel steroid receptor-mediated pressuromodulation antagonism (i.e., hydroxytamoxifen); d) isotrophic cationic semi-polyneutral [1+ semi-Peri (0)] with flexible linear structure: potential for channel receptor-mediated CM endocytosis (i.e., verapamil); e) esotrophic polyneutral [Peri (0)] with compact non-linear structure: non-channel receptor-mediated $\mathrm{CM}$ endocytosis (i.e., colchicine); isotrophic polyneutral [Peri (0)] with non-compact non-linear structure: non-channel receptor-mediated $\mathrm{CM}$ endocytosis (i.e., etoposide); f) anisotropic di-neutral $[00(0)]$ with part-sterol structure: non-channel receptor P-glycoprotein (P-gp)-mediated pressuromodulation (i.e., artemisinin); g) anisotropic polyneutral [semi-Peri (0)] with sterol structure: non-channel receptor-mediated pressuromodulation (endogenous corticosteroids, i.e., cortisol, aldosterone); h) anisotropic cationic neutral $[1+0(0)]$, isotropic cationic neutral [1+ (0) 0], anisotropic non-cationic di-neutral [0 $0(0)]$ or isotropic non-cationic di-neutral [0 (0) 0$]$ with non-linear L-to-U-type step-like structure: non-channel receptor-mediated pressuromodulation antagonism (i.e., growth factor and cytokine receptor antagonists).

\section{Results and Discussion}

Octanol-to-water partition coefficient-to-van der Waals diameter ratio of whole and part structures in the context of xenobiotic structures. The poOWPC or OWPC represents the presence of molecular surface area hydrophilicity due to the presence of functional groups of hydrophilic character, and in the case of small molecule xenobiotics of hydrophilic character, the predicted overall Log OWPC is the sole determinant of the overall tendency for interaction with the aqueous phase and represented by the predicted hydrophilic (-) Log OWPC-to-vdWD ratio $\left(\mathrm{nm}^{-1}\right)$, whereas, in the case of small molecule xenobiotics of lipophilic character with the concomitant presence of hydrophilic moieties sufficiently separated in molecular space (S), the predicted incorporating Log OWPC of the hydrophobic portion is the sole determinant of the specific tendency for interaction with the hydrophobic phase and represented by the predicted lipophilic (+) Log incorpOWPC-to-vdWD ratio $\left(\mathrm{nm}^{-1}\right)$ to interact or associate with the hydrophobic constituents of the CM, either with the CM bilayer cholesterols and phospholipid fatty acid-esters or with $\mathrm{CM}$ protein/receptor hydrophobic cores.

Based on assessment of the 2-D molecular structures of small molecule xenobiotics, those of pure hydrophilic character have a cyclic or linear backbone containing hydrophilic groups, and therefore, pure hydrophilic xenobiotics neither associate with $\mathrm{CM}$ phospholipids nor CM proteins and receptors, while those with lower hydrophilicity (-) Log OWPC-to-vdWD ratios $\left(\mathrm{nm}^{-1}\right)$ can permeate across $\mathrm{CM}$ protein channel aqueous pores analogous to permeation across barrier pores, molecular size permitting (8), which, in the case of the least hydrophilic pure hydrophile xenobiotics is $\leq 0.78 \mathrm{~nm}$ (Tables I and II).

Xenobiotics of overall hydrophilic character with incorporating lipophilicity (small molecule hydro-lipophiles) and of overall lipophilic character in the absence or presence of hydrophilic portions/hydrophilic functional groups (small molecule lipophiles) that are larger than vdWD $\sim 0.78 \mathrm{~nm}$ do not permeate across $\mathrm{CM}$ aqueous channel pores due to a molecular size limitation to permeation, and therefore, instead associate with $\mathrm{CM}$ constituents, either with $\mathrm{CM}$ phospholipids or with CM phospholipid bilayer bilayer-associated proteins. Based on the structural arrangement of atoms, xenobiotics larger than vdWD $\sim 0.78 \mathrm{~nm}$ can be categorized, as follows:

i) Those with non-charged backbone atoms in central linear arrangement in the form of cyclic rings alternating with atoms in chains in the presence or absence of structural anisotropic hydrophilicity (uni-polar hydrophilicity), which results in unstable association with $\mathrm{CM}$ associated-protein core hydrophobicity, whereby such xenobiotics associate 
within CM phospholipid bilayers instead, and pertubation disrupt due to non-biologic interaction spatial displacement of bilayer fatty acid-esters, with the potential for 1ary indirect pressuromodulation at lower concentrations (17) and include cyclosporine A with the capacity for phospholipid interspace widening-disruption upon insertion (Tables III-V).

ii) Those with backbone atoms arranged in non-linear non-compact, or in a step-like configuration of inter-connected cyclic rings, in the presence or absence of alternating with atoms in linear arrangement (L-to-U-type), which results in stable association with $\mathrm{CM}$ proteins/CM peptide receptors and non-interaction with CM bilayers (Tables VI-XI).

Small molecule xenobiotics that permeate across CM channel aqueous pores to arrest nuclear and mitochondrial function. This category includes the least hydrophilic pure hydrophile small molecule xenobiotics that permeate across CM protein channel aqueous pore nuclear membrane (NM) fenestrations and outer-to-inner mitochondrial membrane (MM) aqueous pores to arrest nuclear DNA transcription and RNA translation function (i.e., Ki67) as well as mitochondrial DNA transcription and RNA translation function, followed by arrest of DNA replication function (Tables I and II, Figs. 1 and 2).

This category of CM, NM and MM pore permeable small molecule xenobiotics include:

i) The DNA and RNA alkylating adductors, nitroso-N-methylurea (EMU) (Log OWPC, -0.55; vdWD, $0.54 \mathrm{~nm}$; Log OWPC-to-vdWD ratio, $-1.20 \mathrm{~nm}^{-1}$ ), temozolomide (TMZ) (Log OWPC, -0.45; vdWD, 0.65 nm; Log OWPC-to-vdWD ratio, $\left.-0.70 \mathrm{~nm}^{-1}\right)(18)$ and nitroso-N-ethylurea (ENU) (Log OWPC, -0.22; vdWD, $0.57 \mathrm{~nm}$; Log OWPC-to-vdWD ratio, $\left.-0.38 \mathrm{~nm}^{-1}\right)(19,20)$. EMU, TMZ and ENU arrest replicative nuclear function via association with nitrogenous bases, of DNA, and RNA, strand nucleotides with sufficient affinity to alkylate nucleotide nucleosides involved in base pairing hydrogen bonding, which renders alkylated base segments of DNA, and RNA, non-functional; these DNA and RNA alkylating small molecule xenobiotics, but are not $\mathrm{P} 450$ cytochrome inducers due to insufficient lipophilicities for size of their hydrophobic moiety (Table I and Fig. 1).

ii) The nucleoside substitutors, decitabine (Log OWPC, -2.35; vdWD, $0.70 \mathrm{~nm}$; Log OWPC-to-vdWD ratio, $-3.35 \mathrm{~nm}^{-1}$ ), gemcitabine (Log OWPC, -1.65; vdWD, $0.72 \mathrm{~nm}$; Log OWPC-to-vdWD ratio, -2.29 $\mathrm{nm}^{-1}$ ), 5-fluorouracil (5-FU) (Log OWPC, -0.66; vdWD, $0.56 \mathrm{~nm}$; Log OWPC-to-vdWD ratio, $\left.-1.18 \mathrm{~nm}^{-1}\right)(21)$ and 3-methyladenine (3-MA) (Log OWPC, -0.31; vdWD, $0.61 \mathrm{~nm}$; Log OWPC-to-vdWD ratio, $-0.51 \mathrm{~nm}^{-1}$ ). Decitabine, gemcitabine and 5-FU arrest replicative function via competitive inhibition with endogenous nitrogenous bases for phosphorylation and/or ribosylation enzyme active sites, by substitution into DNA and RNA strands, thereby rendering substituted nucleotide segments of DNA and RNA non-functional. 3-MA, although a nucleotide substitute for adenosine upon ribosylation phosphorylation, does not interfere with DNA helix base pairing upon substitution due to the exterior presence of the methyl group $\left(\mathrm{CH}_{3}\right)$ (as opposed to interior), whereby, the functionality of 3-MA substituted nucleotide segments of DNA is maintained, that which results in increased burst nuclear DNA transcription and competitive activation of mRNA polyadenylation poly(ADP-ribose) polymerase-1 (PARP-1) (22) and in MM oxidative stress with subsequent release of MM apoptosis inducing factor (AIF), AIF binding of X-linked inhibitor of apoptosis factor (XIAF) and generation of free caspases (i.e., caspase-3) with resultant cleavage of transcriptionally active nuclear chromatin (Table II and Fig. 2).

Of such small molecule hydrophilic xenobiotics, those that permeate through CM channel aqueous pores via unrestricted diffusion include those of diameters ranging between 0.54 and $0.65 \mathrm{~nm}$, in the context of overall hydrophilicities for molecular size ranging between -0.38 and $-1.20 \mathrm{~nm}^{-1}$. Those that permeate through CM channel aqueous pores with a tendency towards restricted diffusion include those of larger diameters, 0.70 and $0.72 \mathrm{~nm}$, in the context of greater overall hydrophilicities for molecular size of -2.29 and $-3.35 \mathrm{~nm}^{-1}$. Such small molecule xenobiotics are permeable across $\mathrm{CM}$ protein channel aqueous pores due to the absence of charge, either anionic or cationic, analogous to endogenous molecules such as the nitrogenous bases and nucleosides, which have similar functional groups and fall within a similar range of vdWDs and hydrophilicities for size in the absence of charge, and primarily accumulate in the nucleus, which has NM fenestrations with a functional upper limit of pores of $\sim 9 \mathrm{~nm}$ (23), for which the permeability surface area product is greater than that of the MM pores. Although such small molecule xenobiotics primarily accumulate within the nucleoplasm, they can also accumulate within the mitochondrial cytosol, via permeation across outer-to-inner MM protein channel pores [voltage dependent anion channel (VDAC)] $(24,25)$, across which small molecule endogenous hydrophiles of similar vdWDs and hydrophilicities for size, are permeable (26); meanwhile, larger and charged endogenous small molecule hydrophiles more hydrophilic for size, such as ATP (3- and $\left.\mathrm{Mg}^{2+} \rightarrow 1-\right)$, are not, while smaller and charged endogenous small molecule hydrophiles less hydrophilic for size such as citrate $\left(3-\right.$ and $\left.\mathrm{Ca}^{2+} \rightarrow 1-\right)$, succinate $(2-\rightarrow$ SuccinateH 1- at $\mathrm{pH} \sim 7)$ and $\mathrm{HPO}_{4}\left(2-\rightarrow \mathrm{H}_{2} \mathrm{PO}_{4} 1-\right.$ at $\left.\mathrm{pH} \sim 7\right)$ are insignificantly more permeable, as these have permeabilities that fall within the order of magnitude of that of ATP (24), in contrast to chloride $\left(\mathrm{Cl}^{-}\right)$, an anion that is not significantly permeable across $\mathrm{CM}$ pores with an anionization-to-atomic diameter ratio (AI-to-AD; $\mathrm{nm}^{-1}$ ) of $4.90 \mathrm{~nm}^{-1}$, which is 3 orders of magnitude more permeable than ATP with a permeability coefficient of $1.1 \times 10^{-12} \mathrm{~cm}^{3} / \mathrm{sec}$ (24), findings that which implicate 'kiss-and-run' exocytosis as the basis for ATP release into the cytosol, for secondary permeation into the nucleus.

Small molecule xenobiotics of this category, being of pure hydrophilic character with lesser overall hydrophilicity, are exquisitely permeable across CM aqueous channel pores and into the intra-nuclear compartment, but also into the intra-mitochondrial compartment (27). Thus, such xenobiotic chemotherapies have shown the potential to be uniformly cytotoxic to tumor cells, via effects in both nuclear and mitochondrial compartments in the setting of an actively maintained concentration gradient in vitro, particularly synergistically $(28,29)$. Therefore, in order to demonstrate similar effectiveness in the clinical setting, such small molecule xenobiotics, as well as others discussed herein, must be made to first and foremost selectively accumulate to effective concentrations within tumor tissue, which can only be accomplished upon labile linking to optimally-sized, and designed, nanoparticles within the 8- to 

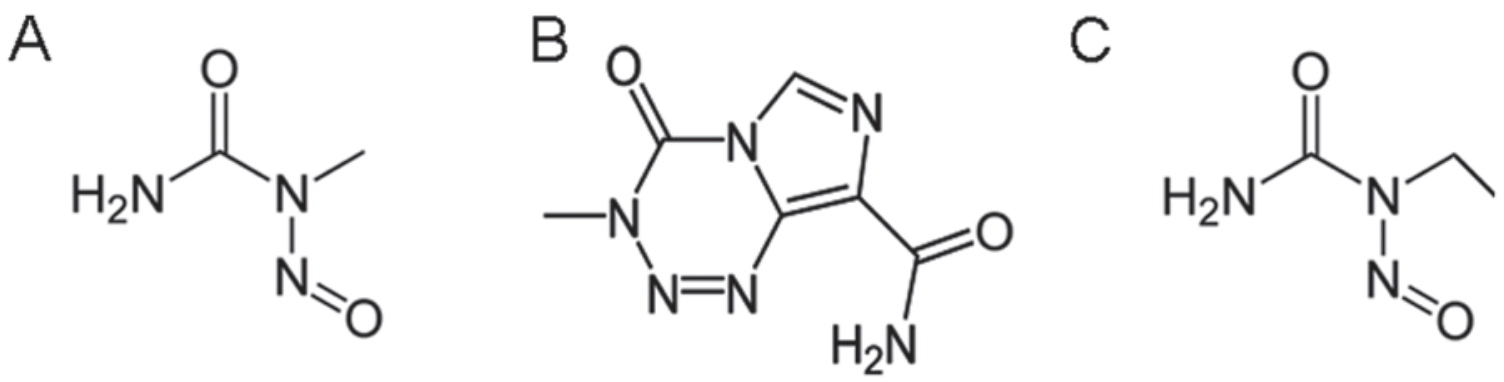

Figure 1. Cell membrane channel aqueous pore permeation and DNA/RNA adduction. (A) Nitroso-N-methylurea, (B) temozolamide, (C) nitroso-n-ethylurea.

9-nm-size range delivered transvascularly (3-7), to ensure uniform cytotoxicity to all tumor tissue cells and minimal risk for subsequent neoplastic transformation of tumor-associated cells including tumor stem cells.

Small molecule xenobiotics that permeate across CM channel aqueous pores to bind to cytochrome P450s: DNA adduction and/or crosslinking. This category includes small molecule xenobiotics, hydro-lipophiles and lipophiles with hydrophilicity, with vdWDs in the 0.74 to $0.67 \mathrm{~nm}$ range, which can permeate across $\mathrm{CM}, \mathrm{NM}$ and $\mathrm{MM}$ aqueous pores with the potential to bind to cytochrome P450s due to the hydrophobicity for size of their hydrophobic moieties, with the potential to arrest nuclear and mitochondrial replication via DNA/RNA alkylation or DNA strand-to-DNA strand crosslinking (Table III and Fig. 3).

This category of CM, NM and MM pore permeable small molecule xenobiotics include:

i) The intra-CM-associated cytochrome P450 hydroxylation-activated $(30,31)$ and intra-MM-associated cytochrome P450 hydroxylation-inactivated $(31,32)$, sub-classified as

a) The intra-CM-associated cytochrome $\mathrm{P} 450$ hydroxylation-activated DNA/RNA guanosine guanine alkylator procarbazine (33) (Log OWPC, -1.70; vdWD, $0.74 \mathrm{~nm}$; Log OWPC-to-vdWD ratio, -2.29 $\mathrm{nm}^{-1}$ ); procarbazine hydrophilic moiety1 (Log OWPC, -0.59; vdWD, $0.51 \mathrm{~nm}$; Log OWPC-to-vdWD ratio, -1.17 $\mathrm{nm}^{-1}$ ); procarbazine hydrophobic moietyl (Log OWPC, 2.51; vdWD, $0.57 \mathrm{~nm}$; Log OWPC-to-vdWD ratio, $4.43 \mathrm{~nm}^{-1}$ ); procarbazine hydrophilic moiety2 (Log OWPC, -1.11; vdWD, $0.43 \mathrm{~nm}$; Log OWPC-to-vdWD ratio, -2.61 $\mathrm{nm}^{-1}$ ); procarbazine hydrophobic moiety2 (Log OWPC, 1.82; vdWD, $0.48 \mathrm{~nm}$; Log OWPC-to-vdWD ratio, $3.75 \mathrm{~nm}^{-1}$ ): procarbazine alkylates DNA/RNA guanosine guanines via its $\mathrm{CH}_{3}-\mathrm{NH}_{2}-\mathrm{NH}_{2}$-terminal hydrophilic moiety1, but without the potential to crosslink (Table III and Fig. 3).

(b) The intra-CM-associated cytochrome $\mathrm{P} 450$ hydroxylation-activated DNA strand-to-DNA strand crosslinkers, cyclophosphamide (34) (Log OWPC, 0.10; vdWD, $0.73 \mathrm{~nm}$; Log OWPC-to-vdWD ratio, $0.14 \mathrm{~nm}^{-1}$ ); cyclophosphamide hydrophilic core (Log OWPC, -1.92; vdWD, $0.59 \mathrm{~nm}$; Log OWPC-to-vdWD ratio, $-3.25 \mathrm{~nm}^{-1}$ ); cyclophosphamide hydrophobic moieties 1 and 2 ( $\log$ OWPC, 1.19; vdWD, $0.48 \mathrm{~nm}$; Log OWPC-to-vdWD ratio, $2.49 \mathrm{~nm}^{-1}$ ) and ifosfamide (Log OWPC, 0.10 ; vdWD, $0.73 \mathrm{~nm} ; \log$ OWPC-to-vdWD ratio, $0.14 \mathrm{~nm}^{-1}$ ); ifosfamide hydrophilic core (Log OWPC, -1.92; vdWD, $0.59 \mathrm{~nm}$; Log OWPC-to-vdWD ratio, $-3.25 \mathrm{~nm}^{-1}$ );<smiles>Nc1ccn([C@@H]2C[C@H](O)[C@H](CO)O2)c(=O)n1</smiles><smiles>Nc1ccn(C2OC(CO)[C@@H](O)C2(F)F)c(=O)n1</smiles><smiles>O=c1[nH]cc(F)c(=O)[nH]1</smiles><smiles>Cn1cnc(N)c2ncnc1-2</smiles>

Figure 2. Cell membrane channel aqueous pore permeation and nucleoside substitution. (A) Decitabine, (B) gemcitabine, (C) 5-fluorouracil, (D) 3-methyladenine.

ifosfamide hydrophobic moieties 1 and 2 ( $\log$ OWPC, 1.19; vdWD, $0.48 \mathrm{~nm}$; Log OWPC-to-vdWD ratio, $2.49 \mathrm{~nm}^{-1}$ ). Cyclophosphamide and ifosfamide crosslink DNA strand-to-DNA strand guanine N7s due to the length of their 2 reactive hydrophobic moieties, $\mathrm{CH}_{2}-\mathrm{CH}_{2}-\mathrm{CL} \times 2$, rendering G-to-G cross linked segments inseparable, non-functional and prone to strand breaks, and can directly inhibit glutathione reductase (37-41) (Table III and Fig. 3).

ii) The intra-CM-associated cytochrome $\mathrm{P} 450$ hydroxylation-inactivated $(31,32,35)$, DNA strand-to-DNA strand crosslinker carmustine (BCNU) (Log OWPC, 0.95; vdWD, $0.67 \mathrm{~nm}$; Log OWPC-to-vdWD ratio, $1.41 \mathrm{~nm}^{-1}$ ). Carmustine crosslinks DNA strand-to-DNA strand guanine N7s (36) due to the length of its 2 reactive hydrophobic moieties, $\mathrm{CH}_{2}-\mathrm{CH}_{2}-\mathrm{Cl} \times 2$, rendering G-to-G cross linked segments inseparable, non-functional and prone to strand breaks, and can directly inhibit glutathione reductase (37-41) (Table III and Fig. 3).

Of such small molecule xenobiotics with intra-structural hydrophobicity, those that are most likely to achieve intra-cellular levels are those that are both of smaller size and relatively less lipophilic, as these can diffuse through CM channel aqueous pores without restriction and partition to a 
sufficient extent into the aqueous phase, which is the case for procarbazine (Log OWPC-to-vdWD ratio, -2.29 $\mathrm{nm}^{-1}$; vdWD, $0.74 \mathrm{~nm}$ ) while those most likely to interact with the CM phospholipid bilayer are those that are of larger size as these are restricted to diffusion through $\mathrm{CM}$ channel aqueous pores, and importantly, those with greater overall molecular lipophilicity cum larger size, as these have the tendency to associate into the phospholipid bilayer among fatty acid-esters. This is the case of those within the overall lipophilicity range of cyclophosphamide/ifosfamide (Log OWPC-to-vdWD ratio, $0.14 \mathrm{~nm}^{-1}$; vdWD, $\left.0.73 \mathrm{~nm}\right)(34,42,43)$ which are of larger size, and carmustine (Log OWPC-to-vdWD ratio, $1.41 \mathrm{~nm}^{-1}$; vdWD, $0.67 \mathrm{~nm}$ ) (44), which is more lipophilic (44), for which there is a greater tendency to associate with and perturb CM phospholipids and the potential for a 1ary indirect pressuromodulation-mediated secondary increase in very high molecular weight (MW) protein transcription (17), while such small molecule xenobiotics of lipophilic character may only achieve intra-cellular levels at significant extracellular concentrations (45), which makes the more lipophilic xenobiotics of this category marginal chemoxenobiotics for effective transvascular delivery into solid tumor tissue (3-7) .

Small molecule xenobiotics that insert in-between CM phospholipids with the potential for lary indirect pressuromodulation. This category includes small molecule xenobiotics with hollow isophilic interiors and molecular lipophilicity in the form of the circumferential presence of lipophilic moieties on the exterior, insert in-between CM phospholipids at the phospholipid glycerol-fatty acid ester junctions (46), and include, cyclosporine A (Log OWPC, 3.64; vdWD, $1.31 \mathrm{~nm}$; Log OWPC-to-vdWD ratio, $2.78 \mathrm{~nm}^{-1}$ ), which has a 5 carbon $(5 \mathrm{C})$ alkene tail that predisposes to $\mathrm{CM}$ phospholipid glycerol-fatty acid ester association rather than with CM receptor protein hydrophobicity (Table IV and Fig. 4).

Cyclosporine A has been shown to decrease the rate of cell division only in the presence of powerful CM receptor pressuromodulators $(47,48)$, which is due to generation of nuclear transcription-driven burst mitochondrial reactive $\mathrm{O}_{2}$ species $(47,49)$ secondary to the increased transcription of the intermediate MW proteins (i.e., p53) and BCL depletion, or in the presence of mitochondrial-associated microtubule network disruptors (49), which is due to concomitant mitochondrial anchorage-mediated MM disruption/dissolution toxicity and generation of free caspases (i.e., free caspase-3). At low intra-tumoral concentrations cyclosporine A has more potential to cause 1ary indirect pressuromodulation (perturbomodulation) (17), that would actually cause an increase in the transcription of very high MW proteins such as secretory proteins (i.e., fibronectin, $240 \mathrm{kDa}$ ) and nuclear division proteins (Ki67, 359 kDa; separase, $230 \mathrm{kDa}$ ) (17). Furthermore, as cyclosporine $\mathrm{A}$ is highly serum protein-bound secondary to its overall lipophilicity for size (Log OWPC-to-vdWD ratio, $2.78 \mathrm{~nm}^{-1}$ ), it is difficult to obtain $\mu \mathrm{M}$ local cyclosporine A intra-tumoral concentrations in standard free drug intravenous chemotherapeutic regimens.

Small molecule xenobiotics that associate with CM cholesterol or phospholipid fatty acid-esters with the potential for lary indirect pressuromodulation. This category includes 


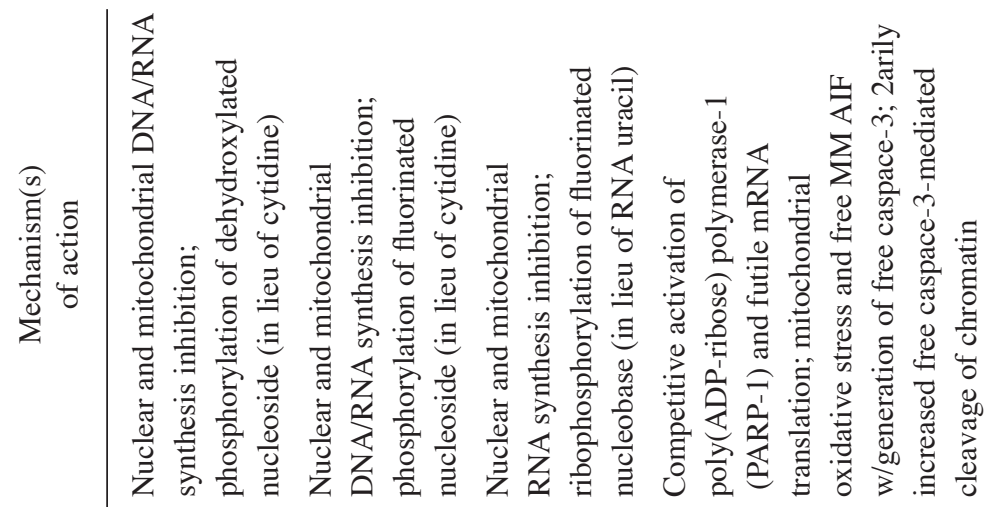

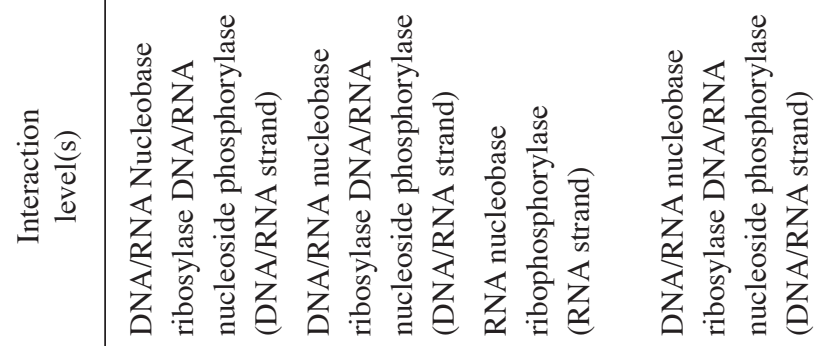

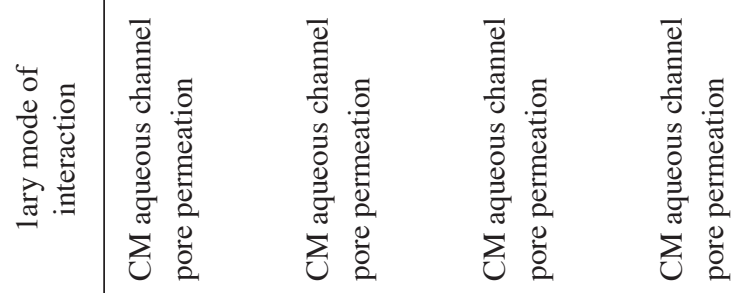

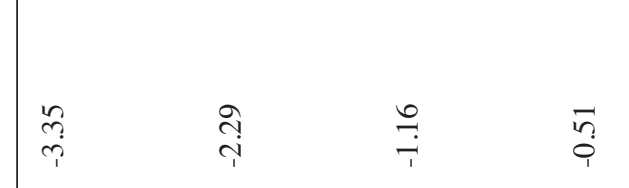

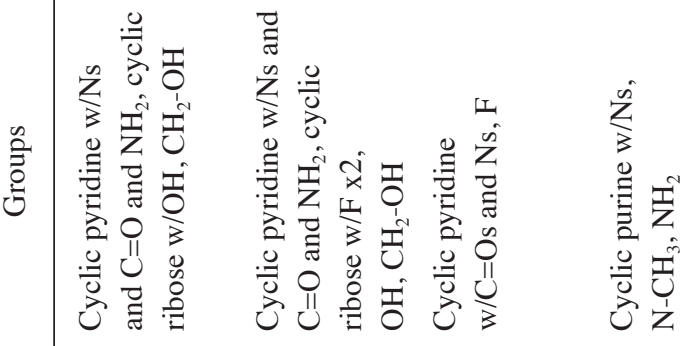




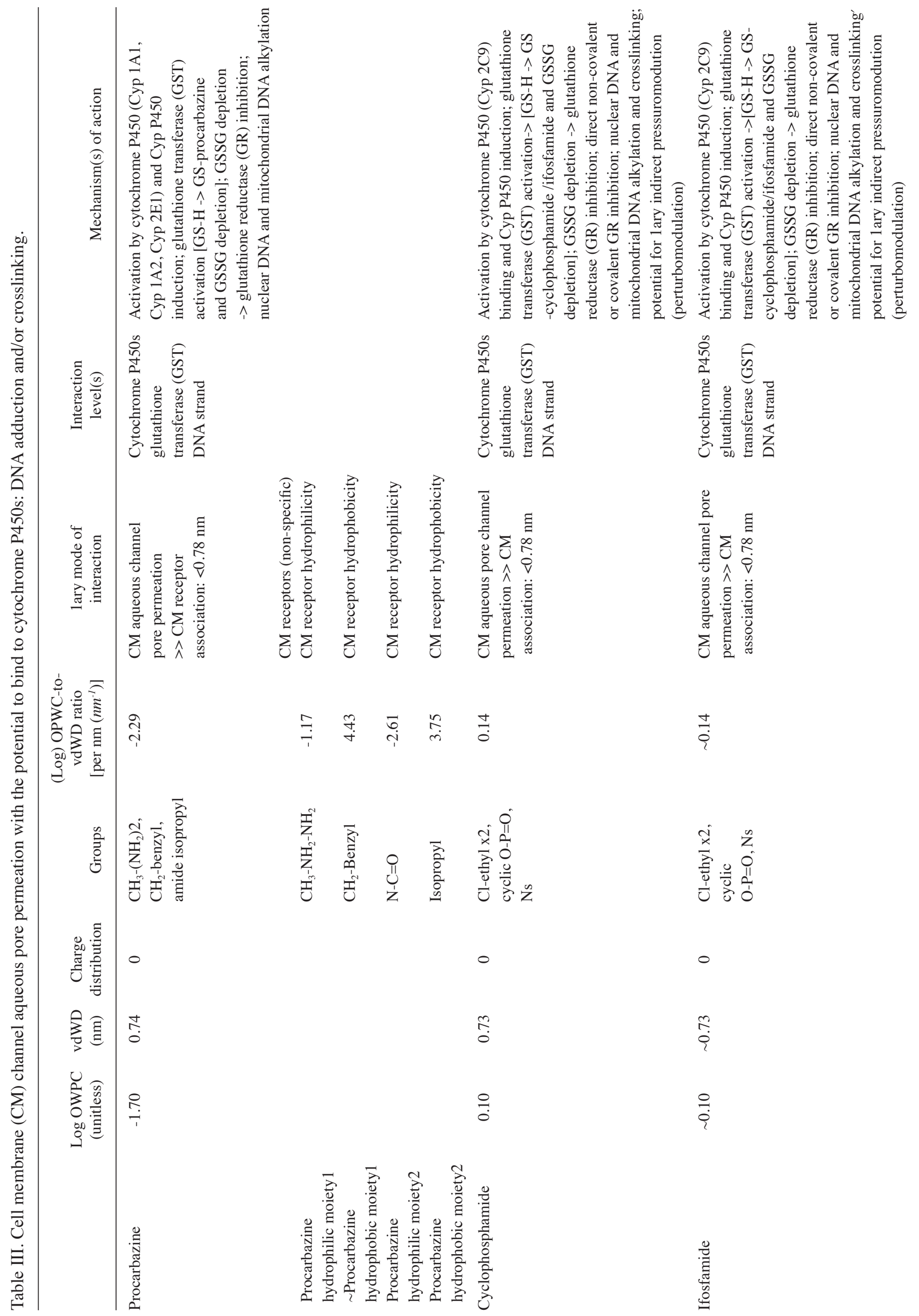




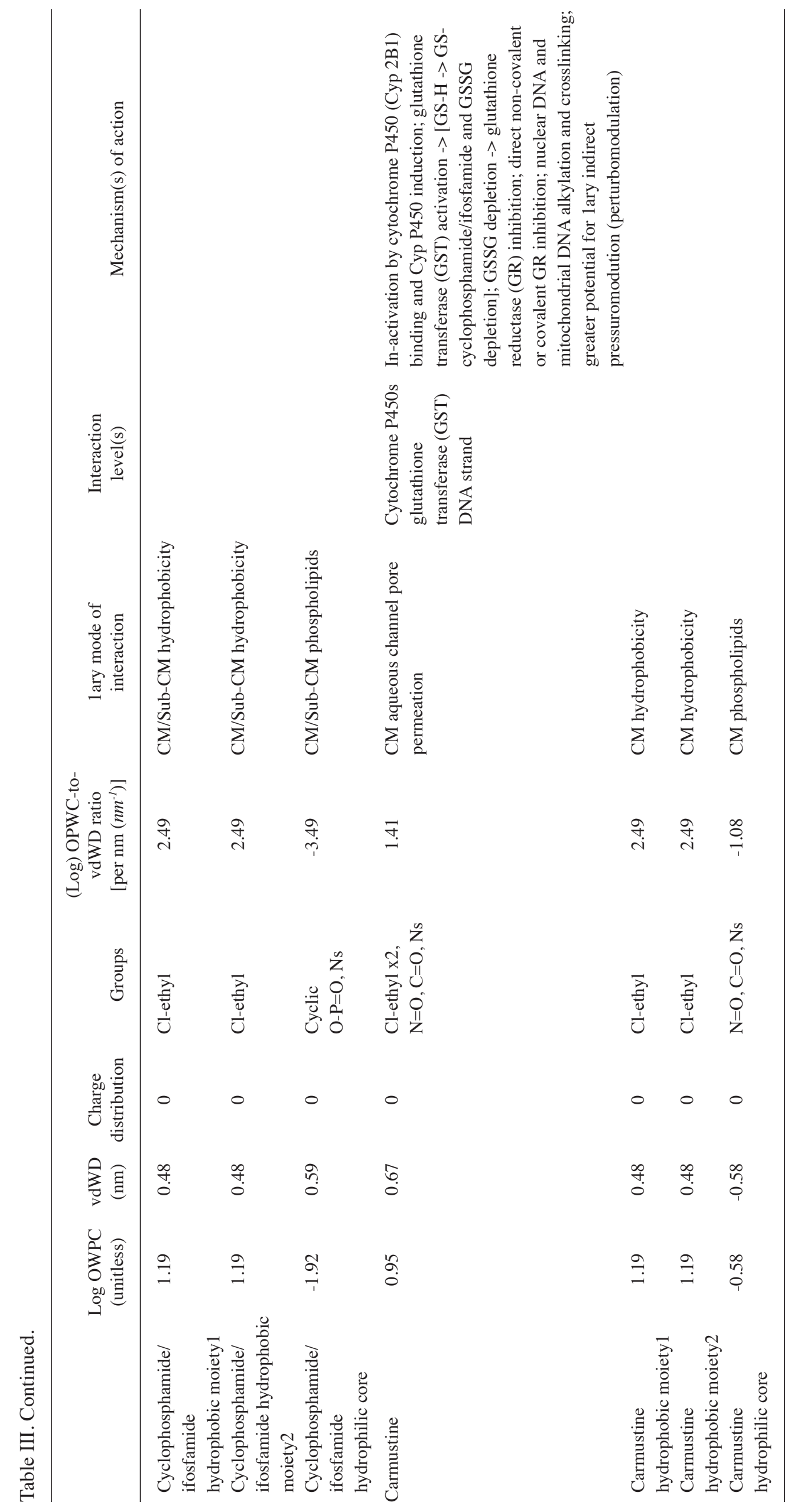


A

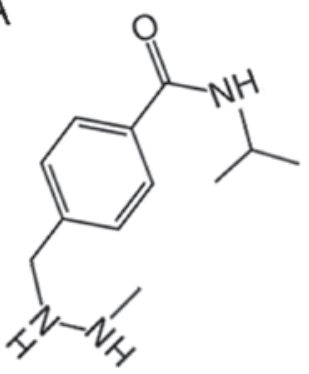

B

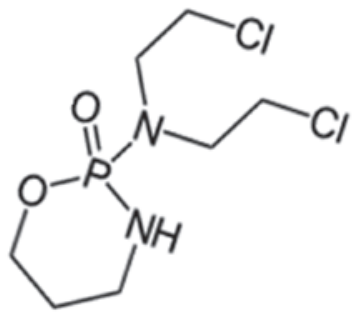

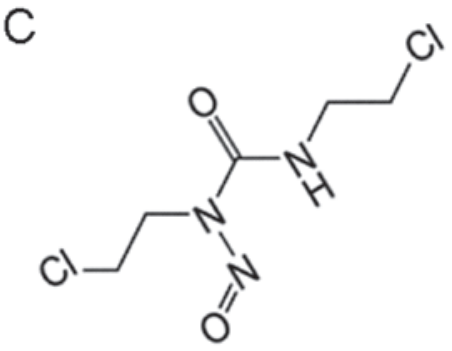

Figure 3. Cell membrane channel aqueous pore permeation and potential to bind to cytochrome P450s: DNA adduction and/or crosslinking. (A) Procarbazine, (B) cyclophosphamide, (C) carmustine.

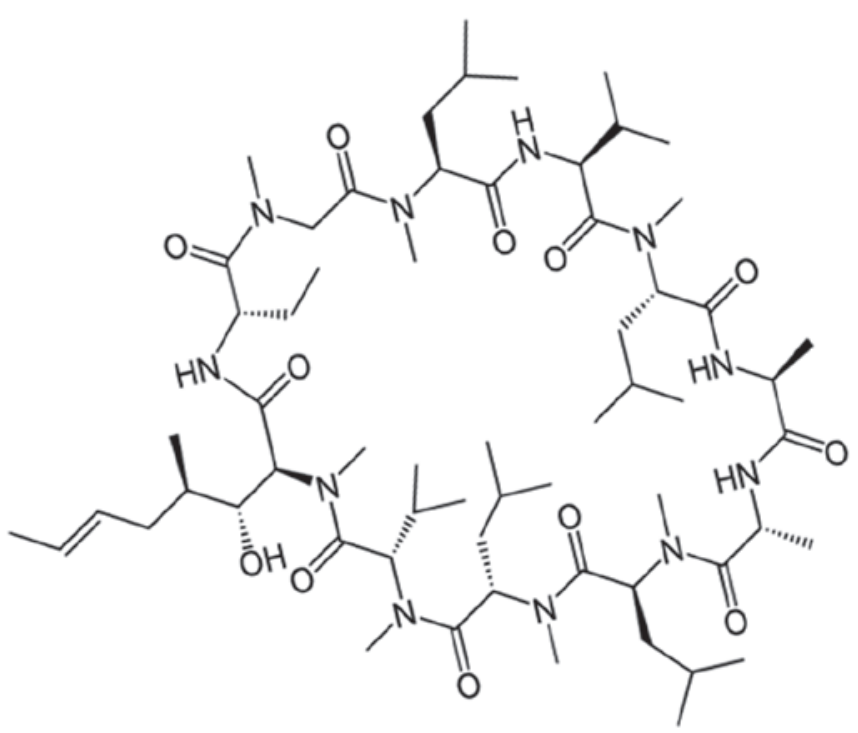

Figure 4. Cell membrane insertoassociation and phospholipid interspace widening with potential for 1ary indirect pressuromodulation. Cyclosporine A.

small molecule xenobiotics, hydro-lipophiles with anisotropic molecular hydrophilicity cum lipophilicity to lipophiles with anisotropic molecular hydrophilicity or absence of, with vdWDs in the 1.18-0.77 $\mathrm{nm}$ range (Table $\mathrm{V}$ and Fig. 5).

Small molecule xenobiotic hydro-lipophiles with anisotropic molecular hydrophilicity cum lipophilicity include: i) nystatin (Log OWPC, -2.00; vdWD, $1.18 \mathrm{~nm}$; Log OWPC-to-vdWD ratio, $-1.70 \mathrm{~nm}^{-1}$ ); ii) amphotericin B (Log OWPC, -1.30; vdWD, $1.17 \mathrm{~nm}$; Log OWPC-to-vdWD ratio, -1.11 $\mathrm{nm}^{-1}$ ); iii) filipin (Log OWPC, -0.15; vdWD, $1.00 \mathrm{~nm}$; Log OWPC-to-vdWD ratio, $-0.15 \mathrm{~nm}^{-1}$ ), with their hydrophobic inner crescent having a lipophilicity for size of $8.32 \mathrm{~nm}^{-1}$ (Log OWPC, 6.73; vdWD, $0.81 \mathrm{~nm}$ ).

Nystatin, amphotericin B and filipin associate with CM bilayer cholesterol with their hydrophobic inner crescent over the exposed outer surface area of CM cholesterol, which is within the range of lipophilicity for the size of the CM bilayer surface cholesterol portion of between 9.25$7.7 \mathrm{~nm}^{-1}$ (Log OWPC, 8.5-7.11; vdWD, $0.92 \mathrm{~nm}$ ), but do not physically incorporate into $\mathrm{CM}$-associated protein receptor isophilic-to-hydrophobic interiors (cores) due to the presence of anisotropic molecular hydrophilicity cum lipophilicity. Thus, such small molecule xenobiotics remove CM choles- terol via cholesteroloassociation with the more exteriorly protruding cholesterol portion to decrease CM cholesterol concentration, thereby, de-stabilizing the CM sufficiently enough to concomitantly cause CM destabilization-mediated extrusion of CM cholesterol-associated proteins/receptors, and as a result, also have the potential to cause a subsequent lary indirect pressuromodulation (perturbomodulation)-mediated secondary increase in very high MW protein transcription (17,50,51) (Table V and Fig. 5).

Small molecule xenobiotic lipophiles with anisotropic molecular hydrophilicity include:

i) Chlorambucil [(Log OWPC, 0.60; vdWD, $0.79 \mathrm{~nm}$; Log OWPC-to-vdWD ratio, $0.76 \mathrm{~nm}^{-1}$ ); chlorambucil hydrophobic core (Log OWPC, 5.26; vdWD, $0.79 \mathrm{~nm}$; Log OWPC-to-vdWD ratio, $\left.6.75 \mathrm{~nm}^{-1}\right)$ ], in the case of small molecule xenobiotic lipophile with anisotropic molecular hydrophilicity, chlorambucil [(Log OWPC, 0.60; vdWD, $0.79 \mathrm{~nm}$; Log OWPC-to-vdWD ratio, $0.76 \mathrm{~nm}^{-1}$ ); chlorambucil hydrophobic core (Log OWPC, 5.26; vdWD, 0.79 nm; Log OWPC-to-vdWD ratio, $\left.6.75 \mathrm{~nm}^{-1}\right)$ ], associates into the CM closely with the CM phospholipid layer-spanning portion of cholesterol that has a lipophilicity of $\sim 7.26 \mathrm{~nm}^{-1}$ which is close to its hydrophobic core lipophilicity of $6.75 \mathrm{~nm}^{-1}$, while transiently stabilizing itself in the layer by concomitantly interacting anisotropically with the layer phospholipid head groups viz a viz its mono-anionic hydrophilic-interacting $\mathrm{COO}^{-}$moiety, to remove cholesterol via cholesteroloassociation secondary to unstable structural association with phospholipid layer fatty acid-ester tails in context of an inability to glyceroloesterify. Therefore, chlorambucil is not an effective intra-cellularly localizing mitochondrial or nuclear DNA/RNA alkylating/bi-functional DNA crosslinking chemoxenobiotic, but instead removes CM cholesterol via cholesteroloassociation with the CM phospholipid layer-spanning interior cholesterol portion to decrease $\mathrm{CM}$ cholesterol concentration $(52,53)$ and as a result, has the potential to cause a subsequent 1ary indirect pressuromodulation (perturbomodulation)-mediated secondary increase in very high MW protein transcription (17) (Table V and Fig. 5).

ii) Melphalan $[(\log$ OWPC, 1.00; vdWD, $0.79 \mathrm{~nm}$; Log OWPC-to-vdWD ratio, $1.27 \mathrm{~nm}^{-1}$ ); melphalan hydrophobic core (Log OWPC, 4.42; vdWD, $0.75 \mathrm{~nm}$; Log OWPC-to-vdWD ratio, $\left.\left.5.86 \mathrm{~nm}^{-1}\right)\right]$. In the case of small molecule xenobiotic lipophile with anisotropic molecular hydrophilicity, melphalan [(Log OWPC, 1.00; vdWD, 0.79 nm; Log OWPC-to-vdWD ratio, $1.27 \mathrm{~nm}^{-1}$ ); melphalan hydrophobic core (Log OWPC, 4.42; vdWD, $0.75 \mathrm{~nm}$; Log OWPC-to-vdWD ratio, $\left.5.86 \mathrm{~nm}^{-1}\right)$ ], 


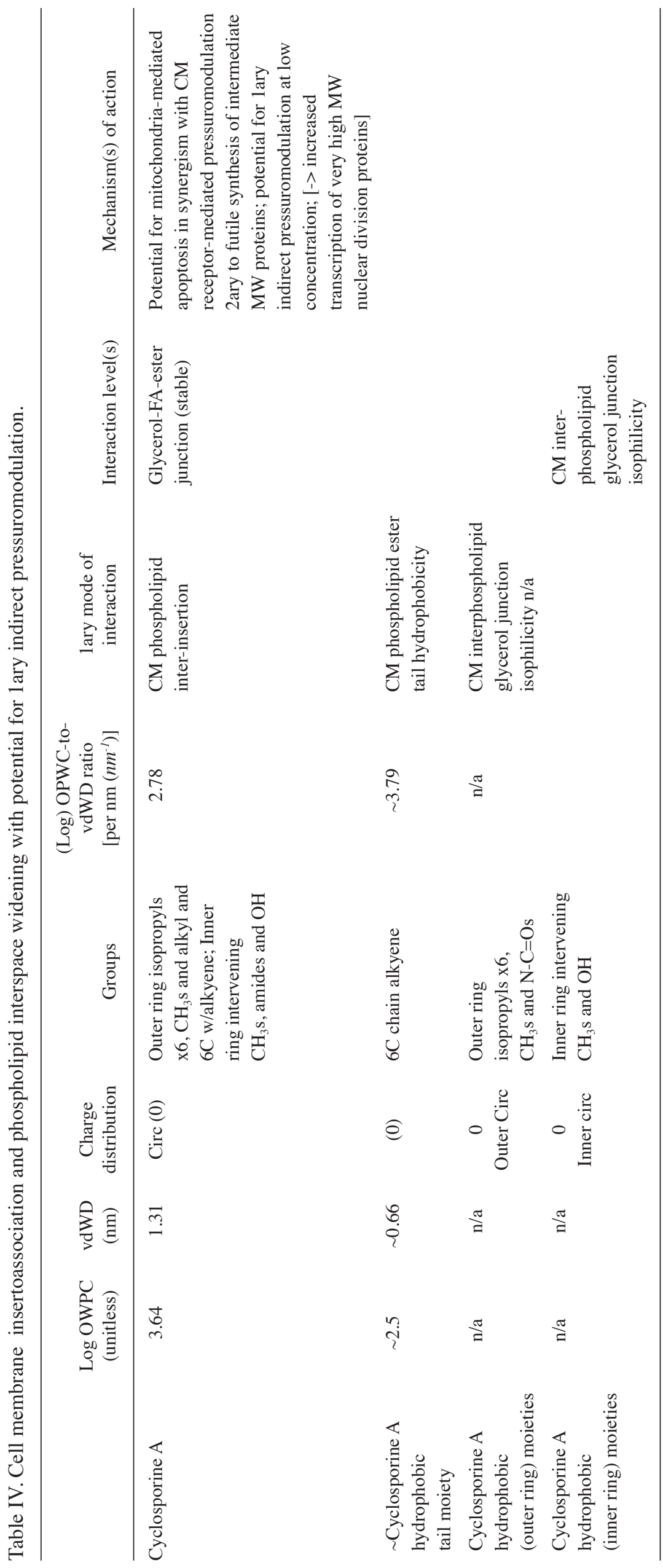




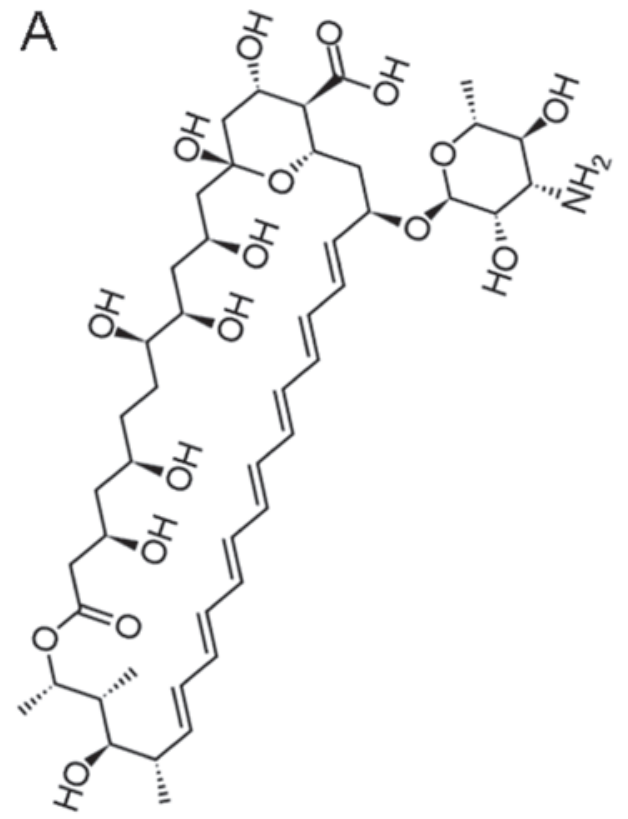<smiles>COC(=O)CCCc1ccc(N(CCCl)CCCl)cc1</smiles><smiles>N[C@@H](Cc1ccc(N(CCCl)CCCl)cc1)C(=O)O</smiles><smiles></smiles>

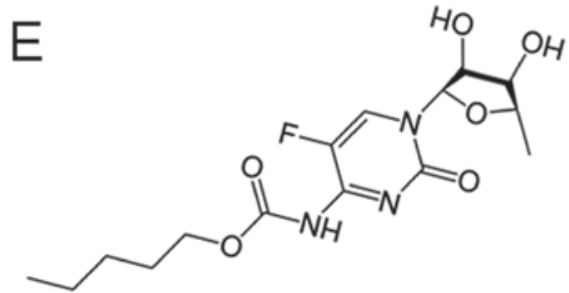<smiles>Cc1ccc(C(O)(Cn2cncn2)Cn2cncn2)c(C)c1</smiles>

Figure 5. Cell membrane (CM) cholesteroloassociation-to-CM phospholipidoassociation: cholesterol removal-to-CM Phospholipid pertubation and potential for 1ary indirect pressuromodulation. (A) Amphotericin B, (B) chlorambucil, (C) melphalan, (D) ketoconazole (at pH 7.4), (E) capecitabine, (F) fluconazole.

associates directly into the CM among the CM phospholipid layer fatty acid-ester tails, rather than with the CM phospholipid layer-spanning interior cholesterol portion, along with more stable association within the layer by virtue of the concomitant anisotropic interaction of its cataniononeutral hydrophilic-interacting $\mathrm{NH}^{+} \mathrm{COO}^{-}$moiety with layer phospholipid head groups, that importantly results in its ability to secondarily subsequently trans-displace across CM phospholipid layers and bilayer over time into the intra-cellular compartment. For this reason, melphalan achieves perceptible intra-cellular concentrations, to which specific cytochrome P450s exist (CYP 3A and CYP 27), but without induction. As a result of only a transient cytochrome $\mathrm{P} 450$ association in the context of higher affinity association with outer mitochondrial membrane (OMM) bilayer layer fatty acid-ester tails due to a hydrophobic core lipophilicity of $5.86 \mathrm{~nm}^{-1}$, melphalan is not an effective intra-cellularly localizing nuclear DNA/RNA alkylating/bi-functional DNA crosslinking chemoxenobiotic. Therefore, the primary mode of melphalan cellular toxicity is mitochondrial (54-56) and mitochondrially-mediated, via initiation of the mitochondrial cellular apoptosis cascade, beginning at the level of the OMM bilayer (57) upon the displacement of AIF $(58,59)$ from the OMM, as follows: i) disassociation of OMM AIF into the cytosol and binding to XIAF (60) with affinity, thereby disassociating XIAF-bound cytosolic-to-nuclear caspases (caspase-3) $(61,62)$ from bound to free caspase forms, which are pro-membranocytotoxic and pro-nucleochromatotoxic and pro-apoptotic in their free forms; in tandem with ii) association of cytosolic-to-nuclear AIF homolog, BCL (63) with the OMM in place of AIF, thereby, shifting the nuclear BCL bound-p53 equilibrium to free p53 (64-66), being the primary constitutive nuclear transcription factor for PUMA/BIM-like proteins $(67,68)$ and BAX/BID-like proteins (66), whereby, avid binding of BCL by the PUMA and BIM-like proteins, being singular $\alpha$-helix peptides, leads to further depletion of free BCL (PUMA-BCL and BIM-BCL). The combination of i) and ii) results in mitochondrially-mediated cellular apoptosis (Table V and Fig. 5).

iii) Ketaconazole [(Log OWPC, 4.19; vdWD, $0.94 \mathrm{~nm}$; Log OWPC-to-vdWD ratio, $\left.4.46 \mathrm{~nm}^{-1}\right)$; ketaconazole hydrophobic moiety1 (Log OWPC, 3.30; vdWD, $0.71 \mathrm{~nm}$; Log OWPC-to-vdWD ratio, $\left.4.64 \mathrm{~nm}^{-1}\right)$ ]. In the case of 


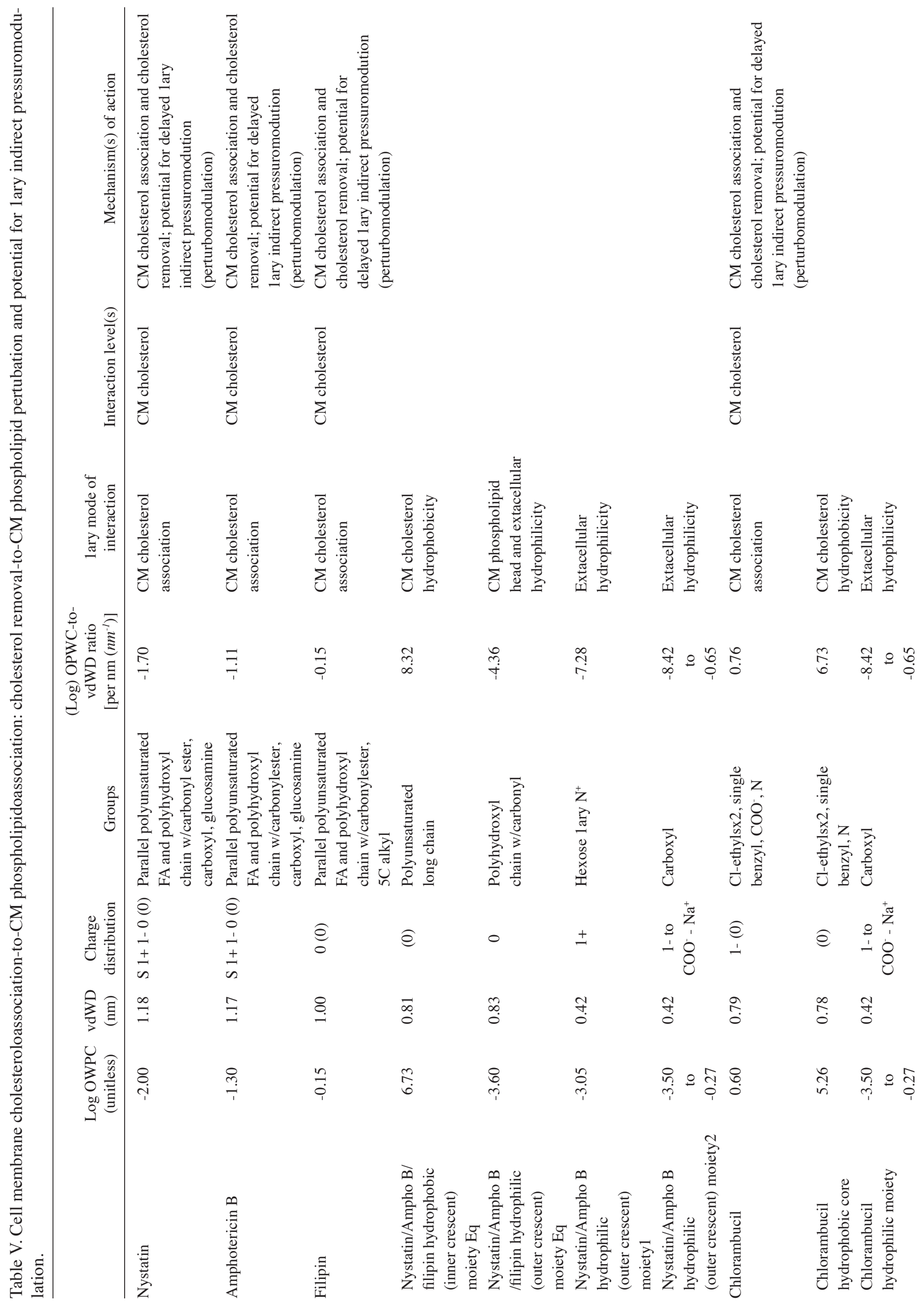




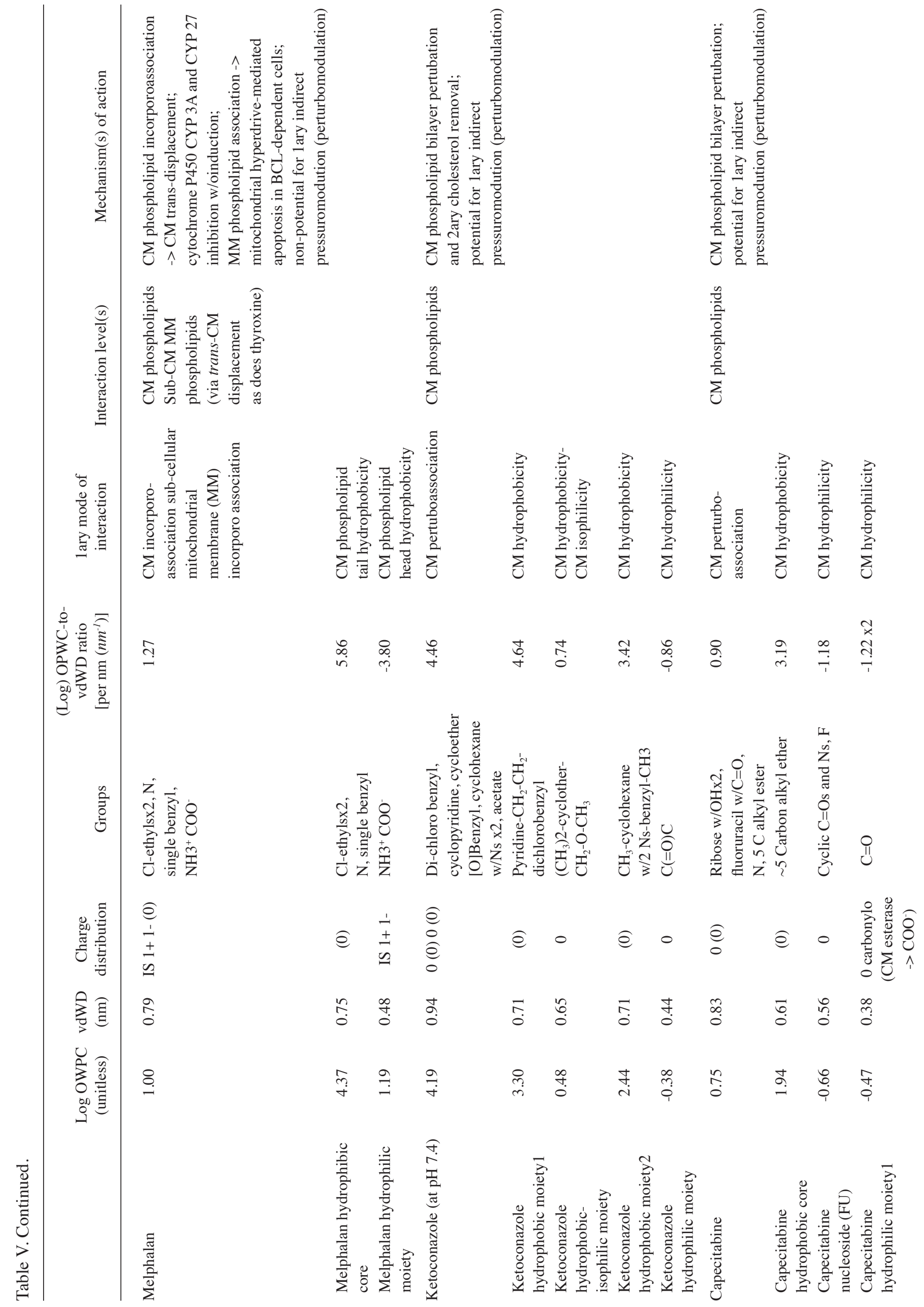




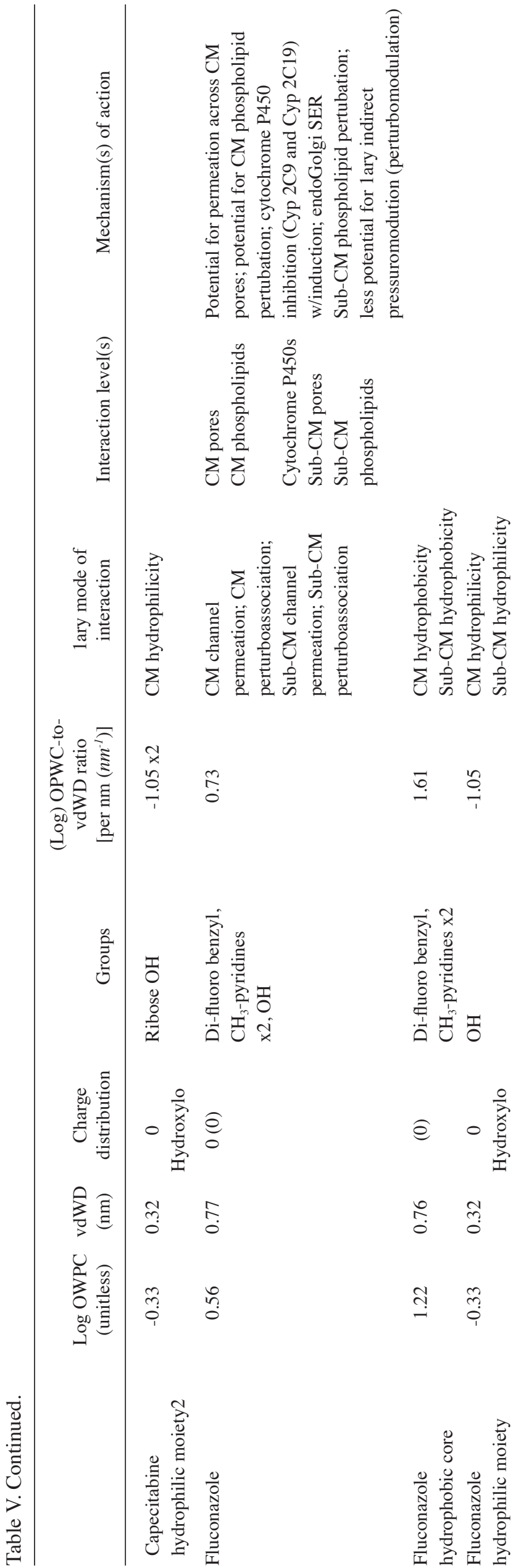

small molecule xenobiotic lipophile without anisotropic molecular hydrophilicity, ketaconazole [(Log OWPC, 4.19; vdWD, $0.94 \mathrm{~nm}$; Log OWPC-to-vdWD ratio, $4.46 \mathrm{~nm}^{-1}$ ); ketaconazole hydrophobic moiety1 (Log OWPC, 3.30; vdWD, $0.71 \mathrm{~nm}$; Log OWPC-to-vdWD ratio, $\left.4.64 \mathrm{~nm}^{-1}\right)$ ], associates directly into the $\mathrm{CM}$ among the $\mathrm{CM}$ phospholipid layer fatty acid-ester tails, but the least stably of those in this category, due to an absence of structural hydrophilic anisotropy. Thus, ketoconazole perturbs the CM bilayer sufficiently enough to secondarily dissociate CM cholesterol from the bilayer, which is the primary mode of ketoconazole cellular toxicity and is attributable to its $\mathrm{CM}$ cholesterol removal secondary to perturbation of the $\mathrm{CM}$ bilayer with an associated initial decrease in $\mathrm{CM}$ and whole cell/intra-cellular pressuromodulation $(17,69,70)$ followed by a secondary increase in very high MW protein transcription due to 1ary indirect pressuromodulation (perturbomodulation) (17), which may result in burst nuclear transcription-associated with mitochondrial oxidative phosphorylation-MM-mediated nuclear and cellular cytotoxicity/apoptosis $(17,71)$ particularly, in the setting of pre-existent concomitant $\mathrm{CM}$ receptor pressuromodulation antagnonism such as that of nocodazole (72), a CM receptor pressuromodulation antagonist (Table $\mathrm{V}$ and Fig. 5).

iv) Capecitabine $[(\log$ OWPC, 0.75 ; vdWD, $0.83 \mathrm{~nm}$; Log OWPC-to-vdWD ratio, $0.90 \mathrm{~nm}^{-1}$ ); capecitabine hydrophobic core (Log OWPC, 1.94; vdWD, $0.61 \mathrm{~nm}$; Log OWPC-to-vdWD ratio, $\left.3.19 \mathrm{~nm}^{-1}\right)$ ].

v) Fluconazole [(Log OWPC, 0.56; vdWD, $0.77 \mathrm{~nm}$; Log OWPC-to-vdWD ratio, $0.73 \mathrm{~nm}^{-1}$ ); fluconazole hydrophobic core (Log OWPC, 1.22; vdWD, $0.76 \mathrm{~nm}$; Log OWPC-to-vdWD ratio, $\left.1.41 \mathrm{~nm}^{-1}\right)$ ].

In the case of small molecule xenobiotic lipophiles with anisotropic molecular hydrophilicity with less incorporating lipophilicity, capecitabine [(Log OWPC, 0.75; vdWD, $0.83 \mathrm{~nm}$; Log OWPC-to-vdWD ratio, $0.90 \mathrm{~nm}^{-1}$ ); capecitabine hydrophobic core (Log OWPC, 1.94; vdWD, $0.61 \mathrm{~nm}$; Log OWPC-to-vdWD ratio, $3.19 \mathrm{~nm}^{-1}$ )] and fluconazole [ $(\log \mathrm{OWPC}, 0.56$; vdWD, $0.77 \mathrm{~nm}$; Log OWPC-to-vdWD ratio, $0.73 \mathrm{~nm}^{-1}$ ); fluconazole hydrophobic core (Log OWPC, 1.22; vdWD, $0.76 \mathrm{~nm}$; Log OWPC-to-vdWD ratio, $\left.1.41 \mathrm{~nm}^{-1}\right)$ ], both associate directly into the $\mathrm{CM}$ among the $\mathrm{CM}$ phospholipid layer fatty acid-ester tails, but due to insufficient hydrophobic portion incorporating lipophilicities in the range of between 3.19 and $1.41 \mathrm{~nm}^{-1}$, only temporarily associate into the CM bilayer, to transiently perturb and disorder CM phospholipids, and of the two, fluconazole (vdWD, $0.77 \mathrm{~nm}$ ) has the potential for CM channel aqueous pore permeation (73), with the potential to also perturb sub-cellular membrane phospholipids including those of the endoGolgi smooth endoplasmic reticulum (SER) with high CM-derived sub-cellular membrane cholesterol phospholipid turnover rates and lower incorporating lipophilicities. In the case of both, capecitabine and fluconazole, the primary mode of cellular toxicity is attributable to perturbation of the $\mathrm{CM}$ bilayer with an associated initial decrease in $\mathrm{CM}$ and whole cell/intra-cellular pressuromodulation (17,74), in which case, of the two, capecitabine has the greater potential to cause a subsequent 1ary indirect pressuromodulation (perturbomodulation)-mediated secondary increase in 
A

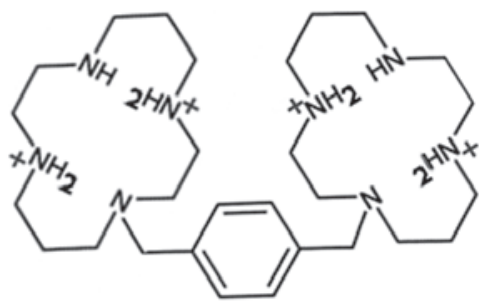

B

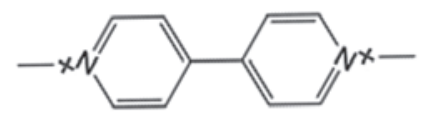

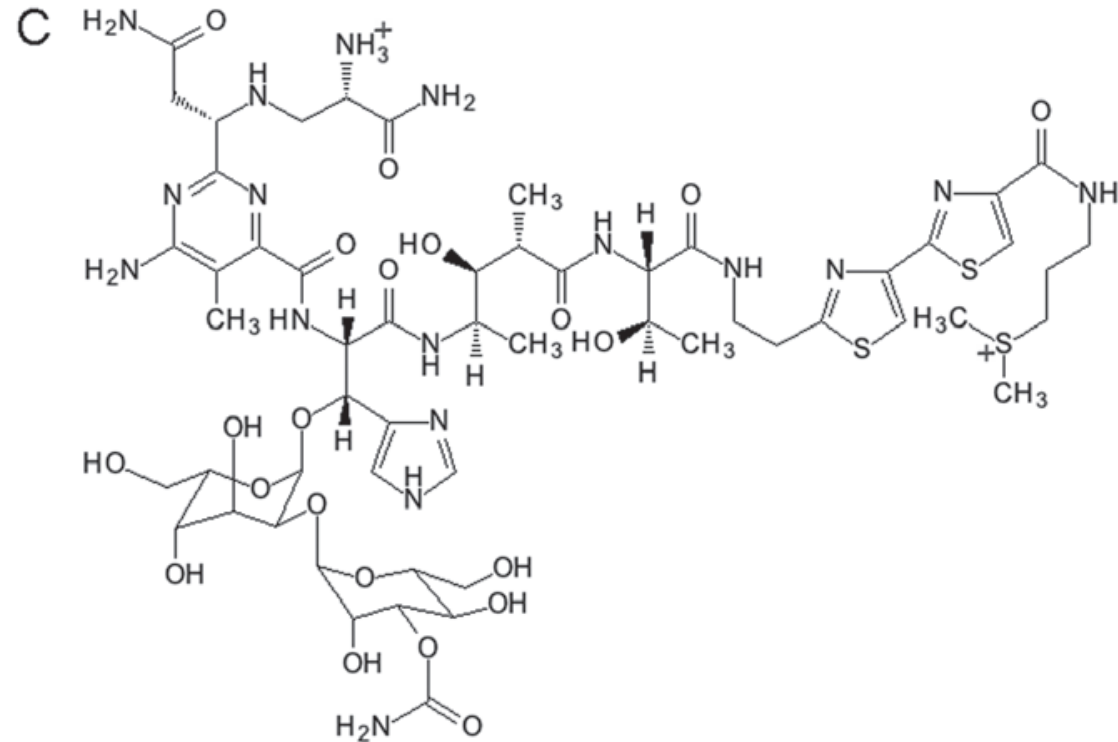

Figure 6. Divalent cationicity-mediated cell membrane (CM) receptor vesiculo-vacuolization endocytosis, sub-cellular vacuolization along with exosome formation with potential for CM receptor-mediated 3ary indirect shift pressuromodulation. (A) AMD3100 (plerixafor), (B) paraquat, (C) bleomycin.

very high MW protein transcription (17), that will result in burst nuclear transcription-associated with mitochondrial oxidative phosphorylation-MM-mediated nuclear and cellular cytotoxicity/apoptosis $(17,74)$. In contrast, fluconazole, which also has the potential to cause a subsequent lary indirect pressuromodulation (perturbomodulation)-mediated secondary increase in very high MW protein transcription, associated with burst nuclear transcription-associated with mitochondrial oxidative phosphorylation-MM-mediated nuclear and cellular cytotoxicity/apoptosis, does so to a lesser extent in comparison to voriconazole (75), which is structurally similar but more lipophilic than fluconazole and itraconazole (75), which is structurally similar to ketoconazole, as fluconazole also concomitantly decreases sub-cellular membrane compliance (Table V and Fig. 5).

Small molecule xenobiotics that cause divalent cationicity-mediated CM receptor vesiculo-vacuolization endocytosis with secondary exosome formation with potential for CM receptor-mediated 3ary indirect pressuromodulation. This category includes small molecule xenobiotic hydro-lipophiles with dual cationicity insufficiently separated (IS) in molecular space and backbone lipophilicity, with vdWDs in the $0.70-1.31 \mathrm{~nm}$ range. By being cationicity-excluded from permeation across CM protein channel aqueous pores, xenobiotics of this category bind to $\mathrm{CM}$ protein receptors, ligand-receptor complexes that endocytose upon xenobiotic binding (Table VI and Fig. 6).

The CM pore impermeable dually-cationic small molecule xenobiotics include:

i) AMD3100 (plerixafor) [(Log OWPC, -5.40; vdWD, $1.00 \mathrm{~nm}$; Log OWPC-to-vdWD ratio, -5.42 $\mathrm{nm}^{-1}$ ); AMD3100 hydrophobic core (Log OWPC, 3.56; vdWD, $0.81 \mathrm{~nm}$; Log OWPC-to-vdWD ratio, $4.39 \mathrm{~nm}^{-1}$ ); AMD3100 hydrophilic moiety $\mathrm{x} 2$ (Log OWPC, -6.55; vdWD, $0.76 \mathrm{~nm}$; Log OWPC-to-vdWD ratio, $-8.63 \mathrm{~nm}^{-1} \mathrm{x} 2,+2$ cationicity per moiety)]; ii) Paraquat $[(\log$ OWPC, -5.56 ; vdWD, $0.70 \mathrm{~nm}$; Log OWPC-to-vdWD ratio, $-7.98 \mathrm{~nm}^{-1}$ ); paraquat hydrophobic core (Log OWPC, 2.96; vdWD, $0.70 \mathrm{~nm}$; Log OWPC-to-vdWD ratio, $\left.4.25 \mathrm{~nm}^{-1}\right)$ ];

iii) Bleomycin [(Log OWPC, -8.50; vdWD, $1.31 \mathrm{~nm}$; Log OWPC-to-vdWD ratio, $-6.50 \mathrm{~nm}^{-1}$ ); bleomycin hydrophobic core (Log OWPC, 3.14; vdWD, $0.94 \mathrm{~nm}$; Log OWPC-to-vdWD ratio, $\left.\left.3.35 \mathrm{~nm}^{-1}\right)\right]$.

AMD3100, paraquat and bleomycin associate with CM CXCR4 (76-78), CM paraquat binding protein (PBP) receptor and CM bleomycin binding protein (BBP) $(79,80)$, respectively, and cause $\mathrm{CM}$ receptor-mediated $\mathrm{CM}$ vesiculo-vacuolization endocytosis and sub-cellular vacuolization-mediated intra-cellular cytotoxicity $(81,82)$, and at least in the case of CM CXCR4 endocytosing xenobiotic, AMD3100, in non-cross talk with lympho-infiltrating cells ( $\mathrm{T}$ cells) in the milieu, which are necessary for the mounting of an appropriate cytotoxic $\mathrm{T}$ cell response (83-85). Furthermore, and importantly, the process of $\mathrm{CM}$ receptor-mediated CM vesiculo-vacuolization endocytosis and sub-cellular vacuolization with secondary $\mathrm{CM}$ exosome release, is a process that rapidly evolves towards a significant decrease in whole cell compliance in tandem with a significant increase in the transcription of very high MW secretory proteins including the collagens (120-190 kDa) and fibronectins $(230 \mathrm{kDa})$ as well as the nuclear cell division-associated proteins including Ki67 (359 kDa) and separase $(230 \mathrm{kDa})(\mathrm{CM}$ receptor-mediated 3ary indirect shift pressuromodulation: receptor endocytic $2+)(17)$, that are associated with a therapy-related risk for fibrosis (86-88) and mitogenesis division $(81,89)$, respectively, along with the increased risk of metastases due to a concomitant decrease in the transcription of intermediate MW cell surface adhesion proteins (Table VI and Fig. 6).

Due to the risk of endocytosis-mediated 3ary indirect pressuromodulation (17), CM pore impermeable dually-cationic small molecule xenobiotics such as AMD3100, paraquat and bleomycin are tumoropotentiators as monochemotherapies, 

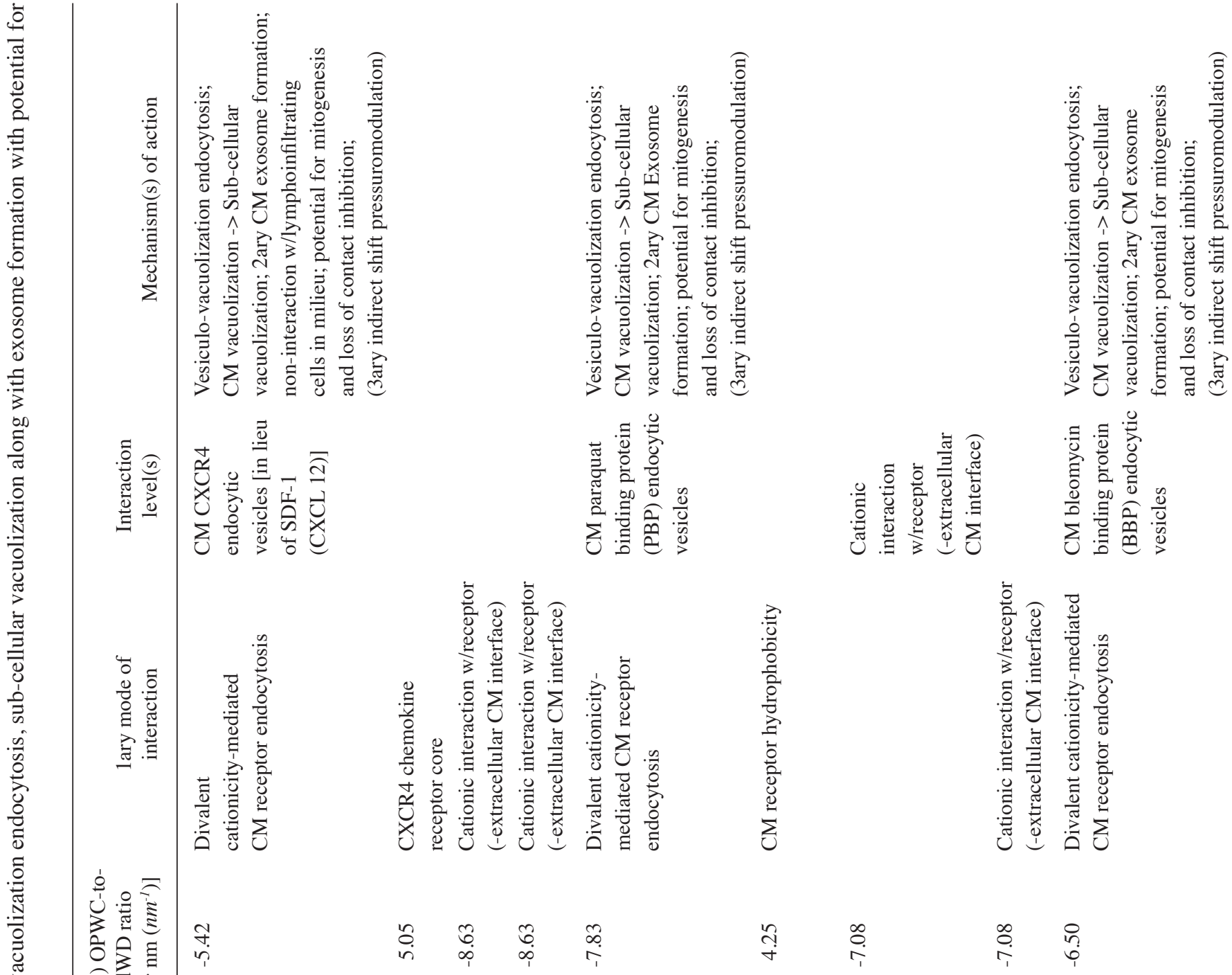

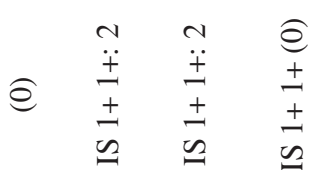

$\begin{array}{llll}0 & 0 & 0 & 0\end{array}$

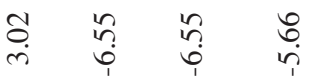

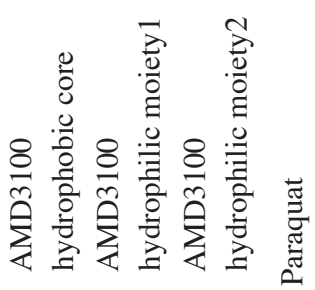

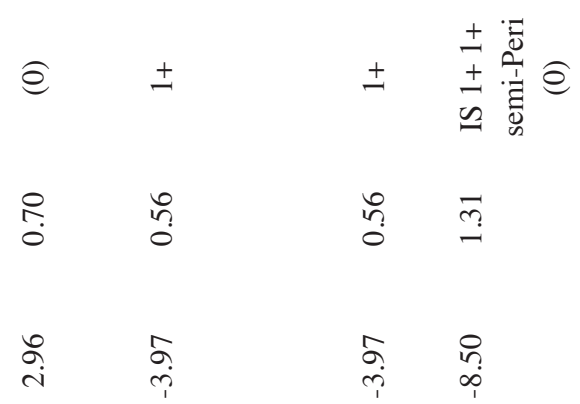

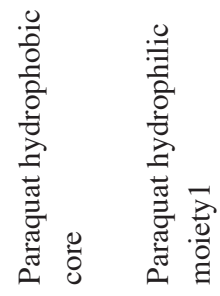

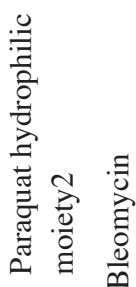




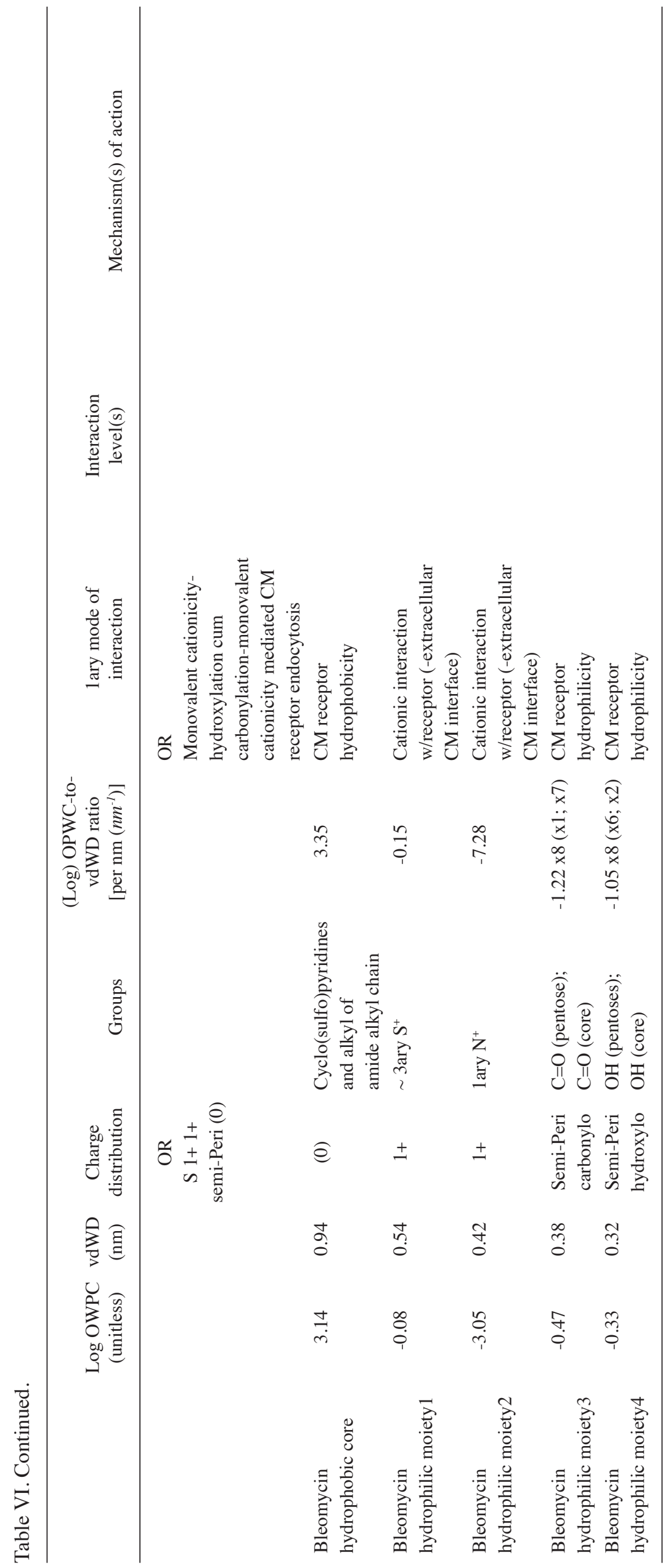




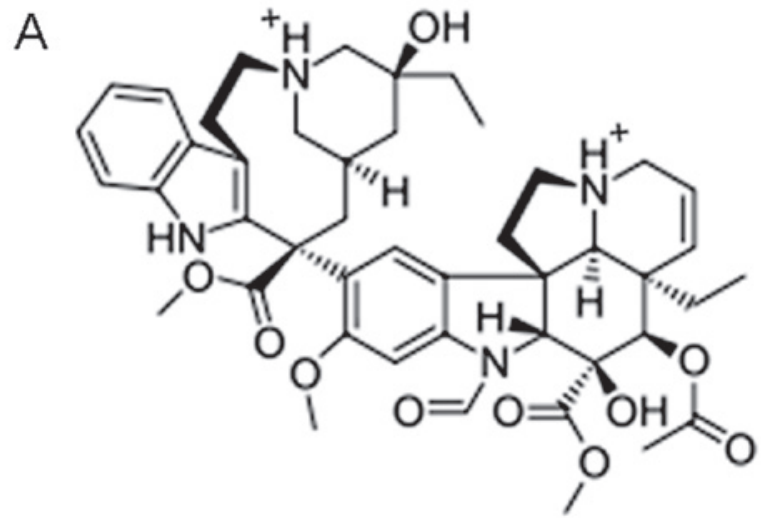

B<smiles>COc1cccc2c1C(=O)c1c(O)c3c(c(O)c1C2=O)C[C@@](O)(C(=O)CO)C[C@@H]3O[C@H]1C[C@H](N)[C@@H](O)[C@H](C)O1</smiles>

Figure 7. Carbonylation/hydroxylation cum cationicity-facilitated cell membrane channel endocytosis and mitochondrial VDAC association: non-association of microtubule tubulin to mitochondrial membrane and mitochondrial anchorage-mediated MM disruption/mitochondria-mediated apoptosis. (A) Vincristine, (B) doxorubicin.

in a concentration dependent manner (48) (atrial naturetic peptide is an endogenous CM receptor 3ary indirect pressuromodulator (17), which at a higher concentration, likely, induces mitochondrial division), the risk of which can be oviated with synergistic additional direct $\mathrm{CM}$ receptor-mediated pressuromodulation as burst nuclear transcription-associated with mitochondrial oxidative phosphorylation-MM-mediated nuclear and cellular cytotoxicity/apoptosis results (89) [dexamethasone is an endogenous CM receptor direct pressuromodulator (17)], as it can also be oviated by synergistic microtubule network inhibition, at the level of the MM VDAC $\gamma$-tubulin (Tables VII and IX, Figs. 7 and 9) (90).

Small molecule xenobiotics that cause carbonylation/hydroxylation cum cationicity-facilitated CM channel endocytosis to localize to the MM VDAC at the $\gamma$-tubulin association interface. This category includes the small molecule xenobiotic hydro-lipophiles with CM channel endocytosing capability due to the presence of sufficient inner incorporating lipophilicity in the context of interacting outer polyhydroxylated carbonylated hydrophilicity in the form of circumferential polyhydroxylated carbonylated hydrophilicity, with vdWDs in the $0.95-1.11 \mathrm{~nm}$ range (17). By being hydrophilic and due to the CM protein channel aqueous pore widths, xenobiotics of this category associate with CM protein channel $\alpha$-helix cum $\alpha$-helix isophilic aqueous pores to induce CM channel endocytosis of the $\mathrm{Ca}^{2+}$ channel (i.e., vincristine) and the $\mathrm{Na}^{+} / \mathrm{K}^{+}$
A

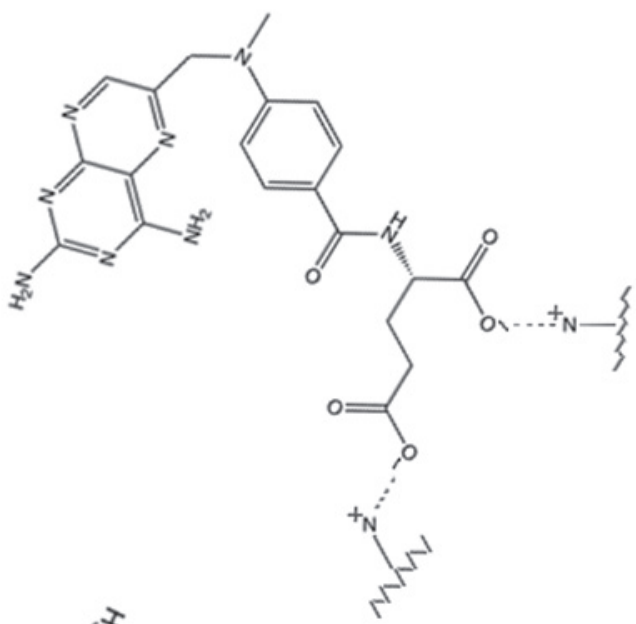

B

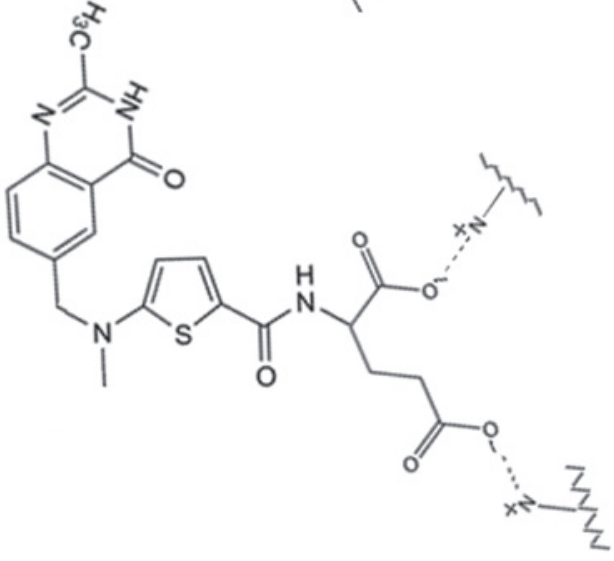

Figure 8. Dual carboxylation-facilitated cell membrane receptor endocytosis: mitochondrial membrane and nuclear rough endoplasmic reticulum membrane vesiculization. (A) Methotrexate, (B) raltitrexed.

ATPase (doxorubicin and daunorubicin), and upon CM channel endocytosis disassociation, associate promiscuously with the inner-to-outer MM VDAC, a non-endocytosable circular $\beta$-helix with voltage-gateable internal short $\alpha$-helix-type chan nel (91) (Table VII and Fig. 7).

The CM channel endocytosing small molecule xenobiotic hydro-lipophiles include: i) vincristine [( $\log$ OWPC, -3.00; vdWD, $1.11 \mathrm{~nm}$; Log OWPC-to-vdWD ratio, -2.69 $\left.\mathrm{nm}^{-1}\right)$; vincristine hydrophobic core (Log OWPC, 5.14; vdWD, $0.96 \mathrm{~nm}$; Log OWPC-to-vdWD ratio, $\left.5.34 \mathrm{~nm}^{-1}\right)$ ]; ii) doxorubicin (adriamycin) [(Log OWPC, -0.79; vdWD, $0.95 \mathrm{~nm}$; Log OWPC-to-vdWD ratio, $-0.83 \mathrm{~nm}^{-1}$ ); doxorubicin hydrophobic core (Log OWPC, 4.88; vdWD, $0.77 \mathrm{~nm}$; Log OWPC-to-vdWD ratio, $\left.6.96 \mathrm{~nm}^{-1}\right)$ ].

Vincristine and doxorubicin associate into the inter- $\alpha$-helix isophilic pores of the $\mathrm{Ca}^{2+}$ channel (92) and $\mathrm{Na}^{+} / \mathrm{K}^{+}$ATPase $(17,50,51)$, respectively, to de-stabilize the $\mathrm{CM}$ interaction of the multi-inter- $\alpha$-helix constructs of such trans-membrane proteins, that results in ligand-associated CM protein channel endocytosis $(93,94)$, followed by intra-cellular ligand CM channel disassociation, and then, subsequent promiscuous MM VDAC channel isophilic pore association (95): thus, the primary mechanism of cellular toxicity for vincristine and doxorubicin is at the level of the mitochondria and MM, and due to the concomitant presence of sufficiently separated (SS) 1+ cationicity in the 
A<smiles>COc1cc([C@H]2c3cc4c(cc3[C@@H](O[C@@H]3O[C@H]5CO[C@H](C)O[C@]5(C)[C@H](O)[C@H]3O)[C@]3(C)COC(=O)[C@H]23)OCO4)cc(OC)c1O</smiles>

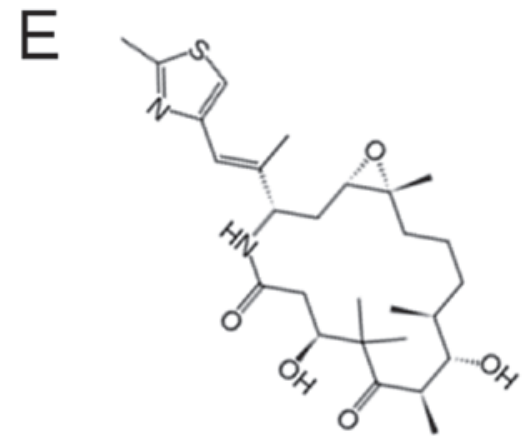

B<smiles>COc1cc(C2c3cc4c(cc3[C@@H](OC3OC5COC(c6cccs6)O[C@H]5C(O)C3O)[C@H]3COC(=O)C23)OCO4)cc(OC)c1O</smiles>

$\mathrm{F}$

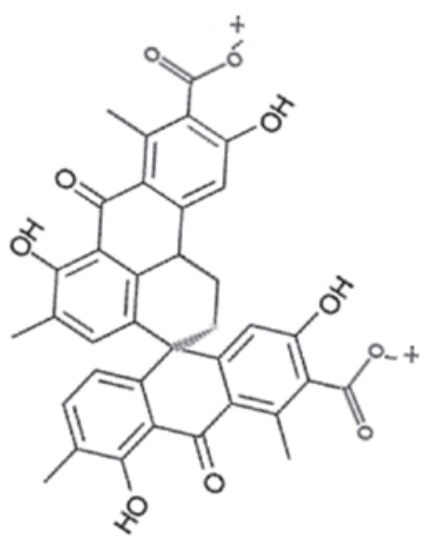

C<smiles>COc1ccc2c(c1)CCCc1cc(OC)c(OC)c(OC)c1-2</smiles><smiles>CC(=O)NCCCNC(C)=O</smiles><smiles>C=CCC1C(=O)CC(C)C(O)C1/C(C)=C(\C)CC(C)CC(OC)C1OC(O)(C(=O)C(=O)N2CCCCC2C(=O)OC(C(C)=CC2CCC(O)C(OC)C2)C(C)C)C(C)CC1OC</smiles>

Figure 9. Hydroxylation/carbonylation/dual carboxylation-facilitated cell membrane receptor endocytosis: tubulin polymerization re-polymerization inhibition and mitochondria-mediated apoptosis to rapamycin-associated protein binding tubulin non-binding. (A) Etoposide, (B) teniposide, (C) colchicine, (D) paclitaxel, (E) ixabepilone, (F) (+/-) spiro-oxanthromicin A, (G) tacrolimus.

former (vincristine) and exteriorly protruding 1+ cationicity in the latter (doxorubicin), that results in non-association of microtubule $\gamma$-tubulin at MM VDAC and non-recruitment of renewed microtubule networks to the $\mathrm{MM}$, mitochondrial anchorage immobility-associated MM disruption/dissolution with liberation of MM AIF and initiation of the mitochondrially-mediated nuclear apoptosis cascade, with the significant potential for inducing cellular apoptosis (96-101), which is due to no significant (in-significant) potential for CM receptor endocytosis-mediated (Pseudo) 3ary indirect pressuromodulation (17) (Table VII and Fig. 7).

The presence of structural cationicity is a pivotal structure distinction between $\mathrm{CM}$ channel endocytosing small molecule xenobiotic hydro-lipophiles such as vincristine and doxorubicin that induce non-association of microtubule $\gamma$-tubulin at MM VDAC and result in CM mitochondrial anchorage non-mobility-mediated MM disruption/mitochondrial-mediated apoptosis, in contrast to those that do not but with instead 

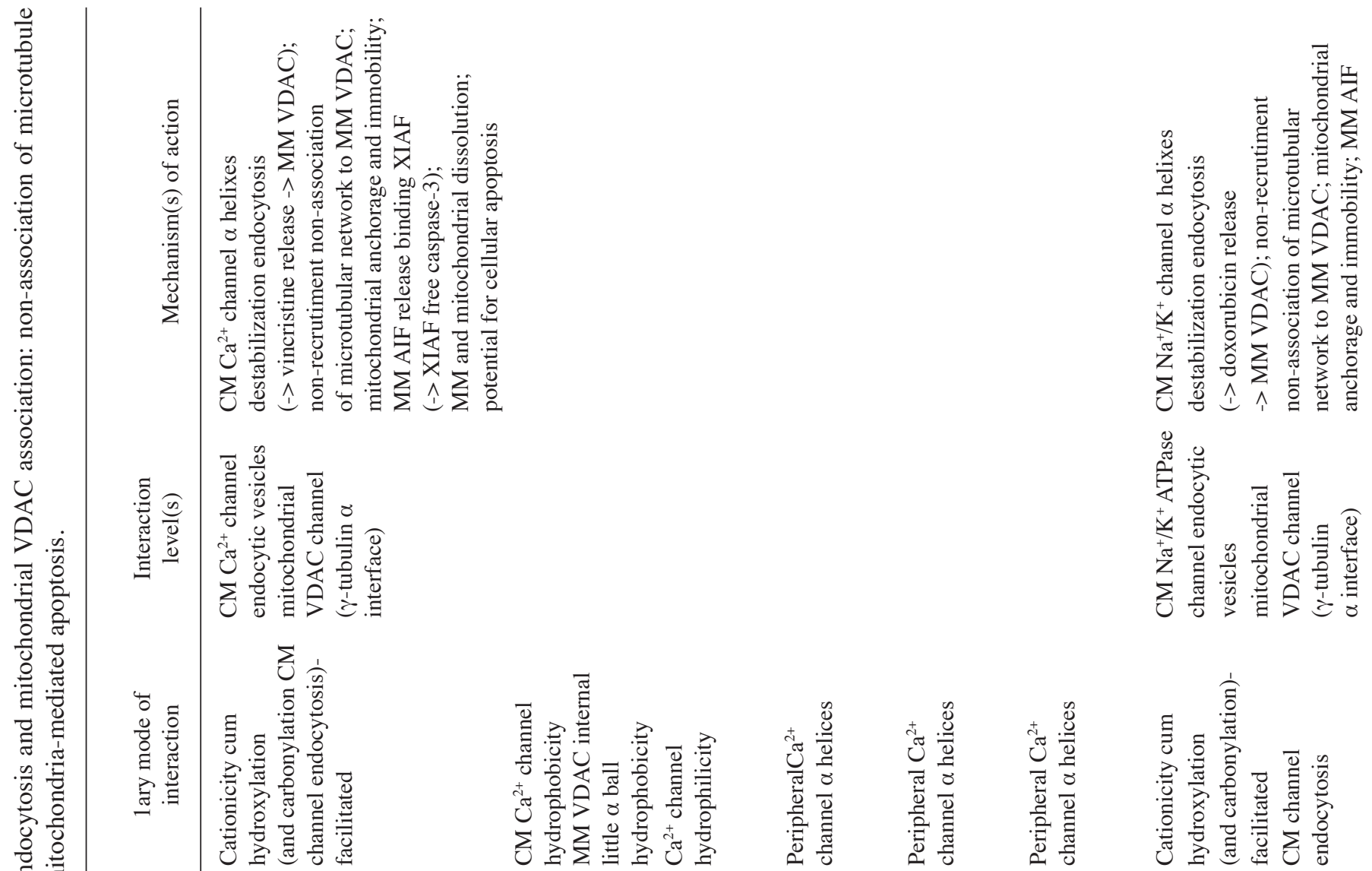

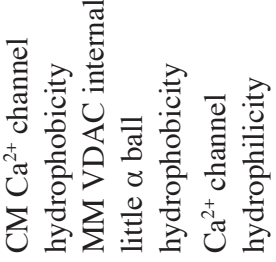
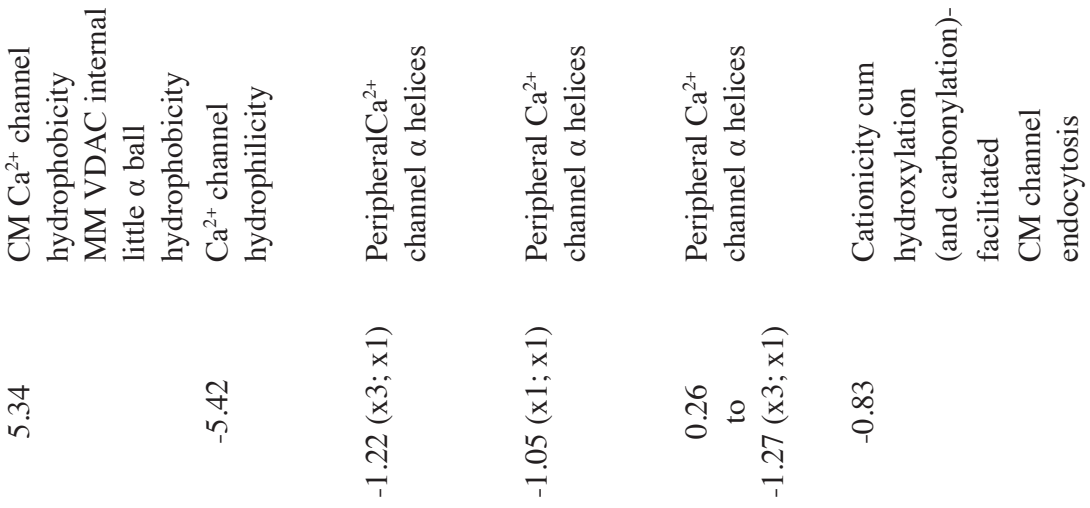

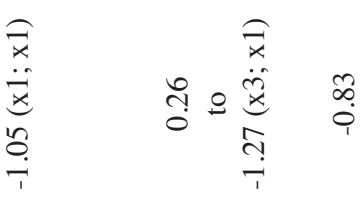

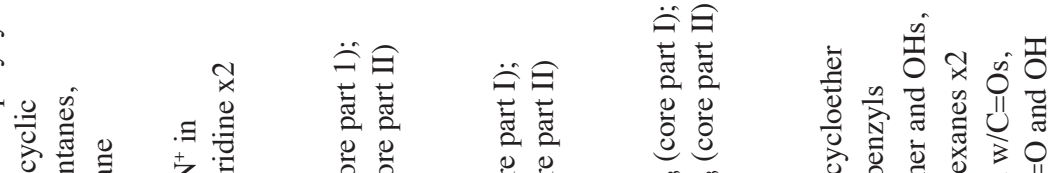

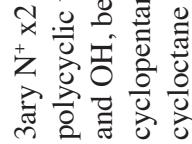

焉

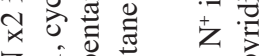

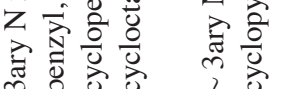

苞苞

总

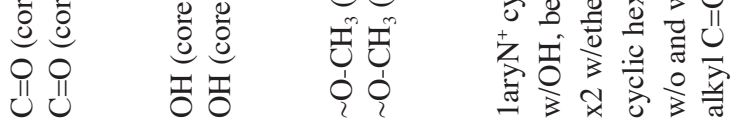

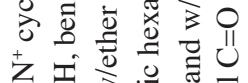

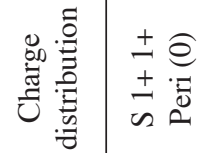

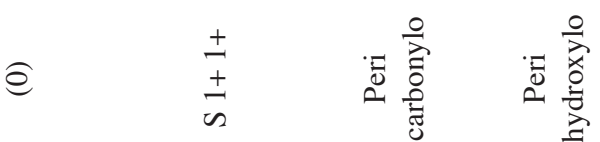

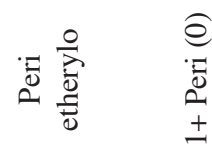

要春

$\stackrel{2}{\circ}$

$\stackrel{\infty}{n} \quad \stackrel{\infty}{0}$

กิ

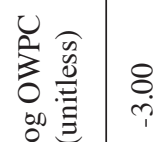

in

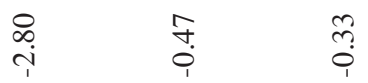

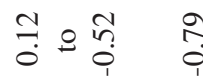

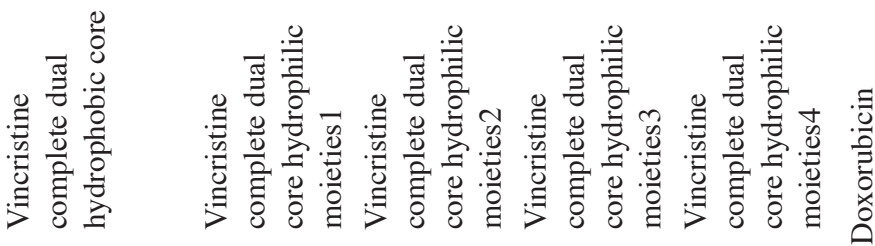




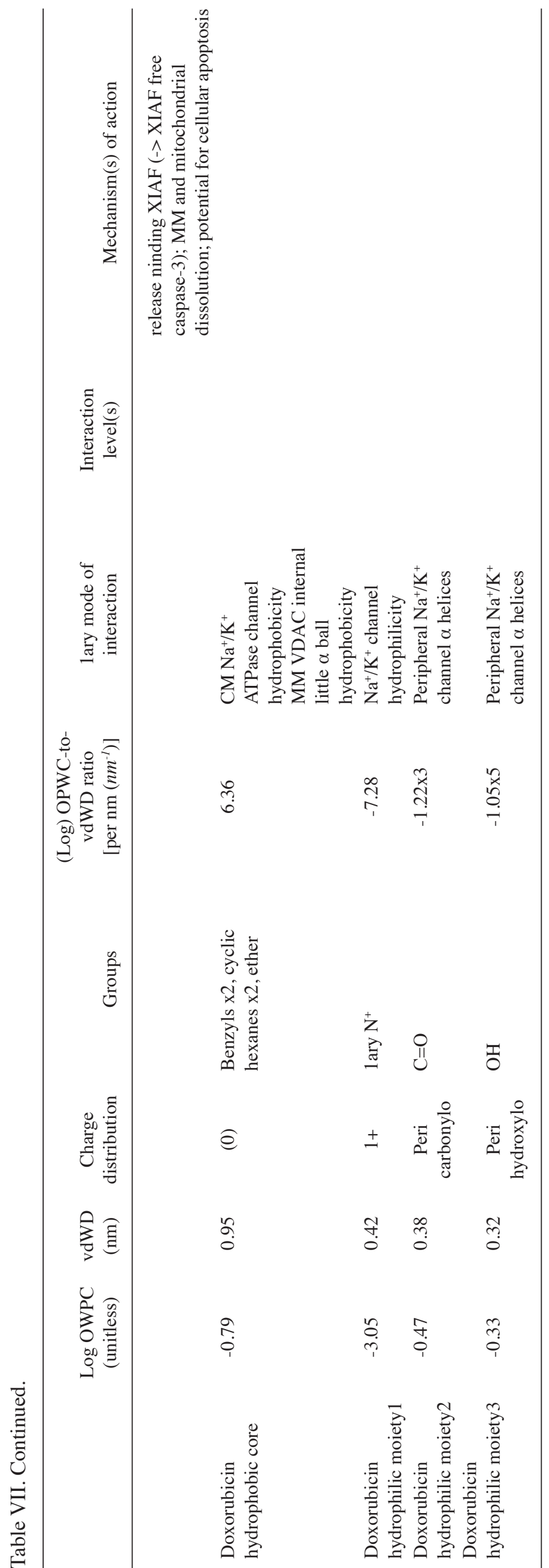

have mitogenic potential, which is the case for ouabain (102), a non-cationic circumferentially carbonylated/hydroxylated hydro-lipophile endocytoser of the $\mathrm{Na}^{+} / \mathrm{K}^{+}$ATPase, with potential to cause epithelilal-to-mesenchymal transformation (EMT) as well as tumoropropagation via CM receptor endocytosis-mediated (Pseudo) 3ary indirect pressuromodulation (17).

The xenobiotics of this category induce endocytosis of their respective channels, the $\mathrm{Ca}^{2+}$ channel $(123 \mathrm{kDa} / \mathrm{P} / \mathrm{Q} \alpha$ subunit MW) (92) (vincristine > verapamil) and the $\mathrm{Na}^{+} / \mathrm{K}^{+}$ATPase channel (112 kDa $\alpha$ subunit MW) (103) (ouabain, momensin, doxorubicin and daunorubicin), which are present on the CM in juxtaposition to one another and to P-gp (non-glycosylated MW $140 \mathrm{kDa}$ ) (104), whereby, ligand-mediated $\mathrm{Ca}^{2+}$ channel-endocytosis of associated CM results in concomitant endocytosis of P-gp (105), that decreases immediate P-gp CM expression. Thus, P-gp overexpression and associated multi-drug resistance emerges, secondarily, in surviving tumor cells with lower compliance set points than before therapy due to the increased transcription of higher MW proteins such as P-gp (11), in which case, intra-cellularly accumulating drug fraction is extruded by its ability to interact with intra-CM P-gp $\alpha$-helixes viz a viz hydro-lipophile incorporating lipophilicity, and induce, $\alpha$-helix apposition pump functionality (104).

Furthermore, true CM P-gp small molecule ligands that associate with the P-gp extracellular loop- $\alpha$-helix are few and far between, and include artemsinin (106), which functions as a P-gp inhibitor but also as a pressuromodulator, thus, P-gp inducer, as do ones with hollow interiors including QZ59-RRR and QZ59-SSS (104); whereas, small molecule ligands with less polyneutral exterior hydrophilicity than vincristine, include quinidine (105), a competitive antagonist of vincristine at the $\mathrm{Ca}^{2+}$ channel, with the ability to obstruct the channel, but without the ability to endocytose it, whereby, it functions as a $\mathrm{Ca}^{2+}$ channel pressuromodulator and inducer, and thus, indirectly as an inducer of $\mathrm{Na}^{+} / \mathrm{K}^{+}$ATPase and P-gp, all present in close $\mathrm{CM}$ pressuromodulating proximity.

Small molecule xenobiotics that cause dual carboxylation-facilitated CM folic acid receptor-mediated endocytosis followed by MM and the rough endoplasmic reticulum membrane folic acid receptor-mediated vesiculization with the potential for CM receptor-mediated (Pseudo) 3ary indirect pressuromodulation. This category includes the small molecule xenobiotic hydro-lipophiles with CM folic acid receptor (FAR) endocytosing capability due to the presence of incorporating lipophilicity in the context of anisotropic interacting outer dual carboxylation hydrophilicity, with vdWDs at $0.89 \mathrm{~nm}$. The xenobiotics of this category associate into the FAR hydrophobic core while concomitantly associating with the hydrophilic exterior FAR cationic (+) R groups via the carboxyl $\left(\mathrm{COO}^{-}\right)$groups $(107)$, which results in a contraction-pull down of the loose non-aligned multi- $\alpha$-helix FAR towards the CM. This results in the endocytosis of the ligand-FAR complex at a much faster rate than that induced by endogenous ligand folic acid (folate), which has a lower $\mathrm{kDa}$ than that of the competitive pro-endocytic xenobiotics of this category (108) (Table VIII and Fig. 8).

The CM FAR endocytosing small molecule xenobiotic hydro-lipophiles include: i) methotrexate [(Log OWPC, -6.60; 
MOLECULAR AND CLINICAL ONCOLOGY 4: 326-368, 2016

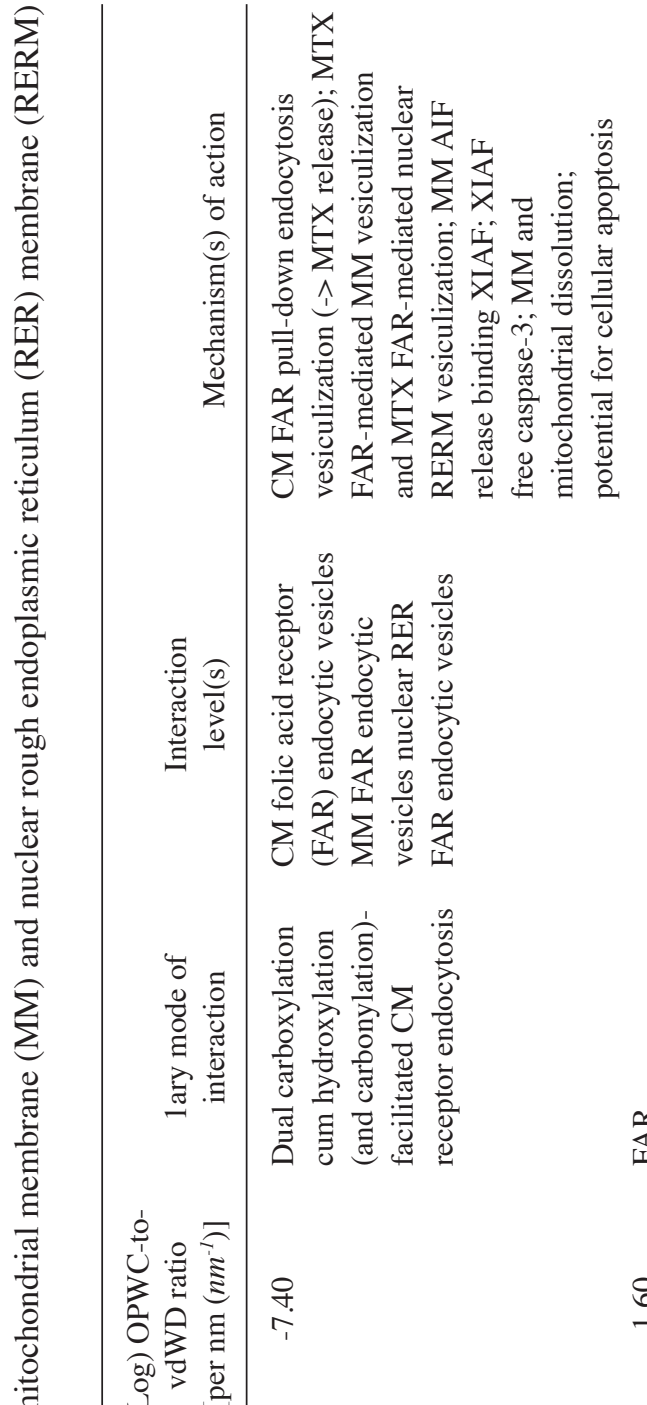

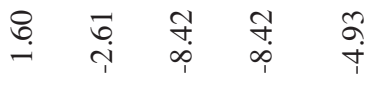

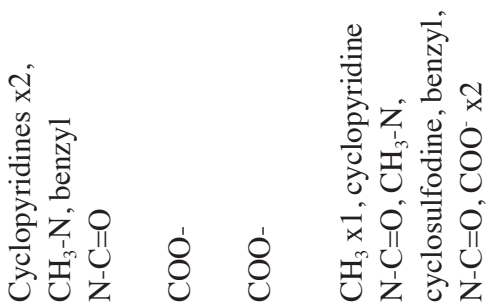

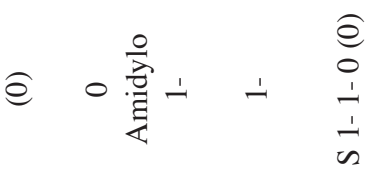

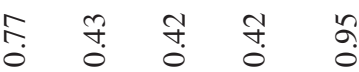

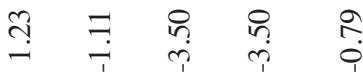

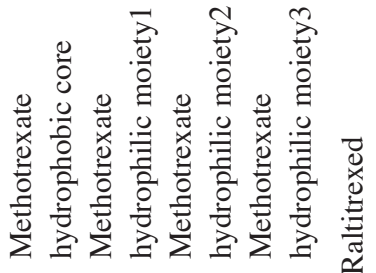

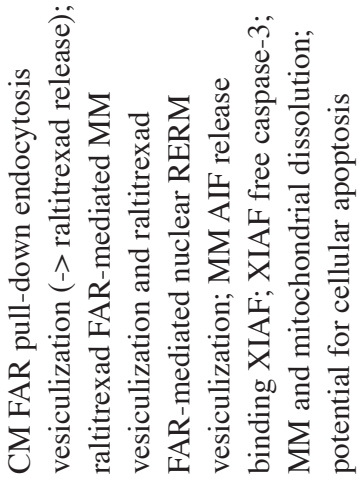
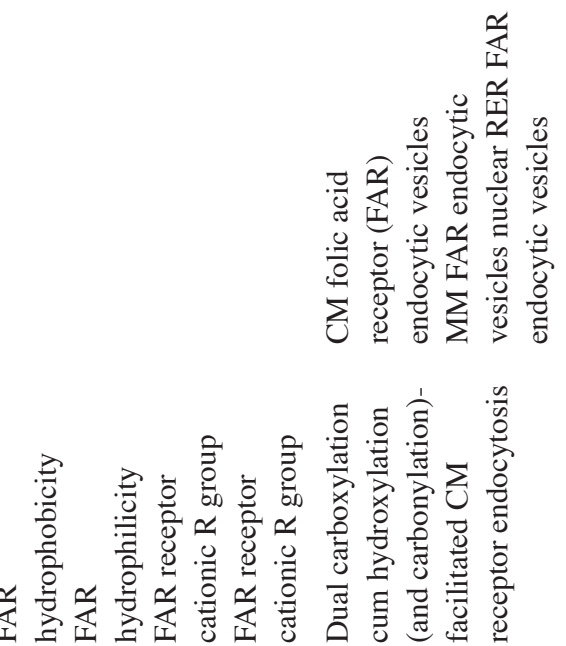

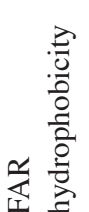

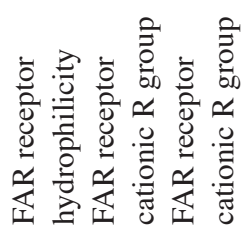

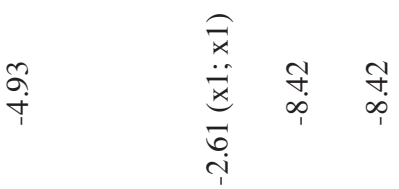

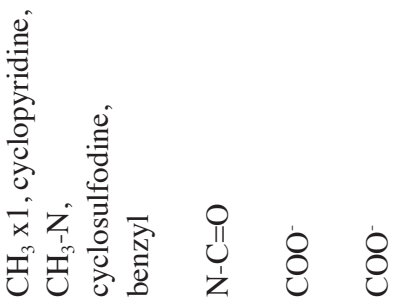

e 0 弯

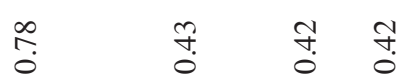

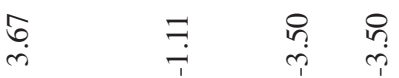

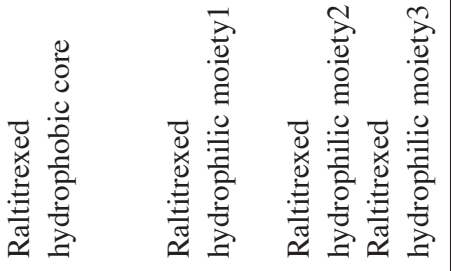




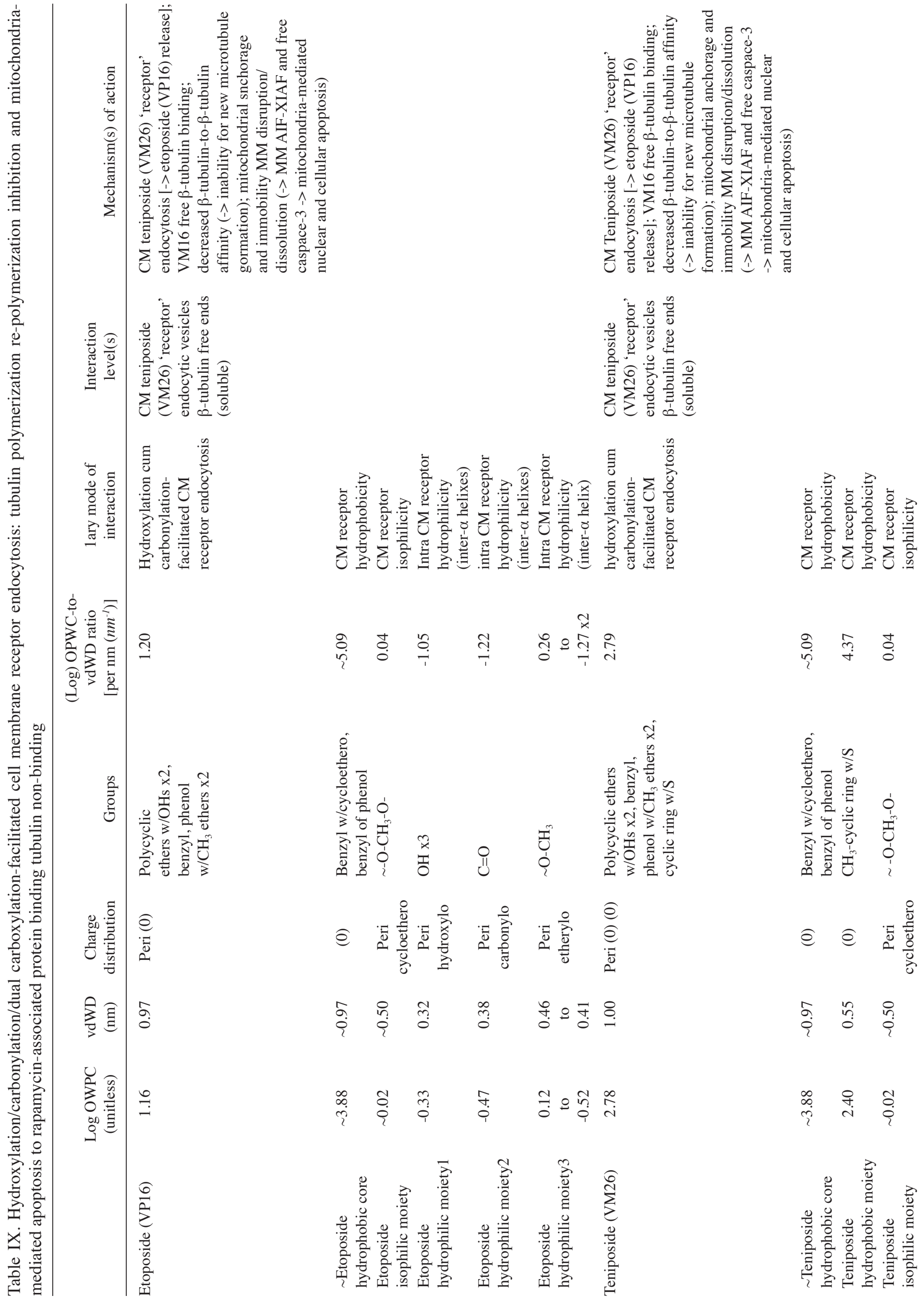



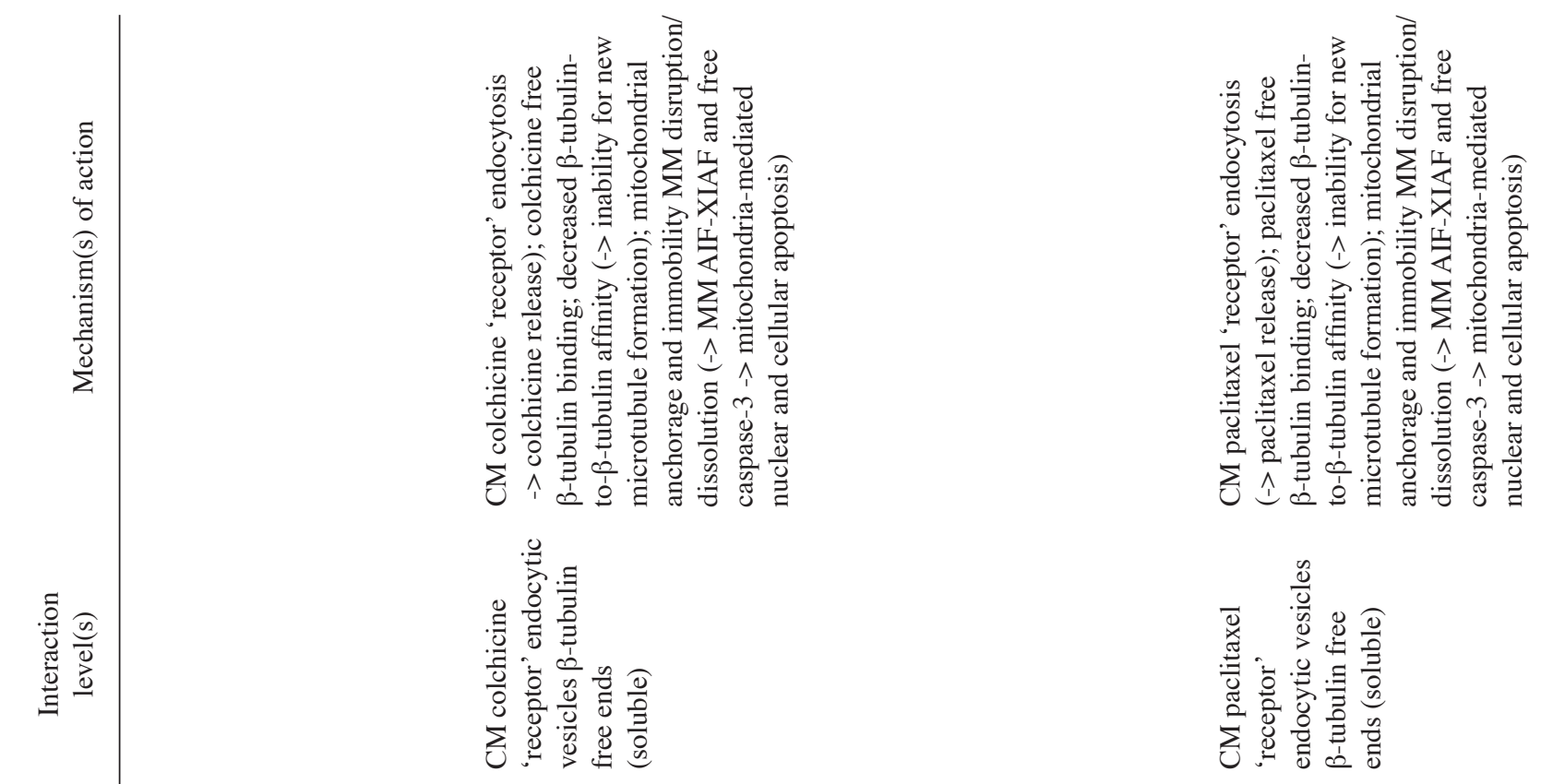

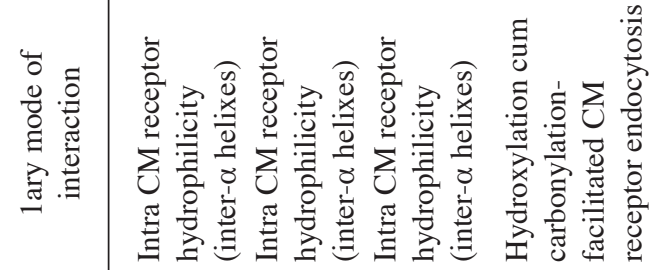

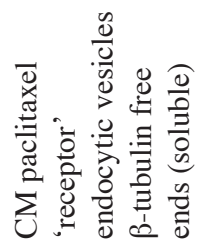

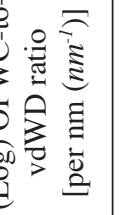

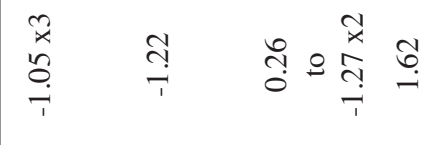

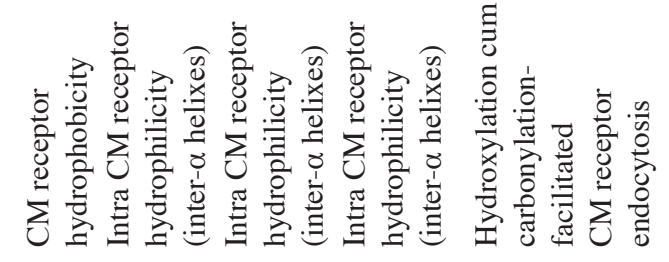

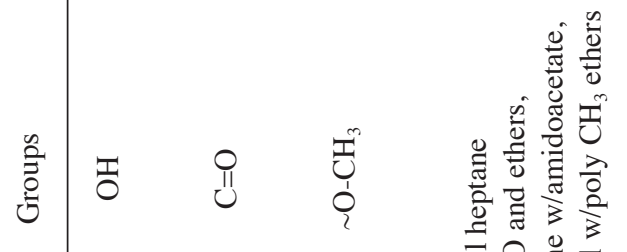

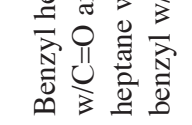

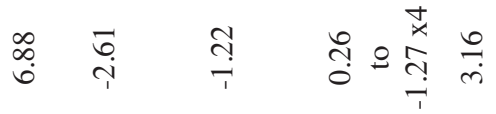

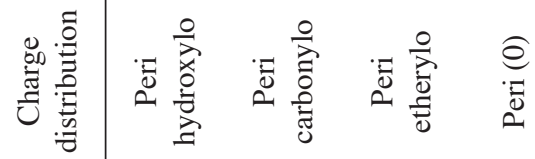

突

竞字焉

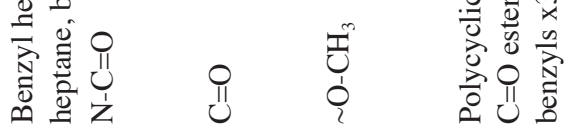

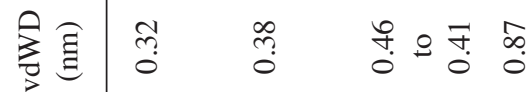

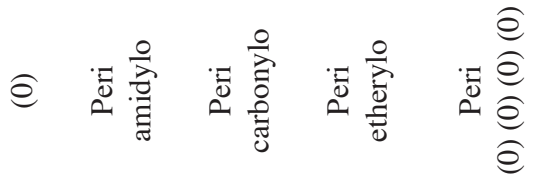

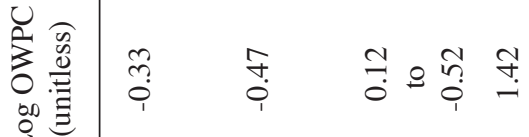

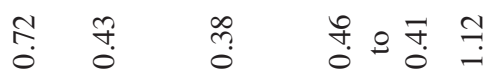

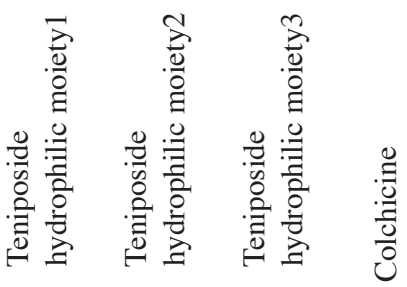

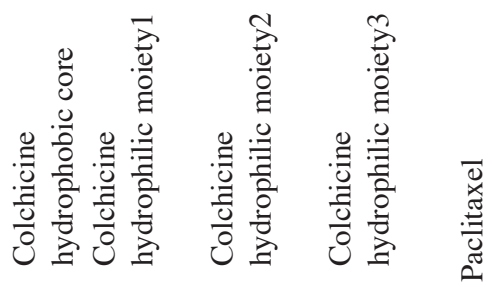




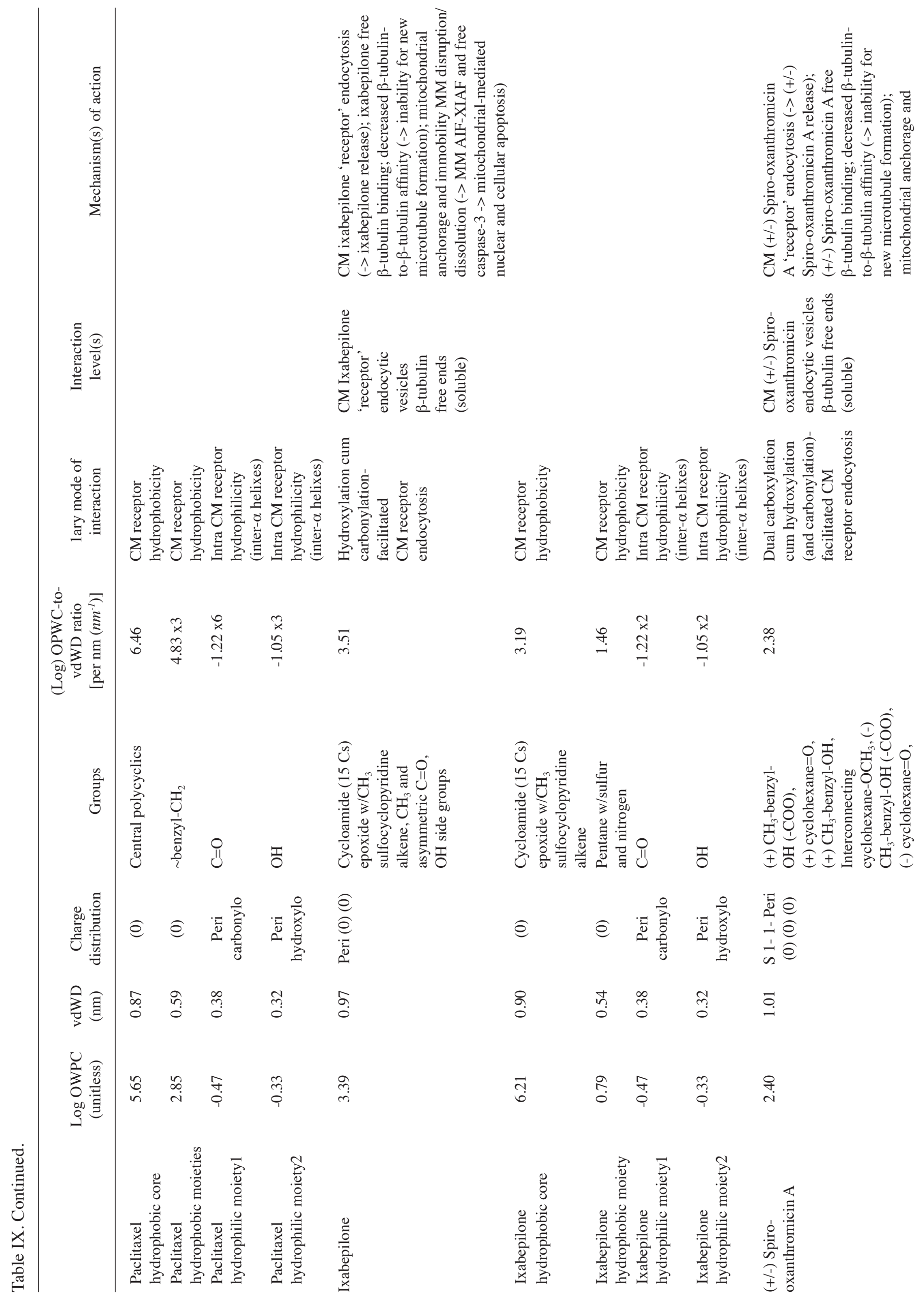



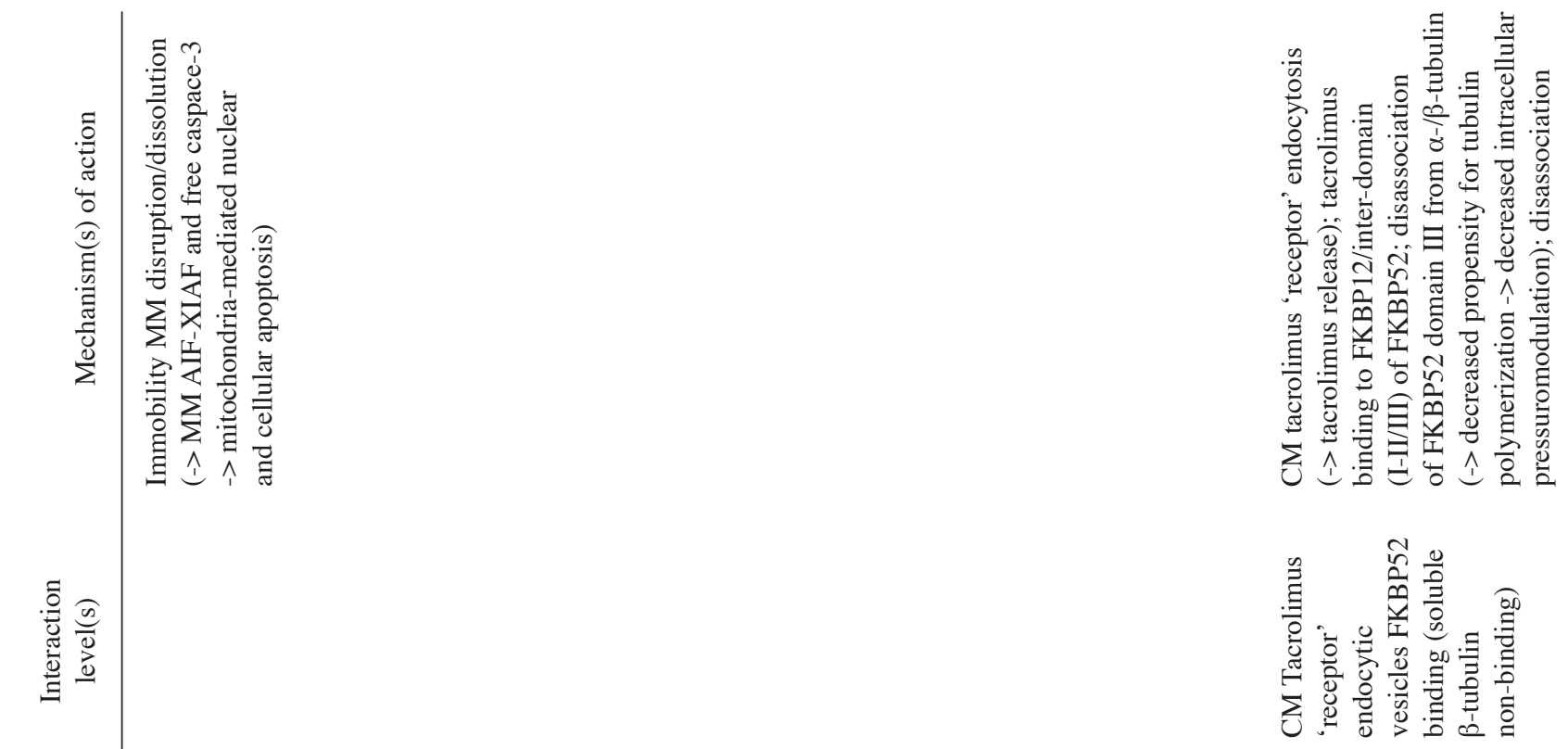

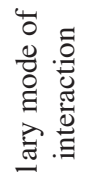

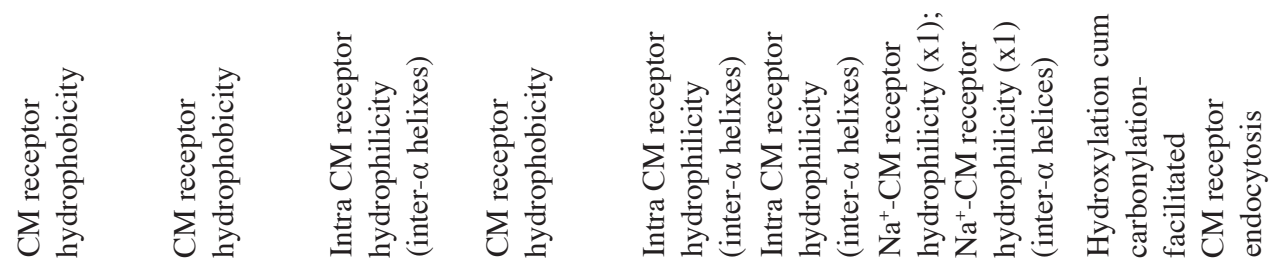

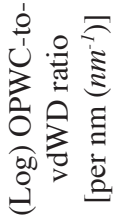

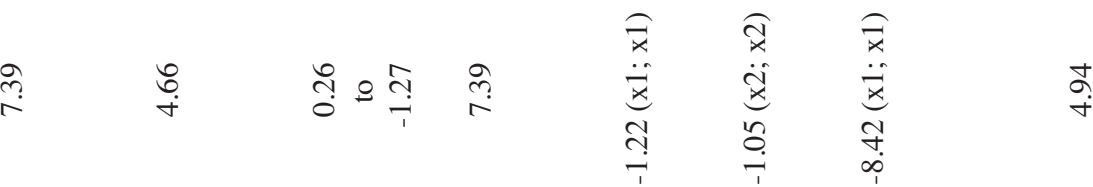

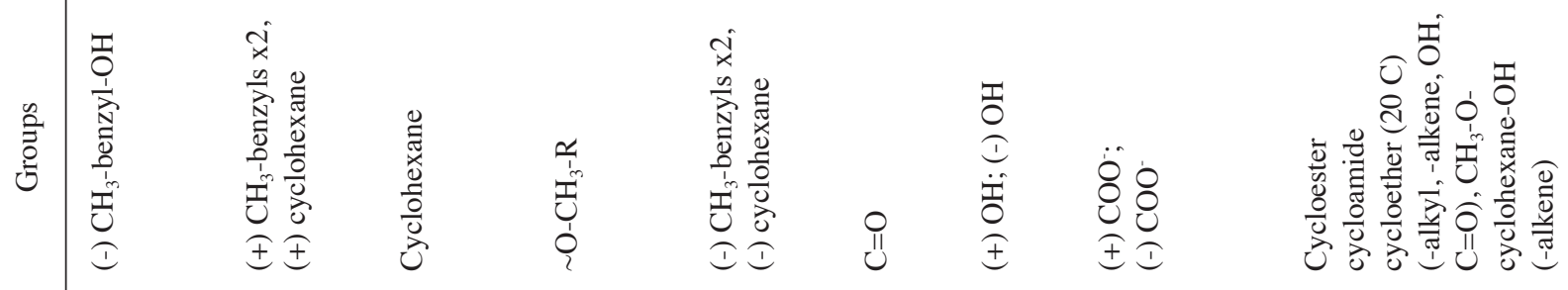

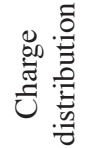

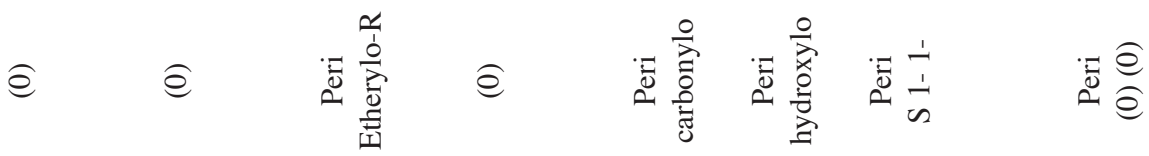

気

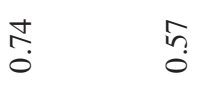

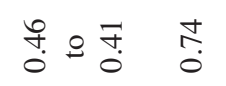

$\stackrel{\infty}{\infty}$ กิ

$\stackrel{m}{=}$

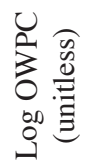

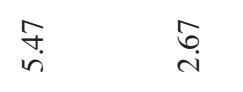

ำำ ำ

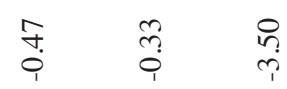

nิ

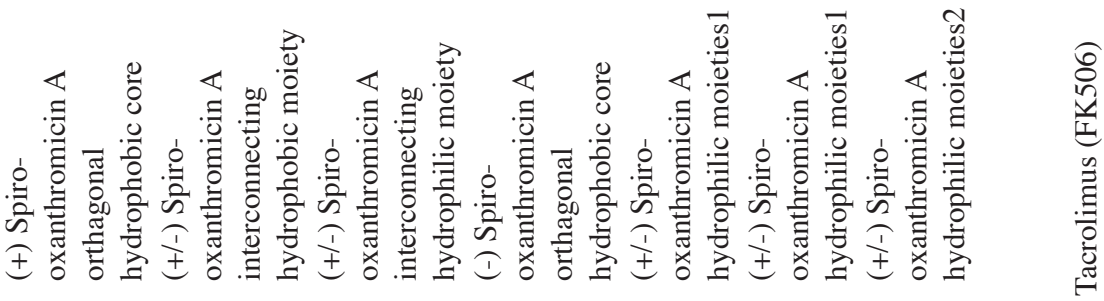




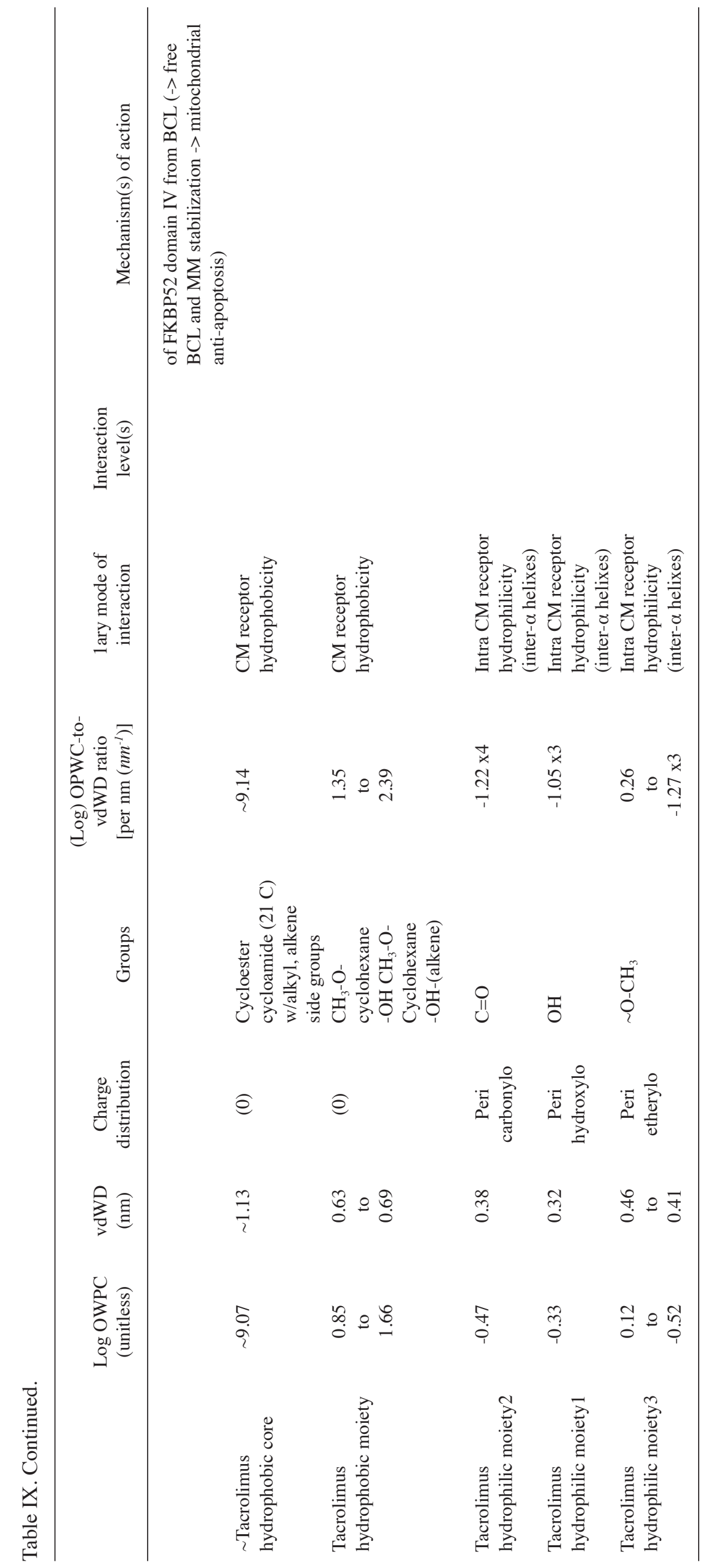


vdWD, $0.89 \mathrm{~nm}$; Log OWPC-to-vdWD ratio, -7.40 $\mathrm{nm}^{-1}$ ); methotrexate hydrophobic core (Log OWPC, 1.23; vdWD, $0.77 \mathrm{~nm}$; Log OWPC-to-vdWD ratio, $\left.1.60 \mathrm{~nm}^{-1}\right)$ ]; ii) raltitrexed (Tomudex) [(Log OWPC, -4.40; vdWD, $0.89 \mathrm{~nm}$; Log OWPC-to-vdWD ratio, $\left.-4.93 \mathrm{~nm}^{-1}\right)$; raltitrexed hydrophobic core (Log OWPC, 3.67; vdWD, 0.78 nm; Log OWPC-to-vdWD ratio, $\left.\left.4.70 \mathrm{~nm}^{-1}\right)\right]$.

Both methotrexate and raltitrexed endocytose the ligand-FAR complex, initially at the level of the CM, the CM FAR, and upon CM FAR endocytosis followed by intra-cellular disassociation, re-associate/bind to the sub-cellular membrane FARs, the MM FAR and the rough endoplasmic reticulum (RER) FAR inducing their endocytosis. This cumulates in increased sub-cellular vesiculization-mediated generation of pro-oxidant reactive oxygen species $(109,110)$, and in case of the mitochondria, vesiculization-mediated loss of MM electromotive potential (109,111-113). Therefore, the mechanism for anti-folate chemoxenobiotic-mediated cellular cytotoxicity is FAR endocytosis-driven sub-cellular pro-oxidant oxidative stress (114-117), particularly mitochondrial, whereby there is only limited potential for CM receptor endocytosis-mediated (Pseudo) 3ary indirect pressuromodulation $(110,118)$ (Table VIII and Fig. 8).

Small molecule xenobiotics that cause hydroxylation/carbonylation/dual carboxylation-facilitated $C M$ receptor endocytosis and tubulin polymerization re-polymerization inhibition and mitochondrial-mediated apoptosis. This category includes the small molecule xenobiotic lipophiles with CM receptor endocytosing capability, with vdWDs in the $0.87-1.01 \mathrm{~nm}$ range. Due the presence of inner incorporating lipophilicity in the context of outer circumferential hydrophilicity in the form of hydroxylation/ carbonylation/etheroylation/dual carboxylation, the xenobiotics of this category associate into multiple $\alpha$-helix-type protein receptor hydrophobic cores to destabilize the protein receptor construct sufficiently enough to cause ligand-associated CM receptor endocytosis followed by intra-cellular disassociation. Re-association with affinity to soluble $\beta$-tubulin inhibits microtubule de-/re-polymerization function and results in mitochondrial anchorage resultant MM disruption/mitochondrial dissolution $(119,120)$. For this reason, small molecule xenobiotics in this category have no significant (in-significant) risk for secondary CM receptor endocytosis-mediated (Pseudo) 3ary indirect pressuromodulation resultant increase in nuclear transcription of very high MW proteins (17) (Table IX and Fig. 9).

The small molecule xenobiotic lipophiles with CM receptor endocytosing capability include: i) etoposide (VP16) [(Log OWPC, 1.16; vdWD, 0.97 nm; Log OWPC-to-vdWD ratio, $\left.1.20 \mathrm{~nm}^{-1}\right)$; etoposide hydrophobic core (Log OWPC, 3.88; vdWD, 0.76 nm; Log OWPC-to-vdWD ratio, $\left.\left.5.09 \mathrm{~nm}^{-1}\right)\right]$; ii) teniposide (VM26) [(Log OWPC, 2.78; vdWD, $1.00 \mathrm{~nm}$; Log OWPC-to-vdWD ratio, $\left.2.79 \mathrm{~nm}^{-1}\right)$; teniposide hydrophobic core (Log OWPC, 3.88; vdWD, $0.76 \mathrm{~nm}$; Log OWPC-to-vdWD ratio, $\left.5.09 \mathrm{~nm}^{-1}\right)$ ]; iii) colchicine [(Log OWPC, 1.42; vdWD, $0.87 \mathrm{~nm}$; Log OWPC-to-vdWD ratio, $1.62 \mathrm{~nm}^{-1}$ ); colchicine hydrophobic core (Log OWPC, 4.98; vdWD, $0.72 \mathrm{~nm}$; Log OWPC-to-vdWD ratio, $\left.6.88 \mathrm{~nm}^{-1}\right)$; iv) paclitaxel [(Log OWPC, 3.54; vdWD, $1.12 \mathrm{~nm}$;
Log OWPC-to-vdWD ratio, $3.16 \mathrm{~nm}^{-1}$ ); paclitaxel hydrophobic core (Log OWPC, 5.65; vdWD, $0.87 \mathrm{~nm}$; Log OWPC-to-vdWD ratio, $\left.\left.\left.6.46 \mathrm{~nm}^{-1}\right)\right] ; \mathrm{v}\right)$ ixabepilone [(Log OWPC, 3.39; vdWD, $0.97 \mathrm{~nm}$; Log OWPC-to-vdWD ratio, $3.51 \mathrm{~nm}^{-1}$ ); ixabepilone hydrophobic core (Log OWPC, 6.21; vdWD, $0.90 \mathrm{~nm}$; Log OWPC-to-vdWD ratio, $\left.6.91 \mathrm{~nm}^{-1}\right)$ ]; vi) (+/-) spiro-oxanthromicin A [(Log OWPC, 2.40; vdWD, $1.01 \mathrm{~nm}$; Log OWPC-to-vdWD ratio, $\left.2.38 \mathrm{~nm}^{-1}\right)$; (+/-) orthogonal spiro-oxanthromicin A hydrophobic cores (Log OWPC, 5.47; vdWD, $0.74 \mathrm{~nm}$ Log OWPC-to-vdWD ratio, $7.39 \mathrm{~nm}^{-1} /$ core)].

For i through vi, CM receptor de-stabilization-mediated endocytosis and intra-cellular re-association with soluble $\beta$-tubulin results in inhibition of microtubule polymerization de-/re-polymerization causing sub-cellular organelle anchorage non-motility, and generates intra-cellular reactive pro-oxidant species concomitant with mitochondrial anchorage immobility-associated MM disruption/dissolution with liberation of MM AIF and initiation of the mitochondrial-mediated nuclear apoptosis cascade (120-131), which have the significant potential for inducing cellular apoptosis, particularly those in incorporating lipophilicities in the intermediate range (Table IX and Fig. 9).

vii) Tacrolimus (FK506) [)Log OWPC, 5.59; vdWD, $1.13 \mathrm{~nm}$; Log OWPC-to-vdWD ratio, $\left.4.94 \mathrm{~nm}^{-1}\right)$; tacrolimus hydrophobic core (Log OWPC, 9.07; vdWD, $0.99 \mathrm{~nm}$; Log OWPC-to-vdWD ratio, $\left.9.14 \mathrm{~nm}^{-1}\right)$ ] and everolimus (132), with greater incorporating lipophilicity $\left(9.14 \mathrm{~nm}^{-1}\right)$ associate with the FKBP12/inter-domain (I-II/III) of FKBP52 (133).

In contrast to i) through vi) of this category, the CM chemokine receptor endocytosing immunosuppressives, tacrolimus, in the case of xenobiotics such as tacrolimus, xenobiotic-induced disassociation of the FKBP52 domain III from $\alpha / \beta$-tubulin results in a slight propensity for inhibition of tubulin de-polymerization (propensity for tubulin polymerization) (133), while the concomitant disassociation of the PUMA-like FKBP52 domain IV from BCL results in generation of cytosolic free BCL, which overcomes mitochondrial anchorage immobility-associated MM disruption due to the MM stabilizing effect of BCL (134-137) (Table IX and Fig. 9).

The CM receptor endocytosing small molecule xenobiotic lipophiles of this category have significant potential to be tumorocytotoxic, particularly in synergism with other tumorocytotoxic chemoxenobiotics [nuclear (i.e., 5-FU) (138) and mitochondrial (i.e., doxorubicin) $(9,138)]$. The primary limitation to efficacy when administered as a part of current free drug chemotherapy regimens is secondary to a high level of serum protein-binding due to overall lipophilicity for size (Log OWPC-to-vdWD ratio range, 1.2-3.51 $\mathrm{nm}^{-1}$ ), which makes it is difficult to obtain micromolar local intra-tumoral concentrations at which they are most effective. Therefore, the overall efficacy of such tumorocytotoxic small molecule xenobiotic lipophiles can be significantly improved via the EPR effect, as has shown to be the case for abraxane, a semi-polydisperse paclitaxel (non-covalent) albumin- microaggregate nanoparticulate $\left(H_{\mathrm{D}} \sim 120 \mathrm{~nm}\right)(139,140)$, which proteolytically degrades into smaller globular paclitaxel (non-covalent) albumin $\left(H_{\mathrm{D}} \sim 7-10 \mathrm{~nm}\right)$ to enter the tumor interstitium, that results in greater local intra-tumoral concentration of improved efficacy of such small molecule chemoxenobiotics (3-7). 
Small molecule xenobiotics that cause CM receptor-mediated pressuromodulation antagonism/partial antagonism of direct $C M$ receptor-mediated pressuromodulation. This category includes the small molecule xenobiotic lipophiles with CM receptor pressuromodulation antagonism/partial antagonism capability, with vdWDs in the $0.86-0.89 \mathrm{~nm}$ range. Due the presence of inner incorporating lipophilicity commensurate with that of the sex steroid receptor hydrophobic cores, the xenobiotics of this category bind to sex steroid receptor complexes with less affinity than endogenous sex steroids, and thus, function as short-duration pressuromodulators, in contrast to the endogenous sex steroids, which are prolonged duration CM receptor pressuromodulators (17) (Table X and Fig. 10).

The small molecule xenobiotic lipophiles with CM receptor pressuromodulation antagonism/partial antagonism capability include:

i) Hydroxytamoxifen (afimoxitene) [(Log OWPC, 3.00; vdWD, $0.89 \mathrm{~nm}$; Log OWPC-to-vdWD ratio, $3.37 \mathrm{~nm}^{-1}$ ); hydroxytamoxifen hydrophobic core ( $\log$ OWPC, 5.36; vdWD, $0.75 \mathrm{~nm}$; Log OWPC-to-vdWD ratio, $\left.7.14 \mathrm{~nm}^{-1}\right)$ ], with hydrophobic core lipophilicity similar to that of the estradiol and estriol sterol backbone (Log OWPC, 5.28; vdWD, $0.78 \mathrm{~nm}$ ) at $6.81 \mathrm{~nm}^{-1}(17)$, which has a bulky unstable exterior extracellularly-interacting hydrophilicity and insufficient for prolonged duration binding to the estrogen receptor (ER) complex (141).

ii) Abiraterone $[(\log$ OWPC, 3.81; vdWD, $0.86 \mathrm{~nm}$; Log OWPC-to-vdWD ratio, $\left.4.41 \mathrm{~nm}^{-1}\right)$; abiraterone hydrophobic core (Log OWPC, 5.42; vdWD, $0.80 \mathrm{~nm}$; Log OWPC-to-vdWD ratio, $\left.6.74 \mathrm{~nm}^{-1}\right)$ ], with hydrophobic core lipophilicity similar to that of the dihydrotestosterone (DHT) sterol backbone (Log OWPC, 5.82; vdWD, $0.81 \mathrm{~nm}$ ) at $7.18 \mathrm{~nm}^{-1}$ (17), which has lesser exterior extracellularly interacting hydrophilicity and insufficient for prolonged duration binding at the DHT receptor complex (142).

The sex steroid competitive antagonist chemoxenobiotics are pressuromodulation/partial pressuromodulation antagonists of the respective $\alpha$-helix-based sex steroid receptor types due to the non-binding of the endogenous small molecule sex steroid pressuromodulators, but their competitive binding to the respective sex steroid hormone receptor complexes still results in impartial pressuromodulation of the $\alpha$-helix-based small molecule sex steroid receptor complex. Thus, the overall effect of CM receptor pressuromodulation antagonism at the sex steroid hormone receptor is sufficient enough to decrease the rate of mitogenesis and cell division by decreasing the rate of protein transcription of very high MW nuclear division proteins, Ki67 (359 kDa) and separase (230 kDa). As such, the sex steroid hormone CM receptor pressuromodulation/partial pressuromodulation antagonists have the potential for temporizing solid tumor growth/progression $(143,144)$, as do upstream releasing hormone inhibitors of luteinising hormone $(\mathrm{LH})$ action on the gonadal sex steroid axis (145), however, in the physiologic state are not tumorocidal (146-148), which is due to the presence of a plethora of CM receptor pressuromodulators in the solid tumor milieu, paracrine and autocrine, and therefore, an abundance of tumor CM receptor-mediated pressuromodulation escape mechanisms, there is a high risk of local and/or metastatic re-occurence upon cessation of sex steroid CM receptor pressuromodulation/partial pressuromodulation antagonist-based chemotherapy (Table X and Fig. 10).
Small molecule xenobiotics that cause CM receptor-mediated pressuromodulation antagonism/partial antagonism of CM receptor-mediated pressuromodulation cum extracellulomodulation with concomitant receptor kinase inhibition. This category includes the small molecule xenobiotic lipophiles and hydro-lipophiles with CM receptor pressuromodulation antagonism/partial antagonism cum pressuromodulation extracellulomodulation and concomitant receptor kinase inhibition capability, with vdWDs in the $0.82-0.97 \mathrm{~nm}$ range. Due to L-to-U-type step-like backbone structural configurations, in context of the presence of inner incorporating lipophilicity commensurate with that of the growth factor and cytokine CM receptor hydrophobic cores, the xenobiotics of this category bind to growth factor and cytokine CM receptor subunits with affinity. In the case of the endogenous growth factors and cytokines [i.e., EGF, ALK, SDF-1 and asialoglycoprotein receptor (AGR) ligand] that bind to $\alpha$-helix-rich receptors (17), the presence of the CM pressuromodulator antagonist/partial antagonist results in non-binding of the endogenous growth factor or cytokine, which results in partial ligand antagonist-mediated CM receptor pressuromodulation; while, in the case of the endogenous growth factors and cytokines (i.e., PDGF, GM-CSF and TRAIL) that bind to $\beta$-helix-based subunit receptors (17), the concomitant presence of the CM pressuromodulator antagonist/ partial antagonist results in less effective, lower affinity binding of the endogenous growth factor or cytokine, which results in partial endogenous growth factor or cytokine-mediated CM receptor pressuromodulation (Table XI and Fig. 11).

The small molecule xenobiotic lipophiles or hydro-lipophiles that bind to $\alpha$-helix-rich receptors in lieu of endogenous growth factors or cytokines as direct CM receptor partial pressuromodulation antagonists (17) include:

i) The EGF receptor antagonists (149-156), gefitinib (Iressa) [(Log OWPC, 3.75; vdWD, 0.89 nm; Log OWPC-to-vdWD ratio, $4.21 \mathrm{~nm}^{-1}$ ); gefitinib hydrophobic core (Log OWPC, 4.21; vdWD, $0.74 \mathrm{~nm}$; Log OWPC-to-vdWD ratio, $\left.5.71 \mathrm{~nm}^{-1}\right)$ ], erlotinib (Tarceva) [(Log OWPC, 3.20; vdWD, $0.87 \mathrm{~nm}$; Log OWPC-to-vdWD ratio, $3.67 \mathrm{~nm}^{-1}$ ); erlotinib hydrophobic core (Log OWPC, 3.61; vdWD, 0.74 nm; Log OWPC-to-vdWD ratio, $\left.\left.4.88 \mathrm{~nm}^{-1}\right)\right]$, lapatinib [( $\log \mathrm{OWPC}, 2.12$; vdWD, $0.96 \mathrm{~nm}$; Log OWPC-to-vdWD ratio, $2.20 \mathrm{~nm}^{-1}$ ); lapatinib hydrophobic core (Log OWPC, 6.68; vdWD, $0.89 \mathrm{~nm}$; Log OWPC-to-vdWD ratio, $\left.7.51 \mathrm{~nm}^{-1}\right)$ ] and afatinib [(Log OWPC, 1.11; vdWD, $0.91 \mathrm{~nm}$; Log OWPC-to-vdWD ratio, $1.22 \mathrm{~nm}^{-1}$ ); afatinib hydrophobic core (Log OWPC, 4.21; vdWD, $0.74 \mathrm{~nm}$; Log OWPC-to-vdWD ratio, $\left.\left.5.71 \mathrm{~nm}^{-1}\right)\right]$.

ii) The ALK receptor antagonists (157-160), ceritinib [(Log OWPC, 3.40; vdWD, $0.97 \mathrm{~nm}$; Log OWPC-to-vdWD ratio, $3.67 \mathrm{~nm}^{-1}$ ); ceritinib hydrophobic core (Log OWPC, 7.16; vdWD, $0.89 \mathrm{~nm}$; Log OWPC-to-vdWD ratio, $\left.8.02 \mathrm{~nm}^{-1}\right)$ ] and crizotinib [(Log OWPC, 1.00; vdWD, $0.88 \mathrm{~nm}$; Log OWPC-to-vdWD ratio, $1.13 \mathrm{~nm}^{-1}$ ); crizotinib hydrophobic core (Log OWPC, 5.96; vdWD, 0.88 nm; Log OWPC-to-vdWD ratio, $\left.\left.6.88 \mathrm{~nm}^{-1}\right)\right]$.

iii) The CXCR receptor antagonist $(76,77,161,162)$, AMD070 [Log OWPC, -0.14; vdWD: $0.85 \mathrm{~nm}$; Log OWPC-to-vdWD ratio, -0.16 $\mathrm{nm}^{-1}$; AMD070 hydrophobic core (Log OWPC, 4.33; vdWD, $0.84 \mathrm{~nm}$; Log OWPC-to-vdWD ratio, $\left.\left.5.13 \mathrm{~nm}^{-1}\right)\right]$.

iv) AGR antagonist (163-169), staurosporine [(Log OWPC, 1.20; vdWD, $0.91 \mathrm{~nm}$; Log OWPC-to-vdWD 

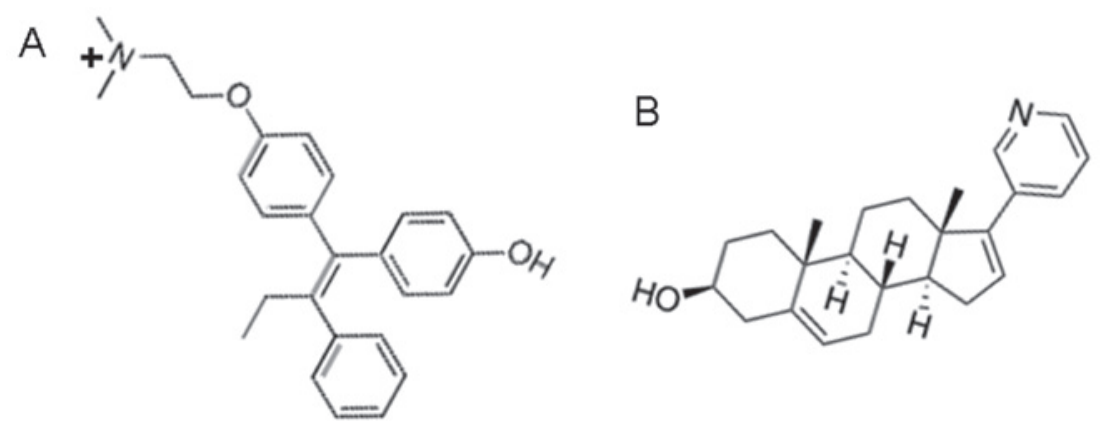

Figure 10. Cell membrane (CM) receptor-mediated pressuromodulation antagonism/partial antagonism: antagonism/partial antagonism of direct CM receptor-mediated pressuromodulation. (A) Hydroxytamoxifen, (B) abiraterone.
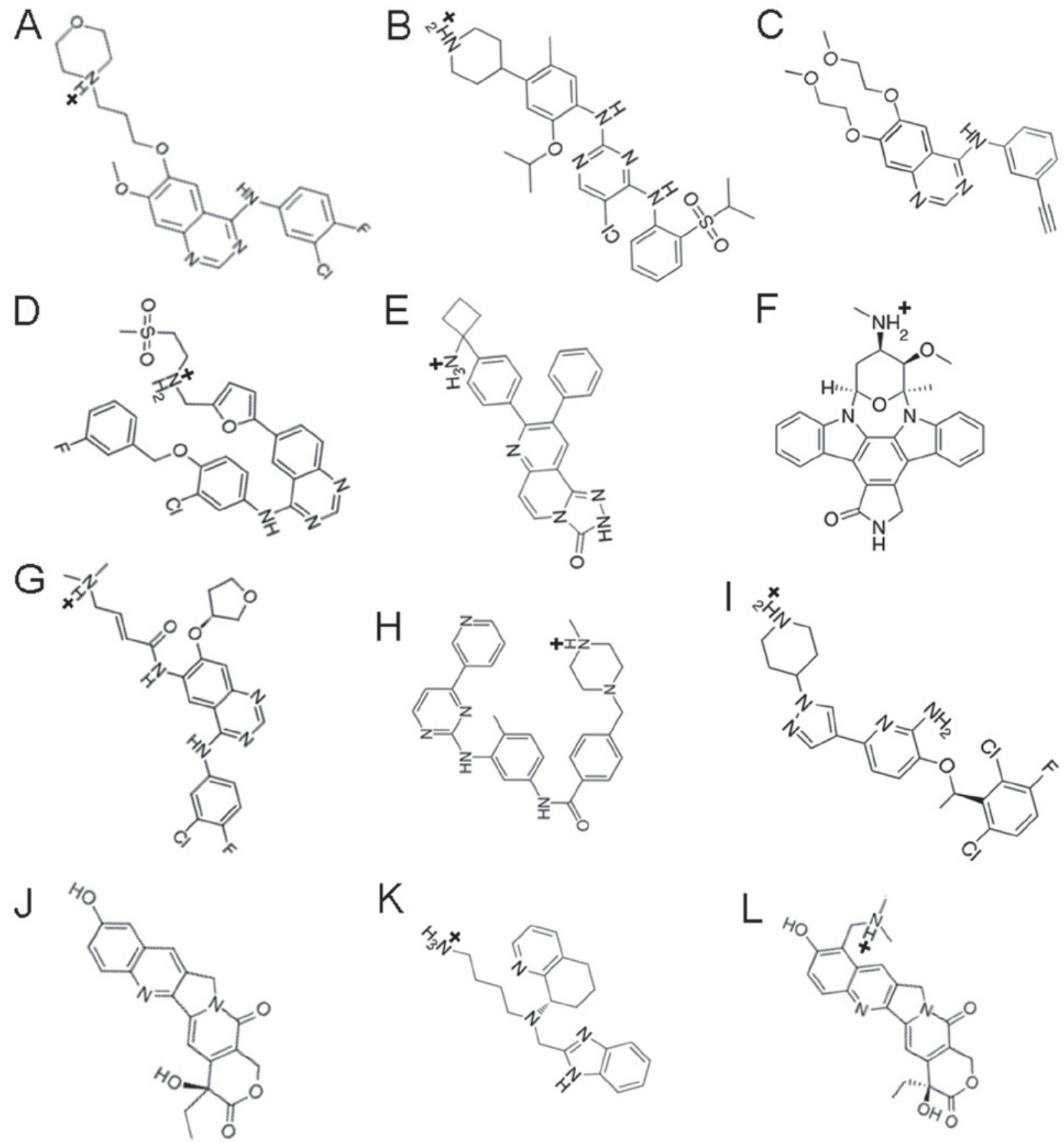

Figure 11. Cell membrane (CM) receptor-mediated antagonism/partial antagonism of pressuromodulation extracellulomodulation with concomitant receptor kinase inhibition: antagonism/partial antagonsim of direct CM receptor-mediated pressuromodulation \pm external cationomodulation $(\geq 3+\geq 1+$ ). (A) Gefitinib (Iressa), (B) ceritinib, (C) erlotinib (Tarceva), (D) lapatinib, (E) MK-2206, (F) staurosporine, (G) afatinib, (H) imatinib (Gleevac; CGP 57148), (I) crizotinib, (J) hydroxycamptothecin, (K) AMD070, (L) topotecan. 


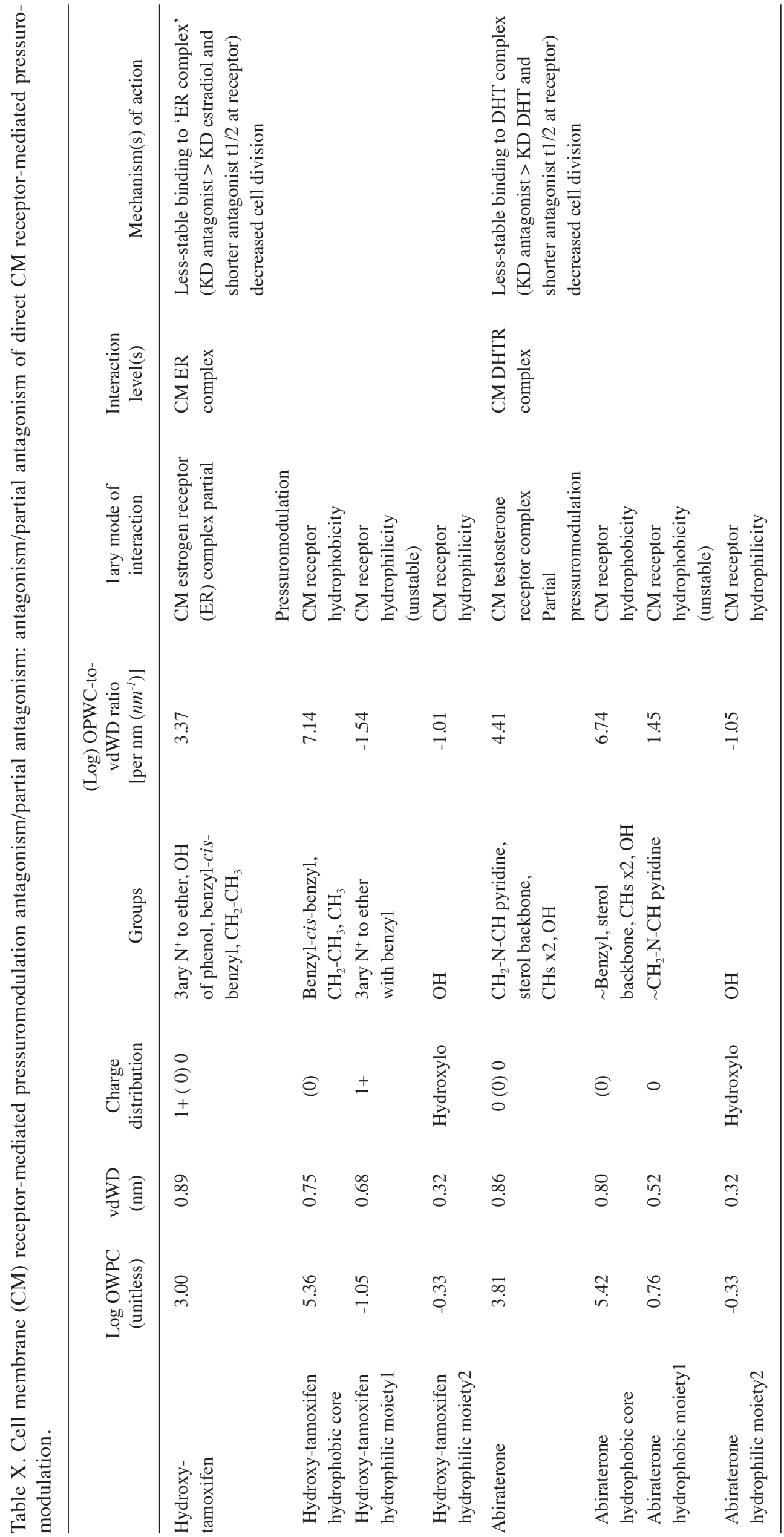




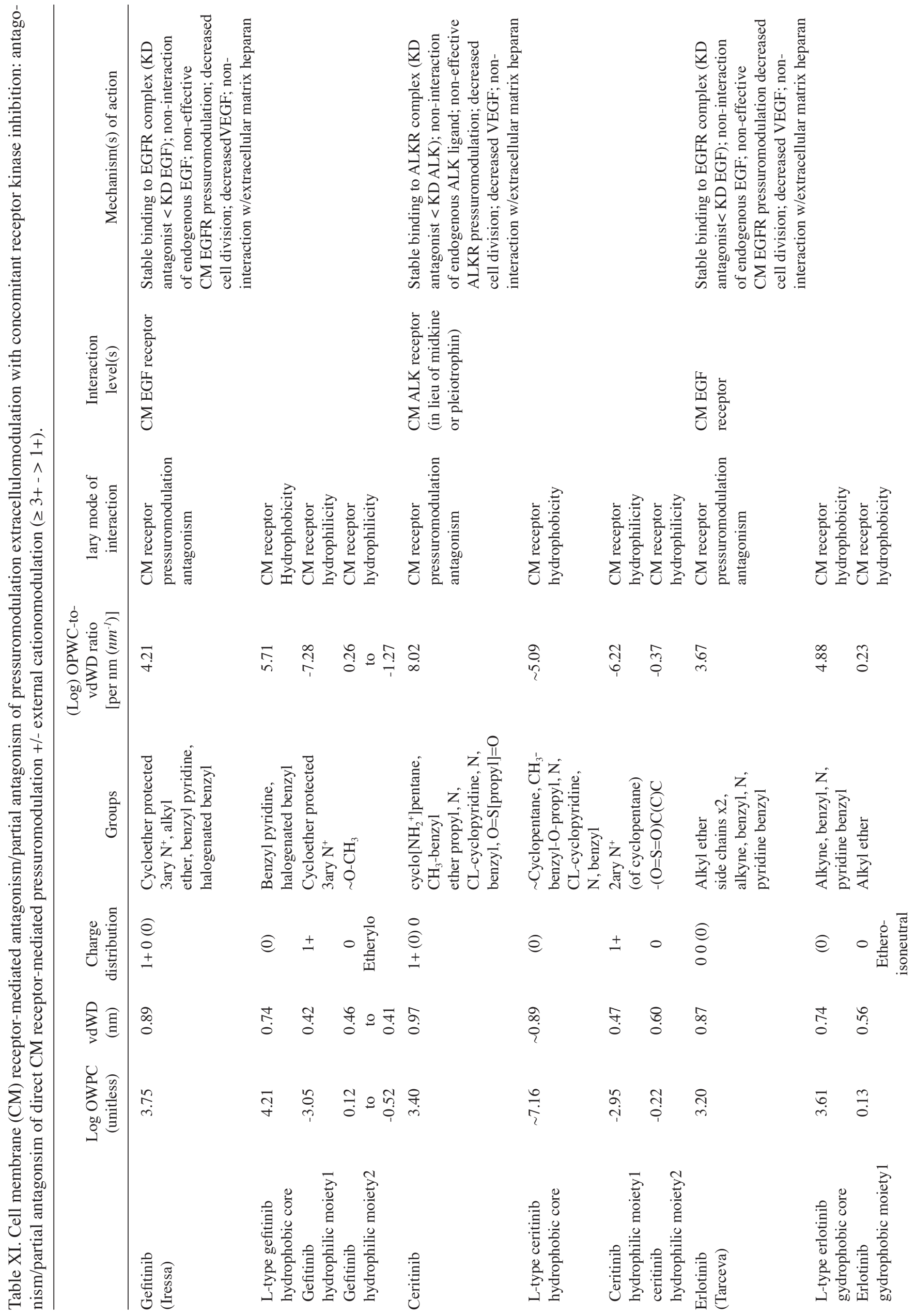




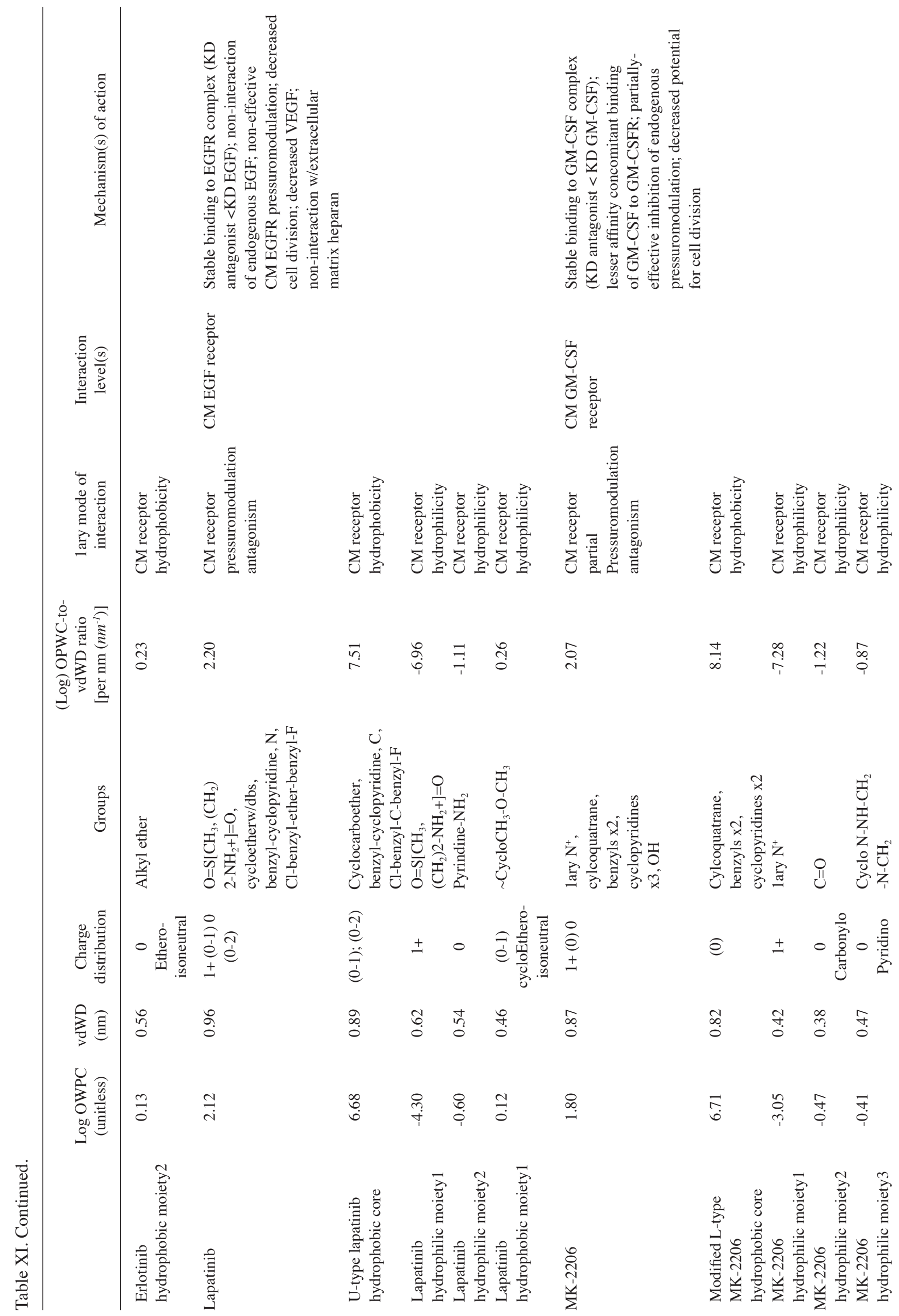




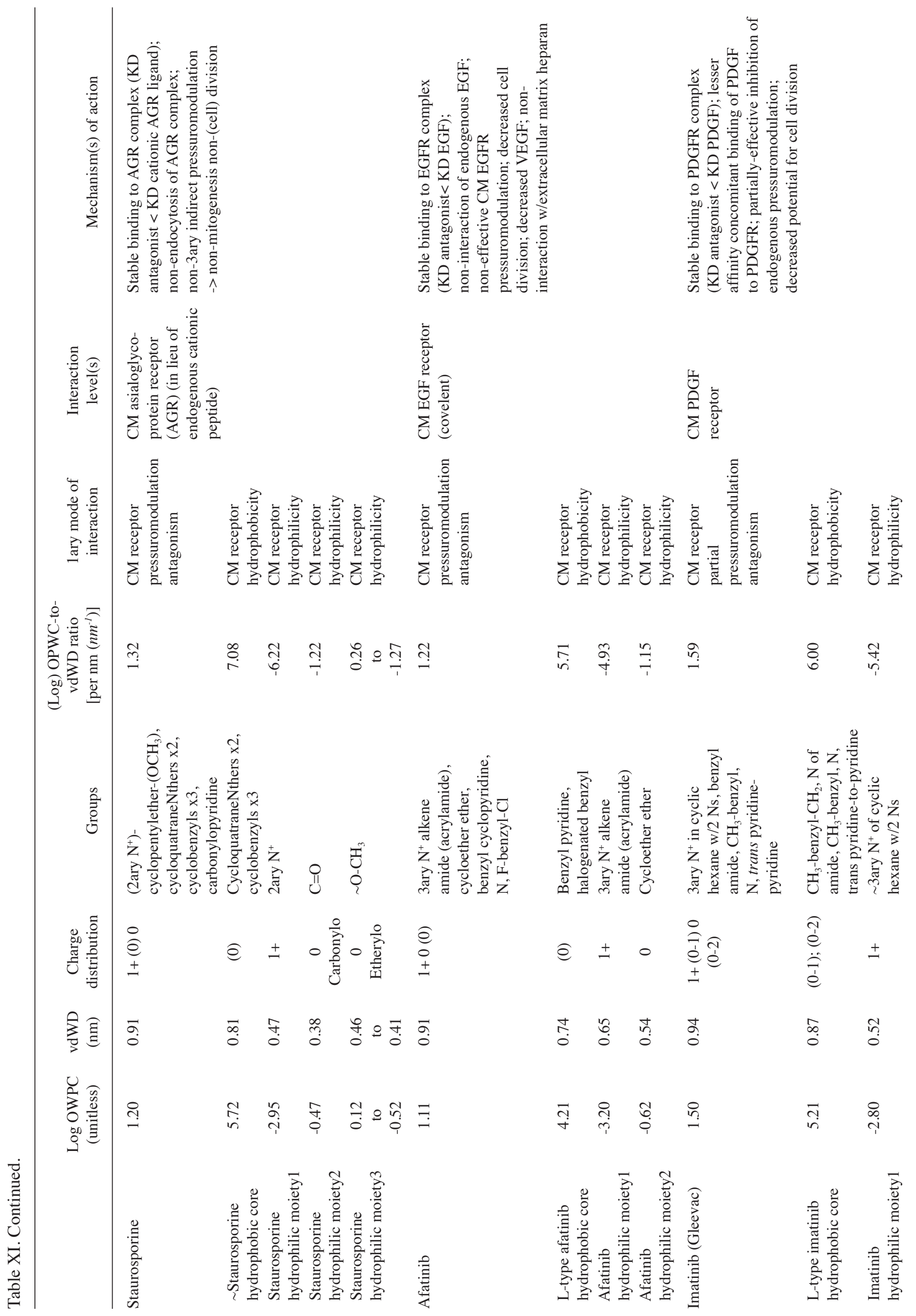




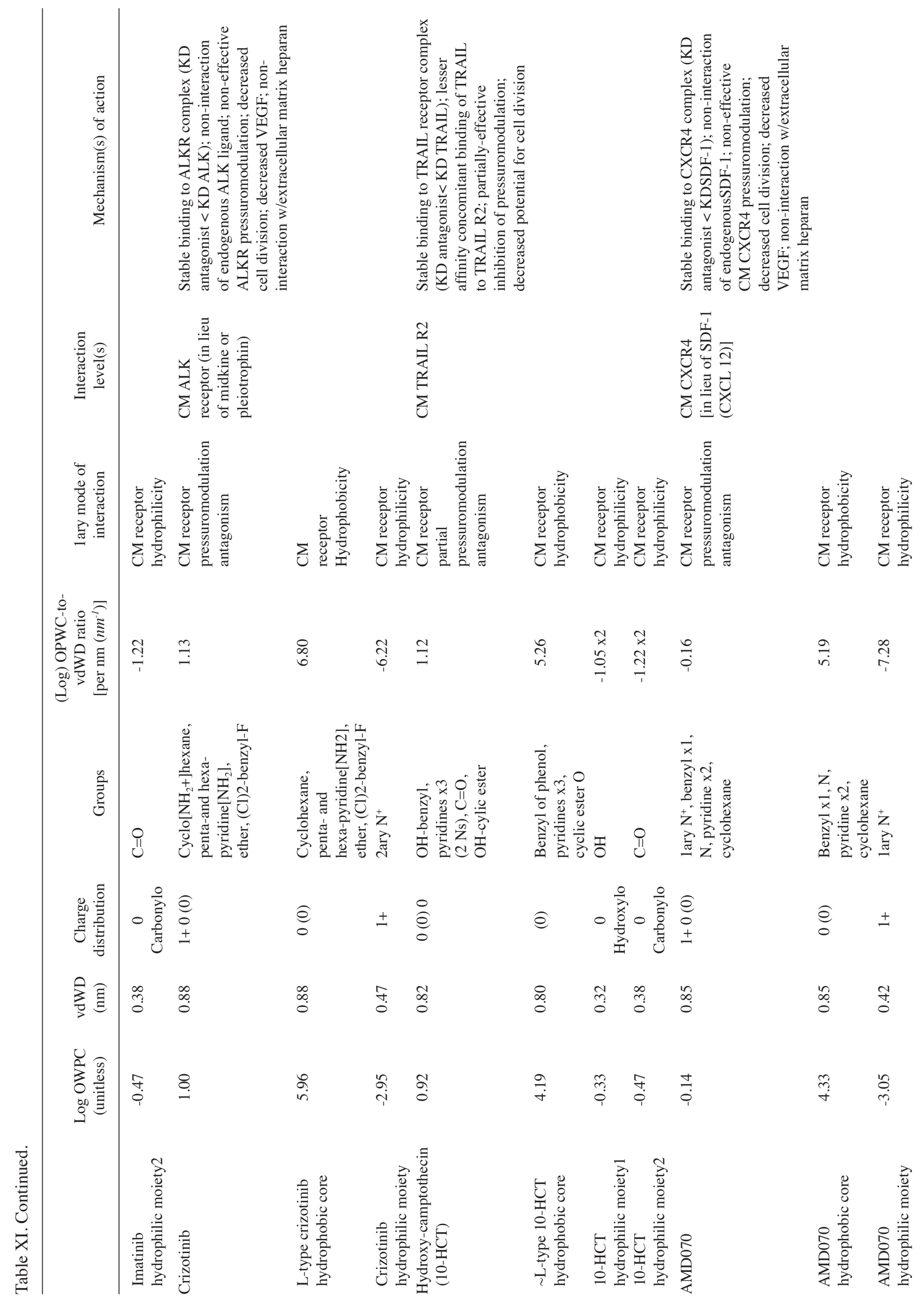




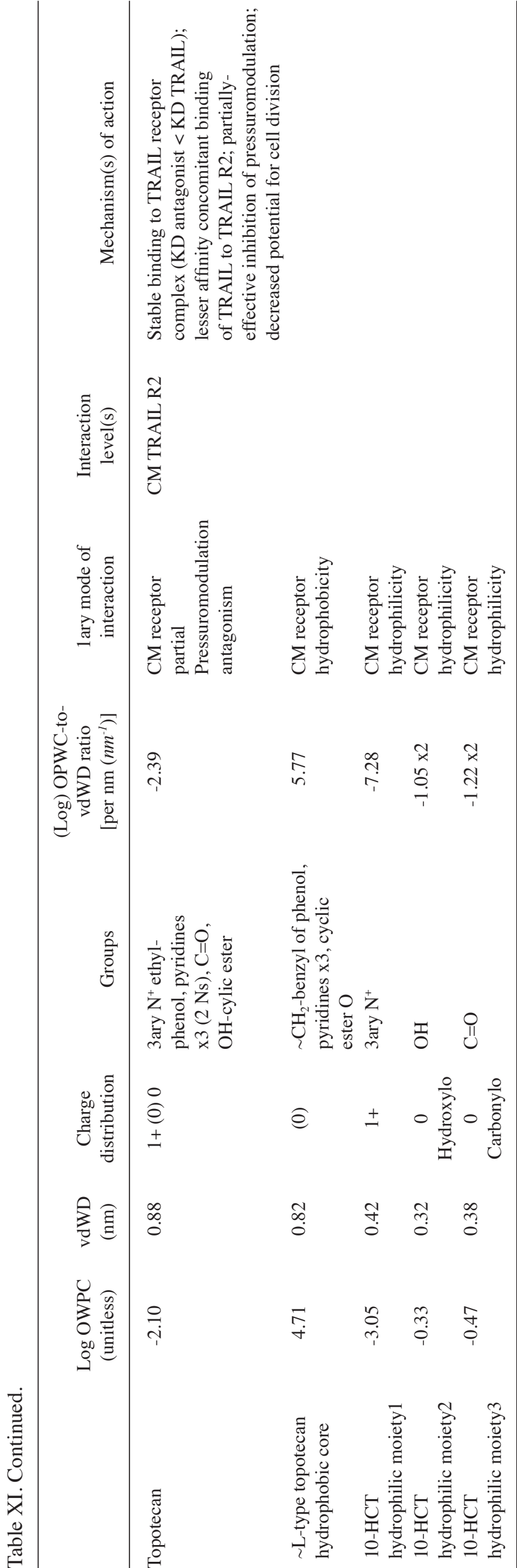

ratio, $1.32 \mathrm{~nm}^{-1}$ ); staurosporine hydrophobic core (Log OWPC, 5.72; vdWD, $0.81 \mathrm{~nm}$; Log OWPC-to-vdWD ratio, $\left.\left.7.08 \mathrm{~nm}^{-1}\right)\right]$.

The EGF receptor antagonists, ALK receptor antagonists and CXCR receptor antagonists cause for a decrease the rate of protein transcription of synthesizable proteins by $\mathrm{CM}$ receptor partial pressuromodulation antagonism of tumor $\mathrm{CM}$ receptors. The decrease in the transcription of the very high MW nuclear cell division proteins, Ki67 (359 kDa) and separase $(230 \mathrm{kDa})(170)$ results in decreased mitogenesis and cell division, while the decrease in the transcription of the lower MW protein forms including VEGF (20 kDa) necessary for autocrine angiogenesis $(154,171)$, and importantly, BCL (26 kDa) necessary for maintenance of MM integrity in tumor cells (BCL-dependent) (59), results in increased mitochondria-mediated apoptosis, particularly in p53-deficient tumor cells (172-174) (Table XI and Fig. 11).

The small molecule xenobiotic lipophiles that bind to multi-subunit polymeric $\beta$-helix $\beta$-helix-based receptors to decrease the binding affinity of endogenous growth factors or cytokines and function as direct $\mathrm{CM}$ receptor pressuromodulation/partial pressuromodulation antagonists (17) include:

i) The PDGF receptor antagonist (175-177), imatinib [Gleevac CGP 57148) [(Log OWPC, 1.50; vdWD, $0.94 \mathrm{~nm}$; Log OWPC-to-vdWD ratio, $1.59 \mathrm{~nm}^{-1}$ ); imatinib hydrophobic core (Log OWPC, 5.21; vdWD, $0.87 \mathrm{~nm}$; Log OWPC-to-vdWD ratio, $\left.\left.6.00 \mathrm{~nm}^{-I}\right)\right]$.

ii) The GM-CSF receptor antagonist $(178,179)$, MK-2206 [(Log OWPC, 1.80; vdWD, $0.87 \mathrm{~nm}$; Log OWPC-to-vdWD ratio, $2.07 \mathrm{~nm}^{-1}$ ); MK-2206 hydrophobic core (Log OWPC, 6.71; vdWD, $0.82 \mathrm{~nm}$; Log OWPC-to-vdWD ratio, $8.14 \mathrm{~nm}^{-1}$ )]:

The PDGF receptor antagonist(s) and GM-CSF receptor antagonist(s), imatinib and MK-2206, still permit concomitant receptor subunit binding of the respective endogenous growth factors, PDGF and GM-CSF, which are prolonged duration endogenous direct $\mathrm{CM}$ receptor pressuromodulators of multi-subunit polymeric $\beta$-helix-based receptors, but decrease the potency of the pressuromodulation effect by causing a decrease in the affinity of the receptors for endogenous PDGF and GM-CSF, respectively. Therefore, a decrease the rate of protein transcription of synthesizable proteins, results in decreased mitogenesis and cell division due to a decrease in the transcription of the very high MW nuclear cell division proteins, Ki67 (359 kDa) and separase (230 kDa) (180), and increases the likelihood of mitochondria-mediated apoptosis in more BCL-dependent tumor cells (181) due to a decrease in the transcription of BCL (26 kDa) (181) (Table XI and Fig. 11).

The small molecule xenobiotic lipophiles or hydro-lipophiles that bind to multi-subunit polymeric $\beta$-helix-based receptors to decrease the binding affinity of endogenous growth factors or cytokines and function as 2ary indirect quad receptor internal pseudo-cationomodulator (SS 1+) pressuromodulation/partial pressuromodulation antagonists (17) include.

The TRAIL receptor antagonists (182-186), a) hydroxycamptothecin [( $\log$ OWPC, 0.92; vdWD, $0.82 \mathrm{~nm}$; Log OWPC-to-vdWD ratio, $1.12 \mathrm{~nm}^{-1}$ ); hydroxycamptothecin hydrophobic core (Log OWPC, 4.19; vdWD, $0.80 \mathrm{~nm}$; Log OWPC-to-vdWD ratio, $\left.5.24 \mathrm{~nm}^{-1}\right)$ ]; b) topotecan [(Log OWPC, -2.10; vdWD, $0.88 \mathrm{~nm}$; Log OWPC-to-vdWD 
ratio, $\left.-2.39 \mathrm{~nm}^{-1}\right)$; topotecan hydrophobic core (Log OWPC, 4.71; vdWD, $0.82 \mathrm{~nm}$; Log OWPC-to-vdWD ratio, $\left.5.77 \mathrm{~nm}^{-1}\right)$ ].

The TRAIL receptor antagonists, hydroxycamptothecin and topotecan, still permit the concomitant binding of the endogenous TRAIL, but decreases the potency of the pressuromodulation effect by causing for a decrease in the affinity of TRAIL R2 for endogenous TRAIL, which is an extremely portent prolonged duration 2ary indirect pressuromodulator multi-subunit poly-meric $\beta$-helix-based receptors (187-191). As such, hydroxycamptothecin and topotecan-mediated CM receptor pressuromodulation antagonism of TRAIL results in TRAIL pressuromodulation-mediated TRAIL R2 chromatin transcription and in auto-induction of TRAIL R2 at the CM (192) as well as in that of the lower-to-higher MW proteins (i.e., VEGF, $20 \mathrm{kDa}$; p21; p53; topoisomerase I, 90 kDa; HIF1- $\alpha$, 93 kDa; P-gp, 140 kDa; topoisomerase II- $\alpha$, $174 \mathrm{kDa})(186,193)$, but not of the highest MW nuclear division-associated proteins (Ki67, $359 \mathrm{kDa}$; separase, $230 \mathrm{kDa}$ ), in which case, the increased transcription of intermediate MW protein, p53 $(53 \mathrm{kDa})(184,186)$, results in the depletion of free BCL (p53-BCL) and in mitochondrial-mediated oxidative stress sufficient to induce apoptosis $(182,183)$ that maybe associated with a secondary decrease in mitogenesis and cell division (182) in synergism with additional CM receptor pressuromodulation antagonism (185) (Table XI and Fig. 11).

The CM receptor growth factor or cytokine pressuromodulation/partial pressuromodulation antagonists, including the direct CM pressuromodulation/partial pressuromodulation antagonists of the hepatocyte growth factor (HGF)/scatter factor (SF) receptor family (194-197), have the potential for halting solid tumor growth/progression during the treatment phase (150). However, due to significant concentrations of growth factor and cytokine $\mathrm{CM}$ receptor pressuromodulators in the solid tumor milieu, paracrine and autocrine, in context of the significant redundancy of growth factor and cytokine receptors on tumor CMs for CM receptor-mediated pressuromodulation, are not tumorocidal in the physiologic state, as evidenced by the high incidence of local solid tumor re-occurence upon cessation of treatment phase, due to the remaining presence of resistant tumor cells overexpressing mutated receptor subtypes (198) and the EMT transformation of epithelium of tumorgenic potential (199), for example, in the case of weak CM pressuromodulator antagonists such as gefitinib $(152,198)$ with greater binding affinities for their receptors.

CM receptor growth factor or cytokine pressuromodulation/partial pressuromodulation antagonism-based synergistic approaches with the potential for tumorocidal tumorocytotoxicity include those employing ones such as staurosporine $(59,164,167,168)$, imatinib (200), MK-2206 (201) and topotecan (186), particularly, upon effective transvascular delivery into solid tumors across VEGF-derived and maintained diaphragm fenestrated tumor blood capillaries (3-8).

In conclusion, based on these observations herein, on the modes, levels and character of interactions of xenobiotics and chemoxenobiotics with cells, analyzed in terms of the predicted conserved biophysical properties, insight has been gained into the specific mechanisms by which chemoxenobiotics enter cells and the organelles with which they interact to induce cytotoxcity. This knowledge is applicable towards improving the effectiveness of combination small chemo- therapy regimens in present clinical use, for the treatment of solid and hematopoietic malignancies, including the order in which chemoxenobiotics are administered in combination treatment regimens, in temporal proximity. It is anticipated that by the application of this study's findings on the modes and character of cellular interactions, existing combination chemotherapy regimens can be designed to be more efficacious, and furthermore, that by the incorporation of this knowledge into the algorithms for the design of personalized cancer treatments, the predictive accuracy of such algorithms can be further optimized.

The observations of this study also underscore the importance of focusing attention on specific CM receptors that mediate the cellular interactions of the various classes of molecular size-restricted chemoxenobiotics, particularly that of pro-endocytic xenobiotics, as the proteomic profiling of the density of these protein receptors across tumor types and grades will result in most sensitive personalized cancer treatments employing existing chemotherapeutic regimens. This being stated, for the curative treatment of solid malignancies, small molecule chemoxenobiotics must be made to selectively accumulate within the micromolar concentrations in the tumor milieu, where they must remain for prolonged duration in order for uniform tumorocidal cytotoxcity to tumor and tumor-associated cells, which will require the further translational development of novel chemotherapeutic regimens employing optimally-sized and -designed biocompatible imageable dendrimer-based nanoparticles bearing labilely attached small molecule chemoxenobiotics.

\section{References}

1. Klassen CD and Watkins IB III (eds). Casarett and Doull's Essentials of Toxicology. McGraw-Hill. New York, NY, 2010.

2. Matsumura Y and Maeda H: A new concept for macromolecular therapeutics in cancer chemotherapy: Mechanism of tumoritropic accumulation of proteins and the antitumor agent Smancs. Cancer Res 46: 6387-6392, 1986.

3. Sarin H: Recent progress towards development of effective systemic chemotherapy for the treatment of malignant brain tumors. J Transl Med 7: 77, 2009.

4. Sarin H: Overcoming the challenges in the effective delivery of chemotherapies to CNS solid tumors. Ther Deliv 1: 289-305, 2010.

5. Sarin H: On the future development of optimally-sized lipid-insoluble systemic therapies for CNS solid tumors and other neuropathologies. Recent Patents CNS Drug Discov 5: 239-252, 2010.

6. Sarin H: Effective transvascular delivery of chemotherapy into cancer cells with imageable nanoparticles in the 7 to 10 nanometer size range. In: Current Advances in the Medical Application of Nanotechnology. Bentham Science Publishers Ltd., pp10-24, 2012.

7. Sarin H: Permeation thresholds for hydrophilic small biomolecules across microvascular and epithelial barriers are predictable on the basis of conserved biophysical properties. In Silico Pharmacol 3: 5, 2015.

8. Sarin H: Translational theranostic methodology for diagnostic imaging and the concomitant treatment of malignant solid tumors. Neurovascular Imaging 1: 3, 2015.

9. Lee CC, Gillies ER, Fox ME, Guillaudeu SJ, Fréchet JM, Dy EE and Szoka FC: A single dose of doxorubicin-functionalized bow-tie dendrimer cures mice bearing C-26 colon carcinomas. Proc Natl Acad Sci USA 103: 16649-16654, 2006.

10. Trédan O, Galmarini CM, Patel K and Tannock IF: Drug resistance and the solid tumor microenvironment. J Natl Cancer Inst 99: 1441-1454, 2007.

11. Rosier RN, Teot LA, Hicks DG, Schwartz C, O'Keefe RJ and Puzas JE: Multiple drug resistance in osteosarcoma. Iowa Orthop J 15: 66-73, 1995. 
12. Kleinschmidt-Demasters BK, Kang JS and Lillehei KO: The burden of radiation-induced central nervous system tumors: A single institution experience. J Neuropathol Exp Neurol 65: 204-216, 2006.

13. Verhoef GE, De Wolf-Peeters C, Ferrant A, Deprez S, Meeus P, Stul M, Zacheé P, Cassiman JJ, Van den Berghe $\mathrm{H}$ and Boogaerts MA: Myelodysplastic syndromes with bone marrow fibrosis: A myelodysplastic disorder with proliferative features. Ann Hematol 63: 235-241, 1991.

14. Doudican NA, Kumar A, Singh NK, Nair PR, Lala DA, Basu K, Talawdekar AA, Sultana Z, Tiwari KK, Tyagi A, et al: Personalization of cancer treatment using predictive simulation. J Transl Med 13: 43, 2015.

15. Pingle SC, Sultana Z, Pastorino S, Jiang P, Mukthavaram R, Chao Y, Bharati IS, Nomura N, Makale M, Abbasi T, et al In silico modeling predicts drug sensitivity of patient-derived cancer cells. J Transl Med 12: 128, 2014.

16. Peacock JD, Cherba D, Kampfschulte K, Smith MK, Monks NR, Webb CP and Steensma M: Molecular-guided therapy predictions reveal drug resistance phenotypes and treatment alternatives in malignant peripheral nerve sheath tumors. J Transl Med 11: 213, 2013.

17. Sarin H: Pressuromodulation at the cell membrane as the basis for small molecule hormone and peptide regulation of cellular and nuclear function. J Transl Med 13: 372, 2015.

18. Newlands ES, Stevens MF, Wedge SR, Wheelhouse RT and Brock C: Temozolomide: A review of its discovery, chemical properties, pre-clinical development and clinical trials. Cancer Treat Rev 23: 35-61, 1997.

19. Johnson RE, Campbell RJ and Laws ER Jr: The cytotoxic effect of ethylnitrosourea on the developing rat cerebellum. Morphologic observations. Acta Neuropathol 55: 257-261, 1981.

20. Kolarić K, Roth A and Fuss V: Combination chemotherapy with 1-methyl-1-nitrosourea and cyclophosphamide in metastatic melanoma. Tumori 64: 89-94, 1978.

21. An Q, Robins P, Lindahl T and Barnes DE: 5-Fluorouracil incorporated into DNA is excised by the Smug1 DNA glycosylase to reduce drug cytotoxicity. Cancer Res 67: 940-945, 2007.

22. Tentori L, Forini O, Fossile E, Muzi A, Vergati M, Portarena I, Amici C, Gold B and Graziani G: N3-methyladenine induces early poly(ADP-ribosylation), reduction of nuclear factor-kappa B DNA binding ability, and nuclear up-regulation of telomerase activity. Mol Pharmacol 67: 572-581, 2005.

23. Paine PL, Moore LC and Horowitz SB: Nuclear envelope permeability. Nature 254: 109-114, 1975.

24. Rostovtseva T and Colombini M: VDAC channels mediate and gate the flow of ATP: Implications for the regulation of mitochondrial function. Biophys J 72: 1954-1962, 1997.

25. Colombini M, Yeung CL, Tung J and König T: The mitochondrial outer membrane channel, VDAC, is regulated by a synthetic polyanion. Biochim Biophys Acta 905: 279-286, 1987.

26. Nobel PS: Mitochondrial permeability for alcohols, aldoses, and amino acids. J Membr Biol 12: 287-299, 1973.

27. Kanzawa T, Germano IM, Komata T, Ito H, Kondo Y and Kondo S: Role of autophagy in temozolomide-induced cytotoxicity for malignant glioma cells. Cell Death Differ 11: 448-457, 2004.

28. Griffin RJ,Arris CE,BleasdaleC,Boyle FT,Calvert AH,CurtinNJ, Dalby C, Kanugula S, Lembicz NK, Newell DR, et al: Resistancemodifying agents. 8. Inhibition of $\mathrm{O}(6)$-alkylguanine-DNA alkyltransferase by $\mathrm{O}(6)$-alkenyl-, $\mathrm{O}(6)$-cycloalkenyl-, and $\mathrm{O}(6)$-(2-oxoalkyl)guanines and potentiation of temozolomide cytotoxicity in vitro by $\mathrm{O}(6)$-(1-cyclopentenylmethyl)guanine. J Med Chem 43: 4071-4083, 2000.

29. Long L and Dolan ME: Role of cytochrome P450 isoenzymes in metabolism of $\mathrm{O}(6)$-benzylguanine: Implications for dacarbazine activation. Clin Cancer Res 7: 4239-4244, 2001.

30. Ortiz de Montellano PR: Cytochrome P450-activated prodrugs. Future Med Chem 5: 213-228, 2013

31. Meyer RP, Podvinec M and Meyer UA: Cytochrome P450 CYP1A1 accumulates in the cytosol of kidney and brain and is activated by heme. Mol Pharmacol 62: 1061-1067, 2002.

32. Sangar MC, Anandatheerthavarada HK, Tang W, Prabu SK, Martin MV, Dostalek M, Guengerich FP and Avadhani NG: Human liver mitochondrial cytochrome P450 2D6 - individual variations and implications in drug metabolism. FEBS J 276 3440-3453, 2009.

33. Pletsa V, Valavanis C, van Delft JH, Steenwinkel MJ and Kyrtopoulos SA: DNA damage and mutagenesis induced by procarbazine in lambda lacZ transgenic mice: Evidence that bone marrow mutations do not arise primarily through miscoding by $\mathrm{O}^{6}$-methylguanine. Carcinogenesis 18: 2191-2196, 1997.
34. Crook TR, Souhami RL and McLean AE: Cytotoxicity, DNA cross-linking, and single strand breaks induced by activated cyclophosphamide and acrolein in human leukemia cells. Cancer Res 46: 5029-5034, 1986

35. Weber GF and Waxman DJ: Denitrosation of the anti-cancer drug 1,3-bis(2-chloroethyl)-1-nitrosourea catalyzed by microsomal glutathione S-transferase and cytochrome P450 monooxygenases. Arch Biochem Biophys 307: 369-378, 1993.

36. Linfoot PA, Gray JW, Dean PN, Marton LJ and Deen DF: Effect of cell cycle position on the survival of 9L cells treated with nitrosoureas that alkylate, cross-link, and carbamoylate. Cancer Res 46: 2402-2406, 1986.

37. Doroshenko N and Doroshenko P: The glutathione reductase inhibitor carmustine induces an influx of $\mathrm{Ca}^{2+}$ in PC12 cells. Eur J Pharmacol 497: 17-24, 2004.

38. Kehrer JP: The effect of BCNU (carmustine) on tissue glutathione reductase activity. Toxicol Lett 17: 63-68, 1983.

39. FitzGerald GB, Bauman C, Hussoin MS and Wick MM: 2,4-Dihydroxybenzylamine: A specific inhibitor of glutathione reductase. Biochem Pharmacol 41: 185-190, 1991.

40. Babson JR and Reed DJ: Inactivation of glutathione reductase by 2-chloroethyl nitrosourea-derived isocyanates. Biochem Biophys Res Commun 83: 754-762, 1978.

41. Bizzozero OA, Ziegler JL, De Jesus G and Bolognani F: Acute depletion of reduced glutathione causes extensive carbonylation of rat brain proteins. J Neurosci Res 83: 656-667, 2006.

42. Street JC, Mahmood U, Matei C and Koutcher JA: In vivo and in vitro studies of cyclophosphamide chemotherapy in a mouse mammary carcinoma by 31P NMR spectroscopy. NMR Biomed 8: 149-158, 1995

43. Street JC and Koutcher JA: Effect of radiotherapy and chemotherapy on composition of tumor membrane phospholipids. Lipids 32: 45-49, 1997.

44. Jilani K and Lang F: Carmustine-induced phosphatidylserine translocation in the erythrocyte membrane. Toxins (Basel) 5: 703-716, 2013.

45. Westphal M, Hilt DC, Bortey E, Delavault P, Olivares R, Warnke PC, Whittle IR, Jääskeläinen J and Ram Z: A phase 3 trial of local chemotherapy with biodegradable carmustine (BCNU) wafers (Gliadel wafers) in patients with primary malignant glioma. Neuro Oncol 5: 79-88, 2003

46. Lambros MP and Rahman YE: Effects of cyclosporin A on model lipid membranes. Chem Phys Lipids 131: 63-69, 2004.

47. Birraux J, Kirby JA, Thomason JM and Taylor JJ: The effect of cyclosporin on cell division and apoptosis in human oral keratinocytes. J Periodontal Res 41: 297-302, 2006.

48. Bokemeyer D, Kramer HJ and Meyer-Lehnert H: Atrial natriuretic peptide blunts the cellular effects of cyclosporine in smooth muscle. Hypertension 21: 166-172, 1993.

49. Raymond MA, Mollica L, Vigneault N, Désormeaux A, Chan JS, Filep JG, Hébert MJ, et al: Blockade of the apoptotic machinery by cyclosporin A redirects cell death toward necrosis in arterial endothelial cells: regulation by reactive oxygen species and cathepsin D. FASEB J 17: 515-517, 2003.

50. Laursen M, Yatime L, Nissen P and Fedosova NU: Crystal structure of the high-affinity $\mathrm{Na}^{+} \mathrm{K}^{+}$-ATPase-ouabain complex with $\mathrm{Mg}^{2+}$ bound in the cation binding site. Proc Natl Acad Sci USA 110: 10958-10963, 2013

51. Liu J, Kesiry R, Periyasamy SM, Malhotra D, Xie Z and Shapiro JI: Ouabain induces endocytosis of plasmalemmal Na/K-ATPase in LLC-PK1 cells by a clathrin-dependent mechanism. Kidney Int 66: 227-241, 2004.

52. Suwalsky M,Hernandez P, Villena F and Sotomayor CP: The anticancer drug chlorambucil interacts with the human erythrocyte membrane and model phospholipid bilayers. Z Naturforsch C 54 1089-1095, 1999.

53. Krigel R, Liebes LF, Pelle E and Silber R: Chlorambucil therapy in hairy cell leukemia: Effects on lipid composition and lymphocyte subpopulations. Blood 60: 272-275, 1982.

54. Matsura T, Kai M, Jiang J, Babu H, Kini V, Kusumoto C, Yamada $\mathrm{K}$ and Kagan VE: Endogenously generated hydrogen peroxide is required for execution of melphalan-induced apoptosis as well as oxidation and externalization of phosphatidylserine. Chem Res Toxicol 17: 685-696, 2004.

55. Tilby MJ, Lawley PD and Farmer PB: Alkylation of DNA by melphalan in relation to immunoassay of melphalan-DNA adducts: Characterization of mono-alkylated and cross-linked products from reaction of melphalan with dGMP and GMP. Chem Biol Interact 73: 183-194, 1990. 
56. Van den Driessche B, Lemière F, Van Dongen W and Esmans EL: Alkylation of DNA by melphalan: Investigation of capillary liquid chromatography-electrospray ionization tandem mass spectrometry in the study of the adducts at the nucleoside level. J Chromatogr B Analyt Technol Biomed Life Sci 785: 21-37, 2003.

57. Rodriguez RJ and Acosta D Jr: Inhibition of mitochondrial function in isolated rate liver mitochondria by azole antifungals. J Biochem Toxicol 11: 127-131, 1996.

58. Maté MJ, Ortiz-Lombardía M, Boitel B, Haouz A, Tello D Susin SA, Penninger J, Kroemer G and Alzari PM: The crystal structure of the mouse apoptosis-inducing factor AIF. Nat Struct Biol 9: 442-446, 2002.

59. Daugas E, Susin SA, Zamzami N, Ferri KF, Irinopoulou T, Larochette N, Prévost MC, Leber B, Andrews D, Penninger J, et al: Mitochondrio-nuclear translocation of AIF in apoptosis and necrosis. FASEB J 14: 729-739, 2000.

60. Lewis EM, Wilkinson AS, Davis NY, Horita DA and Wilkinson JC: Nondegradative ubiquitination of apoptosis inducing factor (AIF) by X-linked inhibitor of apoptosis at a residue critical for AIF-mediated chromatin degradation. Biochemistry 50: 11084-11096, 2011.

61. Wei Y, Fox T, Chambers SP, Sintchak J, Coll JT, Golec JM, Swenson L, Wilson KP and Charifson PS: The structures of caspases $-1,-3,-7$ and -8 reveal the basis for substrate and inhibitor selectivity. Chem Biol 7: 423-432, 2000.

62. Riedl SJ and Shi Y: Molecular mechanisms of caspase regulation during apoptosis. Nat Rev Mol Cell Biol 5: 897-907, 2004.

63. Lindsay J, Esposti MD and Gilmore AP: Bcl-2 proteins and mitochondria - specificity in membrane targeting for death. Biochim Biophys Acta 1813: 532-539, 2011.

64. Miyashita T and Reed JC: Tumor suppressor p53 is a direct transcriptional activator of the human bax gene. Cell 80: 293-299, 1995.

65. Cho Y, Gorina S, Jeffrey PD and Pavletich NP: Crystal structure of a p53 tumor suppressor-DNA complex: Understanding tumorigenic mutations. Science 265: 346-355, 1994.

66. Billen LP, Shamas-Din A and Andrews DW: Bid: A Bax-like BH3 protein. Oncogene 27 (Suppl 1): S93-S104, 2008.

67. Chipuk JE and Green DR: PUMA cooperates with direct activator proteins to promote mitochondrial outer membrane permeabilization and apoptosis. Cell Cycle 8: 2692-2696, 2009.

68. Nakano K and Vousden KH: PUMA, a novel proapoptotic gene, is induced by p53. Mol Cell 7: 683-694, 2001.

69. Loose DS, Kan PB, Hirst MA, Marcus RA and Feldman D: Ketoconazole blocks adrenal steroidogenesis by inhibiting cytochrome P450-dependent enzymes. J Clin Invest 71: 1495-1499, 1983.

70. Greenblatt DJ, Zhao Y, Venkatakrishnan K, Duan SX, Harmatz JS, Parent SJ, Court MH and von Moltke LL: Mechanism of cytochrome P450-3A inhibition by ketoconazole. J Pharm Pharmacol 63: 214-221, 2011.

71. Ho YS, Tsai PW, Yu CF, Liu HL, Chen RJ and Lin JK: Ketoconazole-induced apoptosis through P53-dependent pathway in human colorectal and hepatocellular carcinoma cell lines. Toxicol Appl Pharmacol 153: 39-47, 1998.

72. Wang YJ, Jeng JH, Chen RJ, Tseng H, Chen LC, Liang YC, Lin $\mathrm{CH}$, Chen $\mathrm{CH}$, Chu JS, Ho WL, et al: Ketoconazole potentiates the antitumor effects of nocodazole: In vivo therapy for human tumor xenografts in nude mice. Mol Carcinog 34: 199-210, 2002.

73. Pascual A, García I, Conejo C and Perea EJ: Uptake and intracellular activity of fluconazole in human polymorphonuclear leukocytes. Antimicrob Agents Chemother 37: 187-190, 1993.

74. Ciccolini J, Fina F, Bezulier K, Giacometti S, Roussel M, Evrard A, Cuq P, Romain S, Martin PM and Aubert C: Transmission of apoptosis in human colorectal tumor cells exposed to capecitabine, Xeloda, is mediated via Fas. Mol Cancer Ther 1: 923-927, 2002.

75. Baltch AL, Smith RP, Ritz WJ, Bopp LH and Michelsen PB: Intracellular activity of voriconazole, fluconazole, and itraconazole against Candida albicans in human monocytes with and without activation by GM-CSF and TNF-alpha. J Appl Res 5: 4, 2005

76. Murphy JW, Cho Y, Sachpatzidis A, Fan C, Hodsdon ME and Lolis E: Structural and functional basis of CXCL12 (stromal cell-derived factor-1 $\alpha$ ) binding to heparin. J Biol Chem 282: 10018-10027, 2007.

77. Debnath B, Xu S, Grande F, Garofalo A and Neamati N: Small molecule inhibitors of CXCR4. Theranostics 3: 47-75, 2013.
78. Hatse S, Princen K, Bridger G, De Clercq E and Schols D: Chemokine receptor inhibition by AMD3100 is strictly confined to CXCR4. FEBS Lett 527: 255-262, 2002.

79. Pron G, Belehradek J Jr and Mir LM: Identification of a plasma membrane protein that specifically binds bleomycin. Biochem Biophys Res Commun 194: 333-337, 1993.

80. Pron G, Belehradek J Jr, Orlowski S and Mir LM: Involvement of membrane bleomycin-binding sites in bleomycin cytotoxicity. Biochem Pharmacol 48: 301-310, 1994.

81. Krishan A and Whitlock S: Bleomycin-induced fine structural alterations in cultured mouse fibroblasts and human lymphocytes of neoplastic origin. Cancer Res 33: 777-785, 1973.

82. Pron G, Mahrour N, Orlowski S, Tounekti O, Poddevin B, Belehradek $\mathrm{J} \mathrm{Jr}$ and Mir LM: Internalisation of the bleomycin molecules responsible for bleomycin toxicity: A receptor-mediated endocytosis mechanism. Biochem Pharmacol 57: 45-56, 1999.

83. Ascierto ML, Kmieciak M, Idowu MO, Manjili R, Zhao Y, Grimes M, Dumur C, Wang E, Ramakrishnan V, Wang XY, et al: A signature of immune function genes associated with recurrence-free survival in breast cancer patients. Breast Cancer Res Treat 131: 871-880, 2012

84. Chen L, Huang Z, Yao G, Lyu X, Li J, Hu X, Cai Y, Li W, Li X and Ye C: The expression of CXCL13 and its relation to unfavorable clinical characteristics in young breast cancer. J Transl Med 13: 168, 2015.

85. Stamatopoulos B, Meuleman N, De Bruyn C, Pieters K, Mineur P, Le Roy C, Saint-Georges S, Varin-Blank N, Cymbalista F, Bron D, et al: AMD3100 disrupts the cross-talk between chronic lymphocytic leukemia cells and a mesenchymal stromal or nurse-like cell-based microenvironment: Pre-clinical evidence for its association with chronic lymphocytic leukemia treatments. Haematologica 97: 608-615, 2012.

86. Chen LJ, Ye H, Zhang Q, Li FZ, Song LJ, Yang J, Mu Q, Rao SS, Cai PC, Xiang F, et al: Bleomycin induced epithelial-mesenchymal transition (EMT) in pleural mesothelial cells. Toxicol Appl Pharmacol 283: 75-82, 2015

87. Wu Z, Yang L, Cai L, Zhang M, Cheng X, Yang X and Xu J: Detection of epithelial to mesenchymal transition in airways of a bleomycin induced pulmonary fibrosis model derived from an alpha-smooth muscle actin-Cre transgenic mouse. Respir Res 8: 1, 2007.

88. Yamada A, Aki T, Unuma K, Funakoshi T and Uemura K: Paraquat induces epithelial-mesenchymal transition-like cellular response resulting in fibrogenesis and the prevention of apoptosis in human pulmonary epithelial cells. PLoS One 10: e0120192, 2015.

89. Dik WA, McAnulty RJ, Versnel MA, Naber BA,Zimmermann LJ, Laurent GJ and Mutsaers SE: Short course dexamethasone treatment following injury inhibits bleomycin induced fibrosis in rats. Thorax 58: 765-771, 2003.

90. Domanska UM, Timmer-Bosscha H, Nagengast WB, Oude Munnink TH, Kruizinga RC, Ananias HJ, Kliphuis NM, Huls G, De Vries EG, de Jong IJ, et al: CXCR4 inhibition with AMD3100 sensitizes prostate cancer to docetaxel chemotherapy. Neoplasia 14: 709-718, 2012.

91. Ujwal R, Cascio D, Colletier JP, Faham S, Zhang J, Toro L, Ping P and Abramson J: The crystal structure of mouse VDAC1 at 2.3 A resolution reveals mechanistic insights into metabolite gating. Proc Natl Acad Sci USA 105: 17742-17747, 2008.

92. Catterall WA: Functional subunit structure of voltage-gated calcium channels. Science 253: 1499-1500, 1991.

93. Barańska W, Kujawa M and Kujawska E: Influence of vincristine on the Golgi apparatus in preimplantation development of the mouse embryo. Gegenbaurs Morphol Jahrb 134: 175-184, 1988.

94. Kujawa M, Ochocka M and Moskalewski S: Influence of vincristine on the Golgi complex of leukaemic lymphoblasts. Folia Haematologica 107: 193-203, 1980.

95. Carré M, André N, Carles G, Borghi H, Brichese L, Briand C and Braguer D: Tubulin is an inherent component of mitochondrial membranes that interacts with the voltage-dependent anion channel. J Biol Chem 277: 33664-33669, 2002.

96. Groninger E, Meeuwsen-De Boer GJ, De Graaf SS, Kamps WA and De Bont ES: Vincristine induced apoptosis in acute lymphoblastic leukaemia cells: A mitochondrial controlled pathway regulated by reactive oxygen species? Int J Oncol 21: 1339-1345, 2002

97. Eom YW, Kim MA, Park SS, Goo MJ, Kwon HJ, Sohn S, Kim WH, Yoon G and Choi KS: Two distinct modes of cell death induced by doxorubicin: Apoptosis and cell death through mitotic catastrophe accompanied by senescence-like phenotype. Oncogene 24: 4765-4777, 2005 
98. Gamen S, Anel A, Lasierra P, Alava MA, Martinez-Lorenzo MJ, Piñeiro A and Naval J: Doxorubicin-induced apoptosis in human T-cell leukemia is mediated by caspase-3 activation in a Fas-independent way. FEBS Lett 417: 360-364, 1997.

99. Kuznetsov AV, Margreiter R, Amberger A, Saks V and Grimm M: Changes in mitochondrial redox state, membrane potential and calcium precede mitochondrial dysfunction in doxorubicin-induced cell death. Biochim Biophys Acta 1813: 1144-1152, 2011.

100. Mizutani H, Tada-Oikawa S, Hiraku Y, Kojima M and Kawanishi S: Mechanism of apoptosis induced by doxorubicin through the generation of hydrogen peroxide. Life Sci 76: 1439-1453, 2005.

101. Wang S, Konorev EA, Kotamraju S, Joseph J, Kalivendi S and Kalyanaraman B: Doxorubicin induces apoptosis in normal and tumor cells via distinctly different mechanisms. intermediacy of $\mathrm{H}(2) \mathrm{O}(2)$ - and p53-dependent pathways. J Biol Chem 279: 25535-25543, 2004

102.Golomb E, Hill MR, Brown RG and Keiser HR: Ouabain enhances the mitogenic effect of serum in vascular smooth muscle cells. Am J Hypertens 7: 69-74, 1994.

103. Kanai R, Ogawa H, Vilsen B, Cornelius F and Toyoshima C: Crystal structure of a $\mathrm{Na}^{+}$-bound $\mathrm{Na}^{+}, \mathrm{K}^{+}$-ATPase preceding the E1P state. Nature 502: 201-206, 2013.

104.Aller SG, Yu J, Ward A, Weng Y, Chittaboina S, Zhuo R, Harrell PM, Trinh YT, Zhang Q, Urbatsch IL, et al: Structure of P-glycoprotein reveals a molecular basis for poly-specific drug binding. Science 323: 1718-1722, 2009.

105. Sehested M, Jensen PB, Skovsgaard T, Bindslev N, Demant EJ, Friche E and Vindeløv L: Inhibition of vincristine binding to plasma membrane vesicles from daunorubicin-resistant Ehrlich ascites cells by multidrug resistance modulators. Br J Cancer 60 : 809-814, 1989.

106. Srivalli KMR and Lakshmi P: Overview of P-glycoprotein inhibitors: A rational outlook. Braz J Pharm Sci 48: 353-367, 2012.

107. Chen C, Ke J, Zhou XE, Yi W, Brunzelle JS, Li J, Yong EL, $\mathrm{Xu} \mathrm{HE}$ and Melcher K: Structural basis for molecular recognition of folic acid by folate receptors. Nature 500: 486-489, 2013.

108. Nandini-Kishore SG and Frazier WA: [3H]Methotrexate as a ligand for the folate receptor of Dictyostelium discoideum. Proc Natl Acad Sci USA 78: 7299-7303, 1981.

109. Herman S, Zurgil N and Deutsch M: Low dose methotrexate induces apoptosis with reactive oxygen species involvement in $\mathrm{T}$ lymphocytic cell lines to a greater extent than in monocytic lines. Inflamm Res 54: 273-280, 2005.

110. Ramadan AA, Yousif WB and Ali AM: The effect of methotrexate (MTX) on the small intestine of the mouse. IV. The Golg apparatus, phosphatases and esterases. Funct Dev Morphol 2: $111-119,1992$

111. Ramadan AA, Yousif WB and Ali AM: The effect of methotrexate (MTX) on the small intestine of the mouse. III. Mitochondria and succinic dehydrogenase (SDH). Funct Dev Morphol 2: 3-9, 1992.

112. Pritchard DM, Bower L, Potten CS, Jackman AL and Hickman JA: The importance of p53-independent apoptosis in the intestinal toxicity induced by raltitrexed (ZD1694, Tomudex): genetic differences between BALB/c and DBA/2 mice. Clin Cancer Res 6: 4389-4395, 2000.

113. Xue S, Chen YX, Qin SK, Yang AZ, Wang L, Xu HJ and Geng HY: Raltitrexed induces mitochondrial mediated apoptosis in SGC7901 human gastric cancer cells. Mol Med Rep 10: 1927-1934, 2014.

114. Chattopadhyay S, Moran RG and Goldman ID: Pemetrexed: Biochemical and cellular pharmacology, mechanisms, and clinical applications. Mol Cancer Ther 6: 404-417, 2007.

115. Fischer CD, da Costa M and Rothenberg SP: The heterogeneity and properties of folate binding proteins from chronic myelogenous leukemia cells. Blood 46: 855-867, 1975.

116. Fischer CD, Da Costa M and Rothenberg SP: Properties of purified folate-binding proteins from chronic myelogenous leukemia cells. Biochim Biophys Acta 543: 328-339, 1978.

117. Barford PA, Blair JA and Malghani MA: The effect of methotrexate on folate metabolism in the rat. Br J Cancer 41: 816-820, 1980.

118. Ohbayashi M, Kubota S, Kawase A, Kohyama N, Kobayashi Y and Yamamoto T: Involvement of epithelial-mesenchymal transition in methotrexate-induced pulmonary fibrosis. J Toxicol Sci 39: 319-330, 2014.

119. Shprung T and Gozes I: A novel method for analyzing mitochondrial movement: inhibition by paclitaxel in a pheochromocytoma cell model. J Mol Neurosci 37: 254-262, 2009.
120. Foland TB, Dentler WL, Suprenant KA, Gupta ML Jr and Himes RH: Paclitaxel-induced microtubule stabilization causes mitotic block and apoptotic-like cell death in a paclitaxel-sensitive strain of Saccharomyces cerevisiae. Yeast 22: 971-978, 2005.

121. Salido M, Gonzalez JL and Vilches J: Loss of mitochondrial membrane potential is inhibited by bombesin in etoposide-induced apoptosis in PC-3 prostate carcinoma cells. Mol Cancer Ther 6: 1292-1299, 2007.

122. Mizukami S, Kikuchi K, Higuchi T, Urano Y, Mashima T, Tsuruo $\mathrm{T}$ and Nagano T: Imaging of caspase-3 activation in HeLa cells stimulated with etoposide using a novel fluorescent probe. FEBS Lett 453: 356-360, 1999.

123. Matsushima Y, Kanzawa F, Miyazawa N, Sasaki Y and Saijo N: In vitro antitumor activity of teniposide against carcinoma of the lung in human tumor clonogenic assay. Anticancer Res 6: 921-924, 1986

124. Sánchez-Alcázar JA, Khodjakov A and Schneider E: Anticancer drugs induce increased mitochondrial cytochrome $c$ expression that precedes cell death. Cancer Res 61: 1038-1044, 2001.

125. Uyar D, Takigawa N, Mekhail T, Grabowski D, Markman M, Lee F, Canetta R, Peck R, Bukowski R and Ganapathi R: Apoptotic pathways of epothilone BMS 310705. Gynecol Oncol 91: 173-178, 2003.

126. Thomson AER and Robinson MA: Cytocidal action of colchicine in vitro on lymphocytes in chronic lymphocytic leukaemia. Lancet 2: 868-870, 1967.

127. Chen XM, Liu J, Wang T and Shang J: Colchicine-induced apoptosis in human normal liver L-02 cells by mitochondrial mediated pathways. Toxicol In Vitro 26: 649-655, 2012

128. Jelínek M, Balušíková K, Schmiedlová M, Němcová-Fürstová V, Šrámek J, Stančíková J, Zanardi I, Ojima I and Kovář J: The role of individual caspases in cell death induction by taxanes in breast cancer cells. Cancer Cell Int 15: 8, 2015.

129. André N, Braguer D, Brasseur G, Gonçalves A, Lemesle-Meunier D, Guise S, Jordan MA and Briand C: Paclitaxel induces release of cytochrome $c$ from mitochondria isolated from human neuroblastoma cells'. Cancer Res 60: 5349-5353, 2000.

130. Khawaja NR, Carré M, Kovacic H, Estève MA and Braguer D: Patupilone-induced apoptosis is mediated by mitochondrial reactive oxygen species through Bim relocalization to mitochondria. Mol Pharmacol 74: 1072-1083, 2008.

131. Salim AA, Xiao X, Cho KJ, Piggott AM, Lacey E, Hancock JF and Capon RJ: Rare Streptomyces sp. polyketides as modulators of K-Ras localisation. Org Biomol Chem 12: 4872-4878, 2014.

132. Pusceddu S, Indini A and Procopio G: Everolimus treatment in advanced solid tumors: a personal view. Future Science OA: March 20, 2015 (Epub ahead of print). doi:10.4155/fso.14.1.

133. Chambraud B, Belabes H, Fontaine-Lenoir V, Fellous A and Baulieu EE: The immunophilin FKBP52 specifically binds to tubulin and prevents microtubule formation. FASEB J 21: 2787-2797, 2007.

134. Shirane M and Nakayama KI: Inherent calcineurin inhibitor FKBP38 targets Bcl-2 to mitochondria and inhibits apoptosis. Nat Cell Biol 5: 28-37, 2003.

135. Tanaka K, Fujita N, Higashi Y and Ogawa N: Neuroprotective and antioxidant properties of FKBP-binding immunophilin ligands are independent on the FKBP12 pathway in human cells. Neurosci Lett 330: 147-150, 2002.

136. Simon N, Morin C, Urien S, Tillement JP and Bruguerolle B: Tacrolimus and sirolimus decrease oxidative phosphorylation of isolated rat kidney mitochondria. Br J Pharmacol 138: 369-376, 2003.

137.Zini R, Simon N, Morin C, Thiault L and Tillement JP: Tacrolimus decreases in vitro oxidative phosphorylation of mitochondria from rat forebrain. Life Sci 63: 357-368, 1998

138.Zoli W, Ulivi P, Tesei A, Fabbri F, Rosetti M, Maltoni R, Giunchi DC, Ricotti L, Brigliadori G, Vannini I, et al: Addition of 5-fluorouracil to doxorubicin-paclitaxel sequence increases caspase-dependent apoptosis in breast cancer cell lines. Breast Cancer Res 7: R681-R689, 2005.

139. Yang Y, Niu X, Zhang Q, Hao L, Ding Y and Xu H: The efficacy of abraxane on osteosarcoma xenografts in nude mice and expression of secreted protein, acidic and rich in cysteine. Am J Med Sci 344: 199-205, 2012.

140. Saif MW: U.S. Food and Drug Administration approves paclitaxel protein-bound particles (Abraxane ${ }^{\circledR}$ ) in combination with gemcitabine as first-line treatment of patients with metastatic pancreatic cancer. JOP 14: 686-688, 2013. 
141. Coward P, Lee D, Hull MV and Lehmann JM: 4-Hydroxy tamoxifen binds to and deactivates the estrogen-related receptor gamma. Proc Natl Acad Sci USA 98: 8880-8884, 2001.

142. Richards J, Lim AC, Hay CW, Taylor AE, Wingate A, Nowakowska K, Pezaro C, Carreira S, Goodall J, Arlt W, et al: Interactions of abiraterone, eplerenone, and prednisolone with wild-type and mutant androgen receptor: A rationale for increasing abiraterone exposure or combining with MDV3100. Cancer Res 72: 2176-2182, 2012.

143.Darbre PD and King RJB: Differential effects of steroid hormones on parameters of cell growth. Cancer Res 47: 2937-2944, 1987.

144. Yates J and King RJB: Correlation of growth properties and morphology with hormone responsiveness of mammary tumor cells in culture. Cancer Res 41: 258-262, 1981.

145. Talwar GP, Raina K, Gupta JC, Ray R, Wadhwa S and Ali MM: A recombinant luteinising-hormone-releasinghormone immunogen bioeffective in causing prostatic atrophy. Vaccine 22: 3713-3721, 2004.

146. Brandes AA, Ermani M, Turazzi S, Scelzi E, Berti F, Amistà P, Rotilio A, Licata C and Fiorentino MV: Procarbazine and high-dose tamoxifen as a second-line regimen in recurrent high-grade gliomas: A phase II study. J Clin Oncol 17: 645-650, 1999.

147. de Bono JS, Logothetis CJ, Molina A, Fizazi K, North S, Chu L, Chi KN, Jones RJ, Goodman OB Jr, Saad F, et al; COU-AA-301 Investigators: Abiraterone and increased survival in metastatic prostate cancer. N Engl J Med 364: 1995-2005, 2011.

148. Kosaka T, Miyajima A, Yasumizu Y, Miyazaki Y, Kikuchi E and Oya M: Limited in vitro efficacy of CYP17A1 inhibition on human castration resistant prostate cancer. Steroids 92: 39-44, 2014.

149.Louderbough JMV, Lopez JI and Schroeder JA: Matrix hyaluronan alters epidermal growth factor receptor-dependent cell morphology. Cell Adhes Migr 4: 26-31, 2010.

150.Hara F, Aoe M, Doihara H, Taira N, Shien T, Takahashi H, Yoshitomi S, Tsukuda K, Toyooka S, Ohta T, et al: Antitumor effect of gefitinib ('Iressa') on esophageal squamous cell carcinoma cell lines in vitro and in vivo. Cancer Lett 226: 37-47, 2005.

151. Stegmaier K, Corsello SM, Ross KN, Wong JS, Deangelo DJ and Golub TR: Gefitinib induces myeloid differentiation of acute myeloid leukemia. Blood 106: 2841-2848, 2005.

152. Augustin A, Lamerz J, Meistermann H, Golling S, Scheiblich S, Hermann JC, Duchateau-Nguyen G, Tzouros M, Avila DW, Langen $\mathrm{H}$, et al: Quantitative chemical proteomics profiling differentiates erlotinib from gefitinib in EGFR wild-type non-small cell lung carcinoma cell lines. Mol Cancer Ther 12: $520-529,2013$

153. Huang HL, Chen YC, Huang YC, Yang KC, Pan H, Shih SP and Chen YJ: Lapatinib induces autophagy, apoptosis and megakaryocytic differentiation in chronic myelogenous leukemia K562 cells. PLoS One 6: e29014, 2011.

154.Diaz R, Nguewa PA, Parrondo R, Perez-Stable C, Manrique I, Redrado M, Catena R, Collantes M, Peñuelas I, Díaz-González JA, et al: Antitumor and antiangiogenic effect of the dual EGFR and HER-2 tyrosine kinase inhibitor lapatinib in a lung cancer model. BMC Cancer 10: 188, 2010.

155. Chen G, Noor A, Kronenberger P, Teugels E, Umelo IA and De Grève J: Synergistic effect of afatinib with su11274 in non-small cell lung cancer cells resistant to gefitinib or erlotinib. PLoS One 8: e59708, 2013.

156. Solca F, Dahl G, Zoephel A, Bader G, Sanderson M, Klein C, Kraemer O, Himmelsbach F, Haaksma E and Adolf GR: Target binding properties and cellular activity of afatinib (BIBW 2992), an irreversible ErbB family blocker. J Pharmacol Exp Ther 343: 342-350, 2012.

157. Stoica GE, Kuo A, Powers C, Bowden ET, Sale EB, Riegel AT and Wellstein A: Midkine binds to anaplastic lymphoma kinase (ALK) and acts as a growth factor for different cell types. J Biol Chem 277: 35990-35998, 2002

158. Sumi Y, Muramatsu H, Hata K, Ueda M and Muramatsu T: Midkine enhances early stages of collagen gel contraction. J Biochem 127: 247-251, 2000.

159. Kadomatsu K and Muramatsu T: Midkine and pleiotrophin in neural development and cancer. Cancer Lett 204: 127-143, 2004.

160. Friboulet L, Li N, Katayama R, Lee CC, Gainor JF, Crystal AS, Michellys PY, Awad MM, Yanagitani N, Kim S, et al: The ALK inhibitor ceritinib overcomes crizotinib resistance in non-small cell lung cancer. Cancer Discov 4: 662-673, 2014.
161. Lisignoli G, Toneguzzi S, Piacentini A, Cristino S, Grassi F, Cavallo $\mathrm{C}$ and Facchini A: CXCL12 (SDF-1) and CXCL13 (BCA-1) chemokines significantly induce proliferation and collagen type I expression in osteoblasts from osteoarthritis patients. J Cell Physiol 206: 78-85, 2006.

162. Kalinina OV, Pfeifer $\mathrm{N}$ and Lengauer T: Modelling binding between CCR 5 and CXCR4 receptors and their ligands suggests the surface electrostatic potential of the co-receptor to be a key player in the HIV-1 tropism. Retrovirology 10: 130, 2013.

163. Massarelli I, Chiellini F, Chiellini E and Bianucci AM: Three-dimensional models of the oligomeric human asialoglycoprotein receptor (ASGP-R). Int J Mol Sci 11: 3867-3884, 2010.

164. Fallon RJ and Danaher M: The effect of staurosporine, a protein kinase inhibitor, on asialoglycoprotein receptor endocytosis. Exp Cell Res 203: 420-426, 1992.

165. Trerè D, Fiume L, De Giorgi LB, Di Stefano G, Migaldi M and Derenzini M: The asialoglycoprotein receptor in human hepatocellular carcinomas: Its expression on proliferating cells. Br J Cancer 81: 404-408, 1999.

166. Becherer U, Guatimosim C and Betz W: Effects of staurosporine on exocytosis and endocytosis at frog motor nerve terminals. J Neurosci 21: 782-787, 2001.

167. BelmokhtarCA,Hillion J and Ségal-Bendirdjian E: Staurosporine induces apoptosis through both caspase-dependent and caspase-independent mechanisms. Oncogene 20: 3354-3362, 2001.

168. Zhang XD, Gillespie SK and Hersey P: Staurosporine induces apoptosis of melanoma by both caspase-dependent and -independent apoptotic pathways. Mol Cancer Ther 3: 187-197, 2004

169. Dunai ZA, Imre G, Barna G, Korcsmaros T, Petak I, Bauer PI and Mihalik R: Staurosporine induces necroptotic cell death under caspase-compromised conditions in U937 cells. PLoS One 7: e41945, 2012.

170. Chan KC, Knox WF, Gee JM, Morris J, Nicholson RI, Potten CS and Bundred NJ: Effect of epidermal growth factor receptor tyrosine kinase inhibition on epithelial proliferation in normal and premalignant breast. Cancer Res 62: 122-128, 2002.

171. Maity A, Pore N, Lee J, Solomon D and O'Rourke DM: Epidermal growth factor receptor transcriptionally up-regulates vascular endothelial growth factor expression in human glioblastoma cells via a pathway involving phosphatidylinositol 3 -kinase and distinct from that induced by hypoxia. Cancer Res 60: 5879-5886, 2000.

172. Ouchi T, Monteiro ANA, August A, Aaronson SA and Hanafusa $\mathrm{H}$ : BRCA1 regulates p53-dependent gene expression. Proc Natl Acad Sci USA 95: 2302-2306, 1998.

173. Arizti P, Fang L, Park I, Yin Y, Solomon E, Ouchi T, Aaronson SA and Lee SW: Tumor suppressor p53 is required to modulate BRCA1 expression. Mol Cell Biol 20: 7450-7459, 2000.

174. Andreassen A, Øyjord T, Hovig E, Holm R, Flørenes VA, Nesland JM, Myklebost O, Høie J, Bruland OS, Børresen AL, et al: p53 abnormalities in different subtypes of human sarcomas. Cancer Res 53: 468-471, 1993.

175. O'Hare T, Pollock R, Stoffregen EP, Keats JA, Abdullah OM, Moseson EM, Rivera VM, Tang H, Metcalf CA III, Bohacek RS et al: Inhibition of wild-type and mutant Bcr-Abl by AP23464, a potent ATP-based oncogenic protein kinase inhibitor: Implications for CML. Blood 104: 2532-2539, 2004.

176. Grisolano JL, O'Neal J, Cain J and Tomasson MH: An activated receptor tyrosine kinase, TEL/PDGFbetaR, cooperates with AML1/ETO to induce acute myeloid leukemia in mice. Proc Natl Acad Sci USA 100: 9506-9511, 2003.

177. Aoki M, Nabeshima K, Koga K, Hamasaki M, Suzumiya J, Tamura $\mathrm{K}$ and Iwasaki $\mathrm{H}$ : Imatinib mesylate inhibits cell invasion of malignant peripheral nerve sheath tumor induced by platelet-derived growth factor-BB. Lab Invest 87: 767-779, 2007.

178. Hercus TR, Thomas D, Guthridge MA, Ekert PG, King-Scott J, Parker MW and Lopez AF: The granulocyte-macrophage colony-stimulating factor receptor: linking its structure to cell signaling and its role in disease. Blood 114: 1289-1298, 2009.

179. Ding W, Shanafelt TD, Lesnick CE, Erlichman C, Leis JF, Secreto C, Sassoon TR, Call TG, Bowen DA, Conte M, et al: Akt inhibitor MK2206 selectively targets CLL B-cell receptor induced cytokines, mobilizes lymphocytes and synergizes with bendamustine to induce CLL apoptosis. Br J Haematol 164: 146-150, 2014

180. Zhao Y-Y, Tian Y, Zhang J, Xu F, Yang YP, Huang Y, Zhao HY, Zhang JW, Xue C, Lam MH, et al: Effects of an oral allosteric AKT inhibitor (MK-2206) on human nasopharyngeal cancer in vitro and in vivo. Drug Des Devel Ther 8: 1827-1837, 2014. 
181. Agarwal E, Chaudhuri A, Leiphrakpam PD, Haferbier KL, Brattain MG and Chowdhury S: Akt inhibitor MK-2206 promotes anti-tumor activity and cell death by modulation of AIF and Ezrin in colorectal cancer. BMC Cancer 14: 145, 2014.

182.Fu YR, Yi ZJ, Yan YR and Qiu ZY: Hydroxycamptothecininduced apoptosis in hepatoma SMMC-7721 cells and the role of mitochondrial pathway. Mitochondrion 6: 211-217, 2006.

183. Uckun FM, Stewart CF, Reaman G, Chelstrom LM, Jin J, Chandan-Langlie M, Waddick KG, White J and Evans WE: In vitro and in vivo activity of topotecan against human B-lineage acute lymphoblastic leukemia cells. Blood 85: 2817-2828, 1995.

184. Caserini C, Pratesi G, Tortoreto M, Bedogné B, Carenini N, Supino R, Perego P, Righetti SC and Zunino F: Apoptosis as a determinant of tumor sensitivity to topotecan in human ovarian tumors: preclinical in vitro/in vivo studies. Clin Cancer Res 3 : 955-961, 1997.

185.Kim MK, James J and Annunziata CM: Topotecan synergizes with CHEK1 (CHK1) inhibitor to induce apoptosis in ovarian cancer cells. BMC Cancer 15: 196, 2015.

186. Tolis C, Peters GJ, Ferreira CG, Pinedo HM and Giaccone G: Cell cycle disturbances and apoptosis induced by topotecan and gemcitabine on human lung cancer cell lines. Eur J Cancer 35: 796-807, 1999.

187. Szalay K, Rázga Z and Duda E: TNF inhibits myogenesis and downregulates the expression of myogenic regulatory factors myoD and myogenin. Eur J Cell Biol 74: 391-398, 1997.

188. Fiers W, Beyaert R, Brouckaert P, Everaerdt B, Haegeman C, Suffys P, Tavernier J and Vanhaesebroeck B: TNF: Its potential as an antitumour agent. Dev Biol Stand 69: 143-151, 1988

189. Smith RA and Baglioni C: The active form of tumor necrosis factor is a trimer. J Biol Chem 262: 6951-6954, 1987.

190.Udagawa N, Takahashi N, Jimi E, Matsuzaki K, Tsurukai T, Itoh K, Nakagawa N, Yasuda $\mathrm{H}$, Goto M, Tsuda E, et al: Osteoblasts/stromal cells stimulate osteoclast activation through expression of osteoclast differentiation factor/RANKL but not macrophage colony-stimulating factor: Receptor activator of NF-kappa B ligand. Bone 25: 517-523, 1999.

191. Luan X,Lu Q, Jiang Y,Z Zhang S, Wang Q, Yuan H, Zhao W, Wang J and Wang X: Crystal structure of human RANKL complexed with its decoy receptor osteoprotegerin. J Immunol 189: 245-252, 2012.

192. Ciusani E, Croci D, Gelati M, Calatozzolo C, Sciacca F, Fumagalli L, Balzarotti M, Fariselli L, Boiardi A and Salmaggi A: In vitro effects of topotecan and ionizing radiation on TRAIL/Apo2L-mediated apoptosis in malignant glioma. J Neurooncol 71: 19-25, 2005.

193. Chen S, Gomez SP, McCarley D and Mainwaring MG: Topotecan-induced topoisomerase IIalpha expression increases the sensitivity of the CML cell line K562 to subsequent etoposide plus mitoxantrone treatment. Cancer Chemother Pharmacol 49: 347-355, 2002.
194. Naldini L, Weidner KM, Vigna E, Gaudino G, Bardelli A, Ponzetto C, Narsimhan RP, Hartmann G, Zarnegar R, Michalopoulos GK, et al: Scatter factor and hepatocyte growth factor are indistinguishable ligands for the MET receptor. EMBO J 10: 2867-2878, 1991.

195. Stamos J, Lazarus RA, Yao X, Kirchhofer D and Wiesmann C: Crystal structure of the HGF beta-chain in complex with the Sema domain of the Met receptor. EMBO J 23: 2325-2335, 2004.

196. Paulson AK, Linklater ES, Berghuis BD, App CA, Oostendorp LD, Paulson JE, Pettinga JE, Melnik MK, Vande Woude GF and Graveel CR: MET and ERBB2 are coexpressed in $\mathrm{ERBB}^{+}$breast cancer and contribute to innate resistance. Mol Cancer Res 11: 1112-1121, 2013.

197. Xie Q, Su Y, Dykema K, Johnson J, Koeman J, De Giorgi V, Huang A, Schlegel R, Essenburg C, Kang L, et al: Overexpression of HGF promotes HBV-induced hepatocellular carcinoma progression and is an effective indicator for Met-targeting therapy. Genes Cancer 4: 247-260, 2013.

198. Simonetti S, Molina MA, Queralt C, de Aguirre I, Mayo C, Bertran-Alamillo J, Sanchez JJ, Gonzalez-Larriba JL, Jimenez U, Isla D, et al: Detection of EGFR mutations with mutation-specific antibodies in stage IV non-small-cell lung cancer. J Transl Med 8: 135, 2010.

199. Maseki S, Ijichi K, Tanaka H, Fujii M, Hasegawa Y, Ogawa T, Murakami S, Kondo E and Nakanishi H: Acquisition of EMT phenotype in the gefitinib-resistant cells of a head and neck squamous cell carcinoma cell line through Akt/GSK-3ß/snail signalling pathway. Br J Cancer 106: 1196-1204, 2012.

200. Stahtea XN, Roussidis AE, Kanakis I, Tzanakakis GN, Chalkiadakis G, Mavroudis D, Kletsas D and Karamanos NK: Imatinib inhibits colorectal cancer cell growth and suppresses stromal-induced growth stimulation, MT1-MMP expression and pro-MMP2 activation. Int J Cancer 121: 2808-2814, 2007.

201. Hirai H, Sootome H, Nakatsuru Y, Miyama K, Taguchi S, Tsujioka K, Ueno Y, Hatch H, Majumder PK, Pan BS, et al: MK-2206, an allosteric Akt inhibitor, enhances antitumor efficacy by standard chemotherapeutic agents or molecular targeted drugs in vitro and in vivo. Mol Cancer Ther 9: 1956-1967, 2010. 